Critical evaluation of

systems analysis in ecosystems research and management

G.W.Arnold and CT.deWit(Eds)

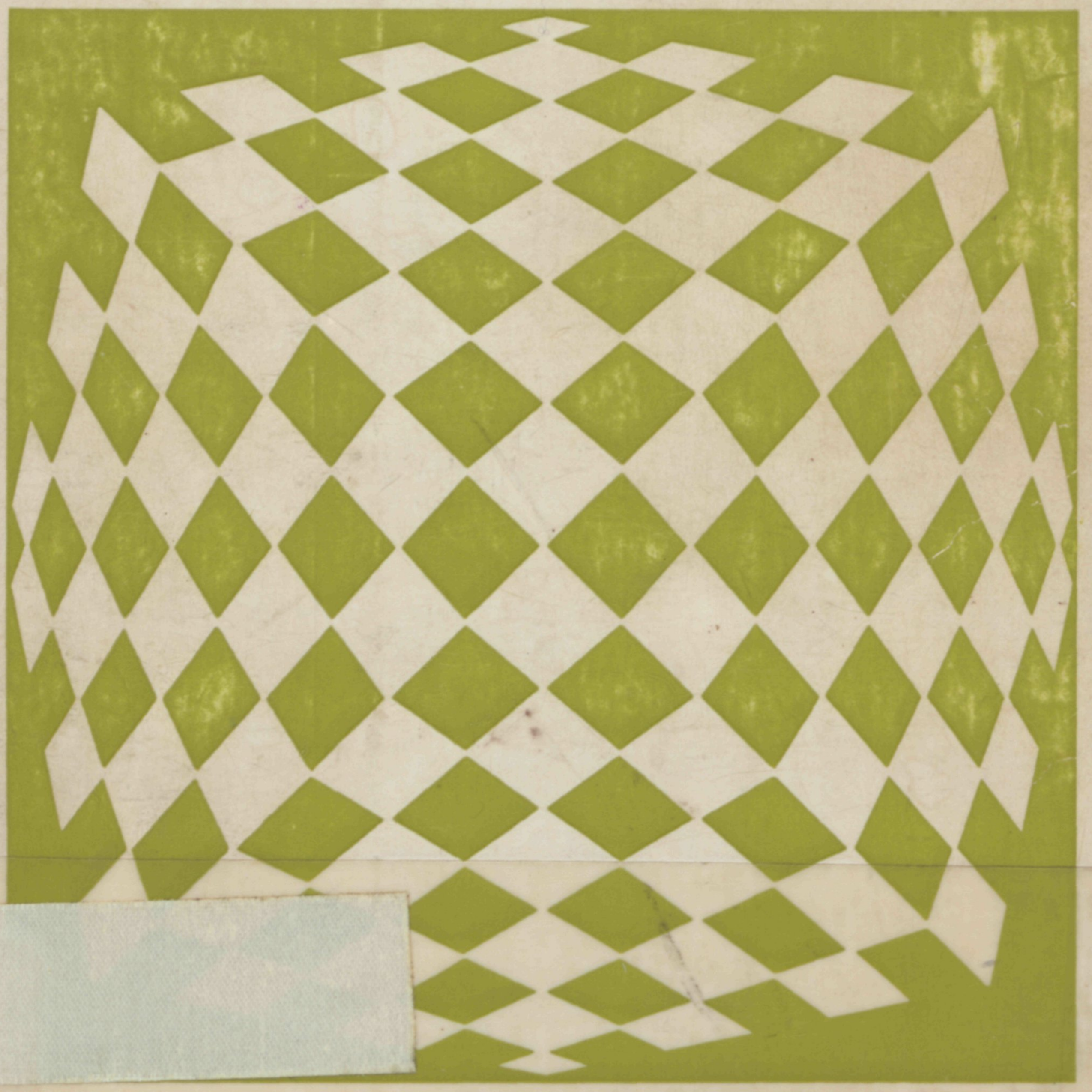


Simulation Monographs

Simulation monographs is a series on computer simulation in agriculture and its supporting sciences 
Critical evaluation of

systems analysis in ecosysterns research and management

G.W.Amold and C.T.deWittEdsl

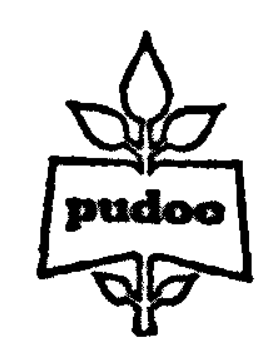

Wageningen

Centre for Agricultural Publishing and Documentation 1976 
Books already published in this series:

C. T. de Wit and $H$. van Keulen

Simulation of transport processes in soils (2nd ed., revised)

1975, 109 pages, ISBN 902200591 7, price Dfl. 15

J. Beek and M. J. Frissel

Simulation of nitrogen behaviour in soils

1973, 76 pages, ISBN 902200440 6, price Dfl. 12.50

C. T. de Wit and J. Goudriaan

Simulation of ecological processes

1974, 167 pages, ISBN 902200496 1, price Dfl. 22.50

H. G. Fransz

The functional response to prey density in an acarine system 1974, 149 pages, ISBN 902200509 7, price Dfl. 20

M. J. Frissel and P. Reiniger

Simulation of accumulation and leaching in soils

1974, 124 pages, ISBN 902200530 0, price Dfl. 17.50

H. van Keulen

Simulation of water use and herbage growth in arid regions

1975, 184 pages, ISBN 902200557 7, price Dfl. 27.50

G. F. Makkink and H. D. J. van Heemst

Simulation of the water balance of arable land and pastures

1975, 87 pages, ISBN 902200566 6, price Dfl. 15

ISBN 9022005933

(C) Centre for Agricultural Publishing and Documentation, Wageningen, the Netherlands, 1976

No part of this book may be reproduced or published in any form, by print, photoprint, microfilm or any other means without written permission from the publisher.

Cover design: Pudoc, Wageningen

Printed in Belgium

BIBLIOTHEER

DiR

LANDBOUWHOGESCHOOL 


\section{Contents}

Preface

C. T. de Wit and G. W. Arnold

Some speculation on simulation

David W. Goodall

The hierarchical approach to model building

H. van Keulen

Evaluation of models

Donald A. Jameson

Management of ecosystems: information supplied by simulation models

Philip C. Miller and Harold A. Mooney

The origin and structure of American arid-zone ecosystems.

The producers: interactions between environment, form,

and function

N. G. Seligman

A critical appraisal of some grassland models

J. N. R. Jeffers

Future prospects of systems analysis in ecology 
This book is a collection of papers presented at and inspired by the First International Congress of Ecology, 9-14 September 1974, the Hague, the Netherlands.

The contributors are:

G. W. Arnold (editor). Division of Land Resources Management CSIRO, Private Bag, P.O. Wembley, Australia

C. T. de Wit (editor). Department of Theoretical Production Ecology, Agricultural University, Wageningen, the Netherlands

David W. Goodall. Division of Land Resources Management CSIRO, Private Bag, P.O. Wembley, Australia

Donald A. Jameson. College of Forestry and Natural Resources, Colorado State University, Fort Collins, Colorado, USA.

J. N. R. Jeffers. Institute of Terrestrial Ecology, Merlewood Research Station, Grange-over-Sands, Cumbria, U.K.

H. van Keulen. Department of Theoretical Production Ecology, Agricultural University, Wageningen, the Netherlands

Philip C. Miller. Department of Biology, San Diego State University, San Diego, California 92115, USA

Harold A. Mooney. Department of Biological Sciences, Stanford University, Stanford, California 94305, USA

N.G. Seligman. Guest worker at the Department of Theoretical Production Ecology, Agricultural University, Wageningen, the Netherlands, on secondment from Agricultural Research Organisation, Volcani Center, Bet Dagan, Israel. 


\section{Preface}

At the 1st International Congress of Ecology at the Hague in September 1974, a symposium was organized by de Wit and Goodall, with the title: 'Critical evaluation of systems analysis and modelling in ecosystems research and management. Data collection and processing for predictive purposes.'

The symposium aroused considerable interest and so the organisers decided to bring together the proceedings, together with other papers, some of which were presented at the Congress, into this book.

As pointed out in the introductory paper it is only in the last decade that some biologists have adopted the systems analysis approach to their problems, an approach long used by engineers and in operations research. It is appropriate to look at the value the approach has proved so far, and to its future role in ecosystems research and management.

The physicist has almost perfect knowledge about the behaviour of the systems with which he works. But the biologist often works with systems about which little is known, and where the response of an organism to a given change in its environment is not fixed. Also, biological systems often have many more feedbacks which means that a change in one part of the system can cause changes in other parts. Thus the construction of simulation models of biological systems for predictive purposes, whilst technically feasible, requires considerable care. The objectives of the model must be explicit since these will largely determine the structure of the model, the functions included and the degree of resolution to which the system is simulated.

Some of the problems of modelling ecosystems are introduced by de Wit and Arnold in the first paper. Goodall's paper gives an illustration of how to use the hierarchical approach to model building. Van Keulen goes on to consider the principles which should govern decisions on the structure of a model in more detail, i.e. the objectives, the boundaries of the model, the processes incorporated in the model, evaluating the output of the model, and the model's behaviour in response to changes in inputs or in the rates of certain processes. 
Two papers illustrate divergent uses of modelling ecosystems. Jameson considers the problem of developing generalized models of grassland ecosystems which will provide the input data for management models; Miller and Mooney use a biological process model to consider the most efficient vegetation forms and functions in two Mediterranean environments and compare these with the vegetation that occurs.

The most widespread effort in ecosystem modelling has been in producing models of grassland systems used by man for livestock production. Seligman critically reviews some of these models. Such criticism should allow future models to be more soundly constructed for their given objectives.

Finally, Jeffers discusses the future prospects of systems analysis in ecology. He looks at the broad application of models and discusses not only the problem of defining and bounding models but also the management of the team needed for model construction and validation and, most importantly, how to communicate the model and its results. Systems analysis, it has been argued, allows a more logical appreciation of ecosystems and the impact of management strategies on them than is normally possible using mental models. With many ecosystems experimental verification of predicted results is impossible because irreversible changes may occur during the process or the time scale and cost of such studies are too great. Yet man will continue to interfere with ecosystems either for better or for worse. Decisions about the type of interference, or management, have to be made. Systems analysis can provide a framework for more soundly based decisions than can be achieved in other ways but only if those analysing and modelling the system do so within a sound conceptual framework, with clear goals in mind and realising that no model is the final synthesis of a problem but merely the beginning point for further study. That study must include physical experimentation since the ecosystems cannot be studied by simulation modelling alone. Modelling is only part of the systems analysis approach to the study of ecosystems.

It is hoped that the papers in this book will help those who will be involved in modelling ecosystems to be more critical and to avoid some of the pitfalls, so that they may provide decision makers with better bases for their decisions, and thus for more efficient management of the earth's resources. 


\section{Some speculation on simulation}

\section{T. de Wit and G. W. Arnold}

\section{Systems and models}

For more than 30 years, considerable attention has been paid in the engineering sciences to the analysis of complex, dynamic systems and with considerable success. The approach, which is now being adopted in the biological sciences, is characterized by the terms: systems, models and simulation. A system is a part of reality that contains interrelated elements, a model is a simplified representation of a system and simulation may be defined as the art of building mathematical models and the study of their properties in reference to those of the system.

Although any model should have definite goals, be lucid and achieve its objective, it seems in practice that goals are too often described in such broad terms that sufficient lucidity is reached only for the initiated and that the models are achieving less than expected by the biologists. For these reasons the word 'art' rather than 'science' is used in the definition of simulation.

It follows from the definition that a model is a system, but the reverse may be true as well. A work of art is a simplified representation or a model of the vision of the artist. A machine is a model of the conception of the engineer and it performs certainly worse than anticipated. And when an engineer applies simulation, he develops models that are in between his conception and reality. The ultimate machine is in fact a model of his simulation model, that is a simplified representation of his mental conception.

Although some would like it otherwise, biological systems are not simplified representations of the conception of the biologist and the inversion of the terms, models and systems does not make any sense. Therefore, it may be that the approach that has been so successful in engineering is not as useful in biology. Fools rush in where wise men fear to tread, and much of the rushing in this field of simulation in biology is done by agronomists, perhaps because they are fools, but may be because they are concerned with systems in which the technical aspects overrule the biological aspects. 
A file with data on an ecosystem may be called a model, but then a model without purpose and lucidity. Uses of the data may be formulated and then lucidity may be introduced by a treatment of the data. This may result in maps that represent aspects of the ecosystem, or in statistical analyses which summarize some of the interrelations. Dynamic models are obtained if the time dimension is introduced during the collection and treatment of the data. But the models remain descriptive, showing only the existence of relations between elements, without any explanation, which is, of course, not their purpose to begin with.

However, models that have the purpose of explaining systems are possible in biology, because various levels of organization are distinguished in this science, as in any other natural science. These different levels of organization may be classified, according to the size of the system and time constants involved, as those of molecules, cell structures, cells, tissues, organs, individuals, populations and eco$r$ systems. Models that are made with the objective of explaining are bridges between levels of organization, which allow the understanding of larger systems with the larger time constants on the basis of the knowledge gained by experimentation on smaller systems with smaller time constants. In this way the properties of membranes may be understood better by studying molecules and the properties of ecosystems L by studying species.

For models that claim to be of the explanatory type, the state-variable approach is gaining wide acceptance. These models are based on the assumption that the state of each system at any moment may be quantitatively characterized and that changes in the state may be described by mathematical equations. This leads to models in which state, rate, and driving variables are distinguished.

State variables are quantities like biomass, animal number for a species, the amount of nitrogen in soil, plant or animal, the water content of the soil; roughly those variables that can still be measured when time stands still as in the world of the Sleeping Beauty are state variables.

Driving variables characterize the interactions at the boundaries of the system and are continuously measured. Examples are macrometeoro- 
logical variables like rain, wind, temperature and radiation, and the food supply or migration of animals over the boundaries of the system. It depends on these boundaries, whether the same variables are driving, state, or rate variables. For instance, the heat stored within a vegetation canopy is a state variable when the system includes micrometeorolocal aspects, but a driving variable which has to be measured when the micrometeorological aspects are excluded from the system.

Each state variable is associated with rate variables that characterize their rate of change at a certain instant as a result of specific processes. These variables give the values of flows of material between state variables, for example, between vegetative biomass and grazing animal. Their value depends on the state and driving variables according to rules that are based on knowledge of the physical, chemical and biological processes that take place and not on a statistical analysis of the behaviour of the system which is being studied. This is the most important distinction between models that describe and models that attempt to explain.

New values of the state variables are found after calculating all rates; the computing process is usually repeated at given time intervals. In its most elementary form this is a process of numerical integration and the simulation program may be replaced by an analytical solution in cases where the equations are simple enough, but this is a rare occurrence.

Most models are too complicated and contain too many discontinuities and random processes to allow straightforward application of numerical integration methods. Various simulation techniques with different 'world views' have been developed to handle such models. Those originating from operation research studies are event-oriented. It is assumed that in general nothing changes and, on the basis of the state of the system and the assumed random processes, the time of occurrence of the next rare event is computed. Time is advanced then towards this moment and the event is executed. The simulation techniques that originated from the engineering sciences assume that continuous changes are dominant and incorporate standard numerical integration techniques. Both simulation techniques are continuously incorporating elements of the other, a process that has advanced to such an extent that the one-time unavoidable discussion on the superiority of the approaches is dying away. At present much more attention is paid to iterative use of computers. 
Especially for the uninitiated, attempts are made to simplify simulation programs into relational diagrams, often according to a method that was developed by Forrester (1971) to represent models of industrial systems. An example of such a relational diagram is in the contribution of Jameson. The state variables are given within rectangles $(\square)$ and the flow of material (water, carbon, nutrients) by solid arrows. The rate control of these flows is presented by the valve symbol $(\bowtie)$ ). The driving and decision variables are given within hexagonals $(\square)$. The dotted lines indicate which state or driving variables affect which rate, without indicating the quantitative aspect: these are the flows of information that are considered.

Rates are not dependent on each other in these state determined systems. Each rate depends at each moment on state and forcing variables only and is therefore computed independently of any other rate. Hence it is never necessary to solve $n$ equations with $n$ unknowns. An example may be needed. It is clear that the rate of growth of a plant, as measured by the increase in weight of its structural tissues, is closely related to the rate of photosynthesis of the leaves. In a statevariable model, this dependency is a result of the simultaneous operation of two independent processes. Photosynthesis contributes to the amount of reserves and this amount is one of the states that determine the rate of growth. At the onset of darkness, photosynthesis stops immediately, but growth proceeds until the reserves are depleted or even longer but then at the expense of existing tissue.

\section{Some practical problems}

The number of state variables that may be distinguished in an ecosystem are depressingly large. They concern not only primary producers, consumers and decomposers, but also the various species, their number, size, age, sex, stage of development etc. For plants, not only the weight and surface area of the leaves are of importance but also their nitrogen and mineral content, their enzymes and other biochemical characteristics. One can continue in this way and therefore a model that is based on full knowledge of all biological, physical and chemical phenomena that occur is never realised. Models are simplified representations of systems and the simplification manifests itself by the limited number of state variables that are considered.

In analogy with other approaches, it is assumed that considerable 
reduction of the number of state variables may be obtained by limiting the boundaries of the model and to focus the interest on those aspects where interest or understanding is most wanted. Then processes can be ordered with respect to their importance and only processes within the limited focus need be handled in detail.

It may be desirable, to focus attention on certain aspects, to have greater detail in those aspects and less detail in others. A modular approach to construction of the model is more manageable than constructing a single large model, i.e. the system can be split into sub-systems or modules like soil water, plant growth, nitrogen cycling, animal food consumption, and growth, etc. Likewise greater lucidity may be obtained by adapting the hierarchial approach discussed by Goodall in this book whereby different levels of resolution and different time-steps can be developed for different aspects of a sub-system or module. For example plant growth might be simulated on a daily time-step from photosynthesis and respiration of individual leaves on an hourly time-step.

The number of state variables that can be considered in any model is very limited, not so much because of the size of the computer or the cost of computer time, but because the research effort that can be invested in any one problem is limited. Models that contain about a hundred state variables are for this reason already very large, but at the same time they may be small compared with the complexity of the ecosystems that are considered.

For each purpose there is somewhere an optimum in the number of state variables that should be considered. At first the applicability of the model to the real world problem increases with increasing number of state variables, but then it decreases again because the addition of new state variables diverts attention from state variables introduced earlier because they were considered more important. The heuristic process of obtaining a set of state variables in order of their importance takes much time and many modelling efforts in ecology are sometimes explicitly but mostly implicitly geared towards this goal.

The validity of a dynamic model is thus always open to question but Wigan (1972) suggested that the following methodology is useful in minimising internal errors and maximising the validity of a model. He proposed five stages. 1) Postulates - the selection of basic assumptions of form and interaction on which the remaining stages are based. 2) Fitting - having selected a set of parameterized functions based on 
the postulates, fit 'best' values to these functions according to defined criteria of 'best' fit. 3) Calibration-given a set of fitted functions (or sub-models), calibrate their interrelationships with direct reference to the overall behaviour of the model and the data which the model aims to reproduce (sensitivity analyses). 4) Identification - ensure that the detail of the calibrated model is justified by the available data (and find the best reduced form if required). 5) Validation - the process of discriminating between different sets of postulates by reference to fresh data not used in the setting up, fitting and calibration process. These principles, written by an engineer concerned with modelling a transportation system apply equally to ecosystems. If such rigour was applied by biologists more often perhaps the value of their models would be greater.

In this way simulation may aid the understanding of important aspects of complex systems, in such a way that their behaviour is visualized and a guide to their management is obtained. But solutions are only accepted as such, if methods to falsify them are available, or to state it more positively, if they can be verified or their usefulness can be proven. Are there models that can be validated? Yes, but only of systems that are repeatable or recur. Only then may the model be derived from the analyses of some systems and validated on others. Examples of repeatable systems are mictobiological (manufacture of vinegar), agricultural (growth of maize) or industrial (manufacture of cars). Examples of recurring systems are stars, individuals of a species and ecological systems with so much resilience that after disturbance the original course of development is restored in due course (peat bogs). These recurring ecological systems appear to the observer at different places at the same time but in different stages. The strength of the fieldecologist lies in his ability to interpret as a time series in one place what is observed in different places at one moment. Repeatable systems can always be analysed by experimentation, but recurring systems sometimes only by observation. There is at present a strong emphasis on the experimental analysis of recurring ecological systems and this is justified because disturbances are dampened and destruction of the system during experimentation may be acceptable because there are many of them.

But there are also unique ecological systems or ecological systems with unique aspects. These are systems in which development is not governed by negative feedback, so that their development is diverse, although 
the origin may be the same. Other systems are unique because of the geographical situation, like some estuaries, lakes, islands and of course the world as a whole. Models of unique systems are concepts that cannot be validated experimentally but only more or less verified by observation of the behaviour of the real system over time. They remain therefore speculative models. The faith in speculative models is strengthened if similar methods of systems analysis applied to repeatable or recurring systems lead to validated models that cannot be falsified. Such models exist of physical systems: speculative models that predict the chances of flooding on the basis of an analysis of the physical processes are trusted although sufficient floods for verification never occur within a human lifespan. Whatever the model predicts, the dykes are strengthened as soon as one flood takes place and this proves that trust of this kind has its limits. Speculative models of ecological systems cannot be trusted as yet, because few models that are properly validated exist and the principles of model-building in ecology are still being developed. This certainly holds for so-called 'world models' unless their results are so obvious that the proper conclusions may be drawn without sophisticated techniques.

But if a speculative model of a unique system is sufficiently trusted, can it be used? For this purpose it is at least necessary to initialize the model so that the values of all the state variables have to be determined within such a short time span that they do not change materially. And this should be done without disturbing the unique system to such an extent that its course of development is affected.

In the final analysis it may appear that the ecologist is in the same position as the outmoded physicist, who claims that it is only necessary to determine at the same time the position, mass and velocity of all gas atoms in his room to predict their future. He may be in an even worse position because he has to live with or even within his unique system and cannot escape the problem by using the law of averages.

\section{References}

Forrester, J. W., 1971. World Dynamics. Cambridge Mass: Wright-Allen Press.

Wigan, M. R., 1972. The fitting, calibration, and validation of simulation models. Simulation 19: 188 . 


\section{The hierarchical approach to model building ${ }^{1}$}

David W. Goodall

\section{Summary}

Decomposition of ecosystems into subsystems (for instance, by spatial or biological dividing lines) can greatly facilitate the modelling process. Another useful tool is the cross-classification of ecosystem components and processes, so that the same model of a particular process can be applied to numerous different ecosystem components.

\section{Introduction}

It is commonplace that all systems can be decomposed into subsystems. If a system consists of a number of components, linked by various types of interaction, including flows of material and information, then any sub-set of these components may be separated as a sub-system, linked to the rest of the system by a sub-set of the interactions - those, in fact, linking the components within the sub-set with those not in the sub-set. And in general a sub-system thus distinguished may be further decomposed into sub-sub-systems. A hierarchical or nested structure is thus implicit in the concept of a system. Ecosystems are no exception. Their complexity may be broken down in a variety of ways, giving a number of smaller entities, each simpler than the whole, but still capable of further subdivision.

To consider an ecosystem in terms of hierarchical structure has at least two advantages. In the first place, it facilitates thought processes. A system of any complexity is almost beyond the powers of direct thought; the human mind cannot grasp in a single effort the interrelations among a large number of components.

1 This paper was prepared within the US/IBP Desert Biome Programme supported by NSF Grant GB 41288. 
The second advantage of the hierarchical approach is practical. If one is concerned to study the behaviour of a system by modelling it, decomposition into simpler sub-systems greatly facilitates the task. Particularly if computer modelling is intended, the structure of programming languages lends itself excellently to the hierarchical approach, where each sub-system may be matched with a sub-routine, and sub-routines may, like sub-systems, be nested indefinitely.

To divide the task of modelling an ecosystem into sub-routines has many advantages. The likelihood of error increases at a rate more than proportional to the length of the programme, so that division of the programme into sections which may be written and tested separately usually reduces substantially the time, effort and cost involved. Also, sub-division of the task makes possible the allocation of sub-tasks to separate groups, thus spreading the work load, involving a greater range of personnel (perhaps with specialized knowledge), and enabling the modelling effort to proceed along several channels in parallel rather than as a serial operation with the resulting bottlenecks.

\section{Principles for recognition of sub-systems}

The way in which an ecosystem may be broken down into sub-systems for modelling are legion, so we should give some consideration to the principles upon which this decomposition should be based.

In the first place, if a number of different individuals or groups of modellers are involved, an obvious factor will be the types of expertise available and required for different parts of the model. The optimum size of a group to take responsibility for a specific and limited modelling task is fairly small - almost certainly under ten. This will be difficult if each sub-task encompasses a wide range of disciplines; consequently, a decomposition in terms of disciplines may well be appropriate, though it is important to provide opportunities for criticism of each sub-model from other disciplines.

Another criterion is concerned with validation. Models need to be validated by comparing a set of outputs from the model with those of real-life systems having the same inputs. And, if the model is constructed of sub-models, the latter should also similarly be validated. This implies that the set of inputs and outputs for each sub-model should be easily measured - and, for preference, (in the case of inputs) controlled. Then the sub-models may be validated separately, and only 
the results of combining them need to be tested on the scale of the full model.

Third: the various sub-systems should be selected so that they lend themselves to treatment at different levels of complexity. This will be particularly important if the development of each sub-model is the task of a separate group of modellers. So long as the inputs and outputs (a required set of outputs, and a maximum set of inputs) for each submodel have been determined in advance, each sub-model can be developed in versions of varying complexity, differing only in their internal structure. The various sets of sub-models will then be mutually compatible. The process of modelling can proceed iteratively, but the iterations for the various sub-systems can be mutually independent. If processes on different time scales are incorporated in the model, it is very desirable that they should be treated in separate sub-models. The time scale appropriate for bacterial activity, for instance, is much shorter than that for vertebrate demography. If processes with such different time scales are included in the same sub-model - which will usually involve using the same time step - adequate computer treatment may become very difficult; it may also be highly uneconomic. It may also be advantageous to distinguish sub-systems on the basis of internal homogeneity in respects other than their time scale. If the various entities within a sub-system behave similarly, undergo the same processes, and are influenced by the same variables, it becomes much easier to model that sub-system with satisfactory detail and accuracy.

Another criterion which appeals intuitively is that of limited interactions. Ideally, if the system can be divided into sub-systems which do not interact at all, the task of modelling at the whole system level is complete, and the whole operation can be performed at the sub-system level. Similarly, if the system can be so divided that the interactions (material flow, information transfer) between sub-systems are minimal, the major task will be in building the sub-system models - which are, ex hypothesi, simpler to construct than those for the system as a whole. There seems a possibility that this criterion may conflict with that of the former paragraph, and in this case a judicious balance must be struck. 


\section{Types of subdivision}

Let us consider, then, the ways in which an ecosystem might be divided for modelling purposes.

One obvious method is spatially, both horizontally and vertically. One obvious place for possible division is at the surface of the soil. Many components of the system are either above or below the soil, but not both: and many processes, too, are limited to one or the other portion of the system. Horizontally, one also has the possibility of useful subdivision. Spatial patterning is a commonplace of ecosystem study. Substrate differences, topography, the organisms themselves, all serve to differentiate the system and its dynamics on the horizontal plane. Accordingly one may separate sub-systems horizontally which are much more homogeneous internally than the system as a whole.

Quite a different possibility is provided by the biological composition of the ecosystem. Conspecific populations of organisms show a high degree of homogeneity in their behaviour, so that the species constitutes a very natural sub-system in decomposing an ecosystem for modelling purposes. If one groups species, the loss of homogeneity may be fairly limited if they are grouped according to their interrelations with other species outside the group, so that they constitute a reasonably homogeneous set within the system as a whole. Clearly, subdivision in terms of biological categories (species or groups) lends itself very well to hierarchical treatment, though the taxonomic hierarchy will usually not be the most appropriate.

Other ways of decomposing the system may, in plants, for instance, be based on distinguishing organ types as separate sub-systems: the foliage; the roots; the storage organs; and so forth. Stages of development may also constitute a useful basis for distinguishing sub-systems: seeds may be separated from seedlings or mature plants, eggs from larvae or adult insects. For some purposes, these subdivisions could take the place of those based on biological species or group; for others, they might constitute different levels of a hierarchical structure. So far, we have considered sub-systems in terms of components; but processes or groups of processes can also constitute sub-systems. Within the foliage of a species, one could for instance treat the processes concerned with photosynthesis, with translocation, and with leaf fall as separate sub-systems; or within an animal species feeding, mortality and reproduction could be regarded in the same way. And 
processes can be broken down hierarchically just as can components. Photosynthesis can be divided, for instance, into energy capture and conversion, carbon dioxide access, and carbohydrate synthesis; mammalian reproduction can be divided into ovulation, sexual encounter, fertilization, pregnancy, and parturition.

\section{Cross-classification}

It has become apparent from what has been said that a hierarchical approach alone may not be the most appropriate method of breaking down an ecosystem for modelling purposes. Classifications for different processes may interlock rather than subdivide, and the appropriate level of subdivision may depend on the particular process under consideration. In an ecosystem model, accordingly, one needs a structure more flexible than a strict hierarchy of sub-models - the principles of cross-classification and ad hoc classifications need to supplement that of hierarchy.

By this, I mean that the components and processes in an ecosystem may be classified in a number of independent but mutually compatible ways, and that the classification used may differ from process to process. Thus, one may classify plant tissue, for instance, according to organ type, species, age, and location vertically and horizontally. The process of photosynthesis, say, will be limited to certain organ types (those containing chlorophyll); but the rate will differ with all the crossclassifications of those organ types. The values of constants for the process may vary with organ type, species and age; the effect of location does not usually take the form of different values of the constants, but depends on local variation in the values of the factors which affect the process. If we consider, on the other hand, transfer of material from plants to large herbivores, location may be irrelevant, and only the three other classifications may be relevant.

Looking now at the large herbivores themselves, they may be divided (for instance) by species, sex and age. For the modelling of feeding habits, age may be of little importance and sex of none; but for demographic processes they are all-important. Thus, modelling should introduce the various cross-classifications only in processes to which they are relevant.

The general method of constructing ecosystem models which is adumbrated here - with a hierarchical structure of sub-models, each of 
modular form, which can be replaced by other modules similar in respect of input/output structure, and with processes activated only in respect of those cross-clasifications to which they are relevant-lends itself to an iterative process of model construction and improvement. In each part of the model, alternative structures, and degrees of resolution in respect of the different cross-classifications, may be tested in their effects on the outputs obtained, and in their agreement with those of the real-life system modelled.

\section{An example}

To fix our ideas, let us consider that we are to model an area of savannah woodland in Queensland, grazed by cattle and wallabies, and that our task is to predict the mean rate of gain in weight by the cattle, averaged over the whole year. Our first very simple model (Fig. 1) consists of three compartments only, with flows of energy among them.

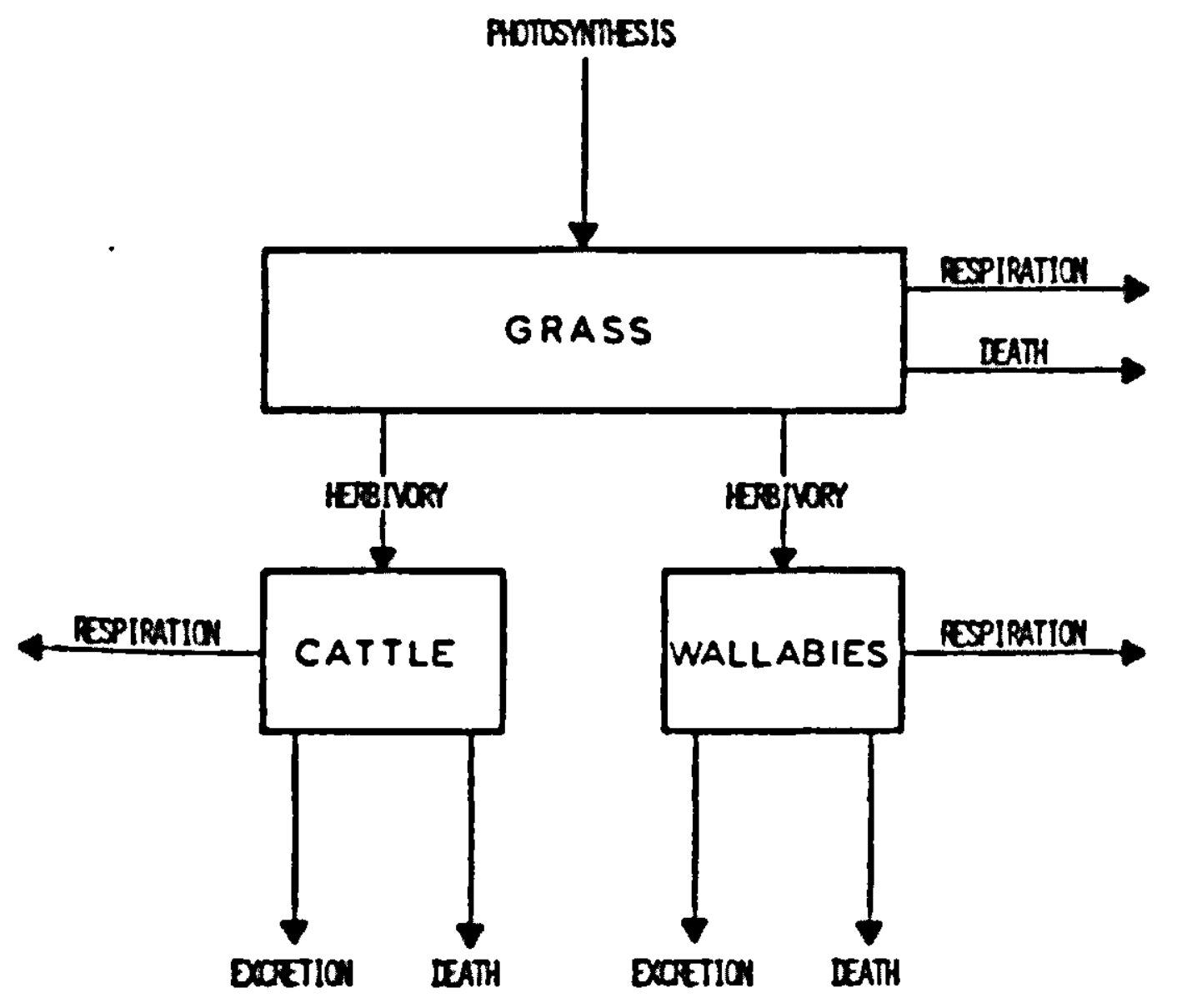

Fig. 1

It is clear, however, that spatial heterogeneity is too important to ignore - the grasses grow differently, and differ in proportions, under the scattered trees and in the interspaces; so the first decomposition distinguishes these two sub-systems within the 'plant' sub-system of the simplest model (Fig. 2). 


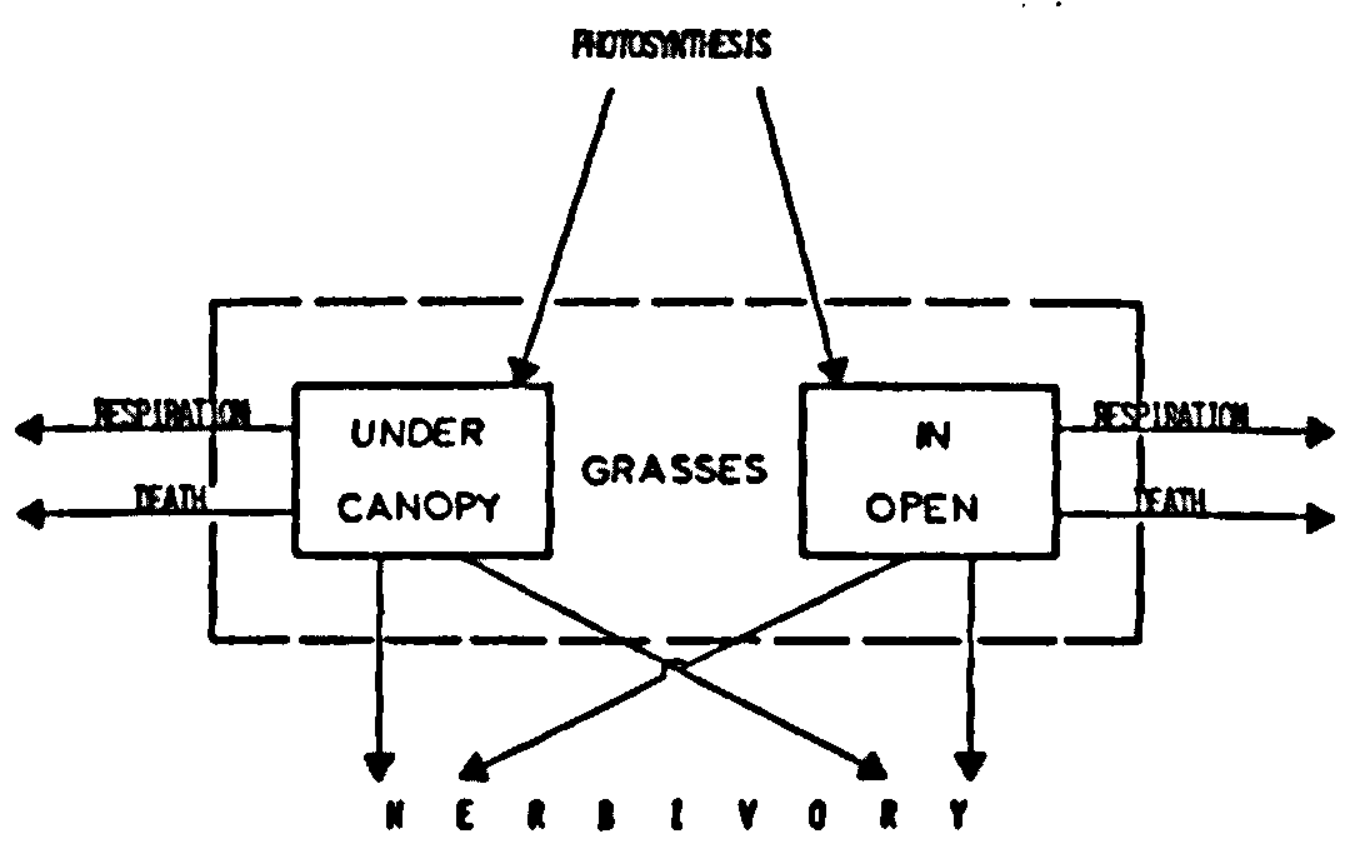

Fig. 2

We now focus our attention on one of these plant sub-systems and consider in more detail what will be needed in order to model the foliage available for consumption by the herbivores, and thus determining the weight gain by the cattle. The grasses under the tree canopy gain energy by photosynthesis, lose it by respiration, by herbivore consumption, by leaf-fall and death. But there are two important species, Heteropogon contortus and Themeda australis, differing markedly in palatability to cattle, so this provides the next hierarchical decomposition of this subsystem (Fig. 3).

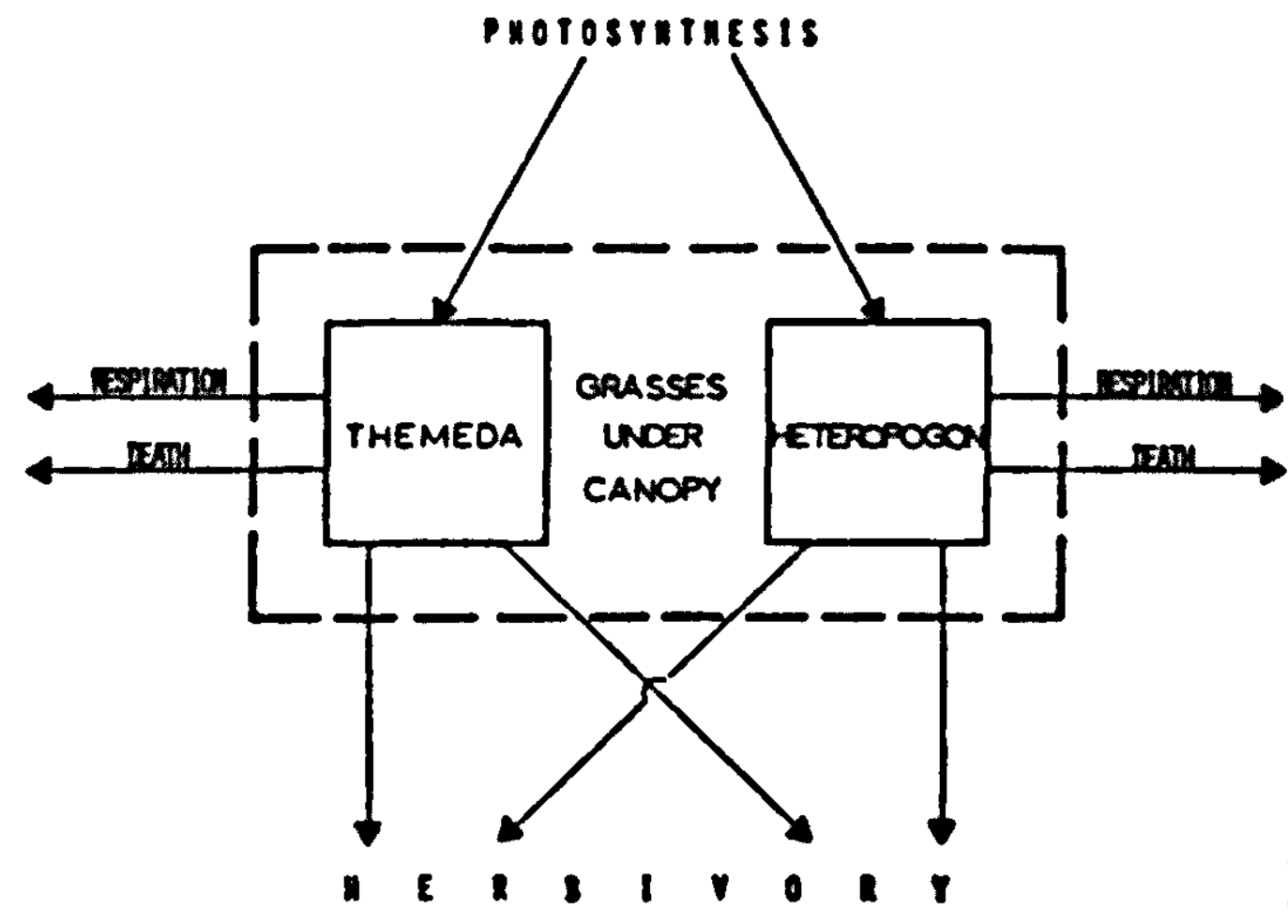

Fig. 3

Considering now the sub-system of Themeda australis under the tree canopy, we recognize several compartments - the active leaves, the inflorescences, the bases, the dead leaves, the roots (Fig. 4).

So we narrow the focus again to a still smaller sub-system - the active leaves. Here again energy changes are a balance between photosyn- 


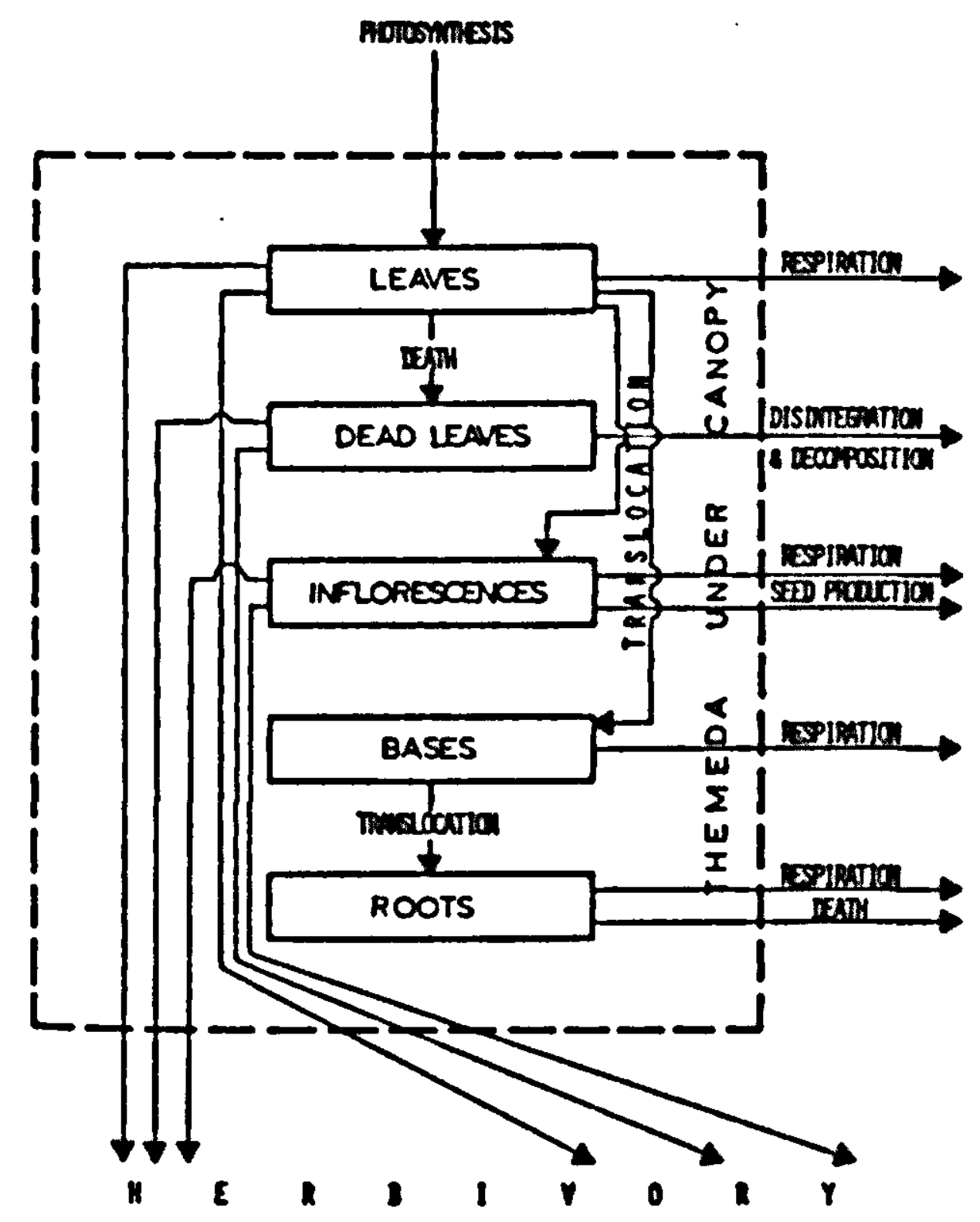

Fig. 4

thesis, respiration, consumption and death, together now with translocation. And we focus our attention on photosynthesis, noting that the rate is dependent on certain external factors - irradiation and temperature among them-and some internal ones, including leaf water status, and the content of certain nutrients (Fig. 5).

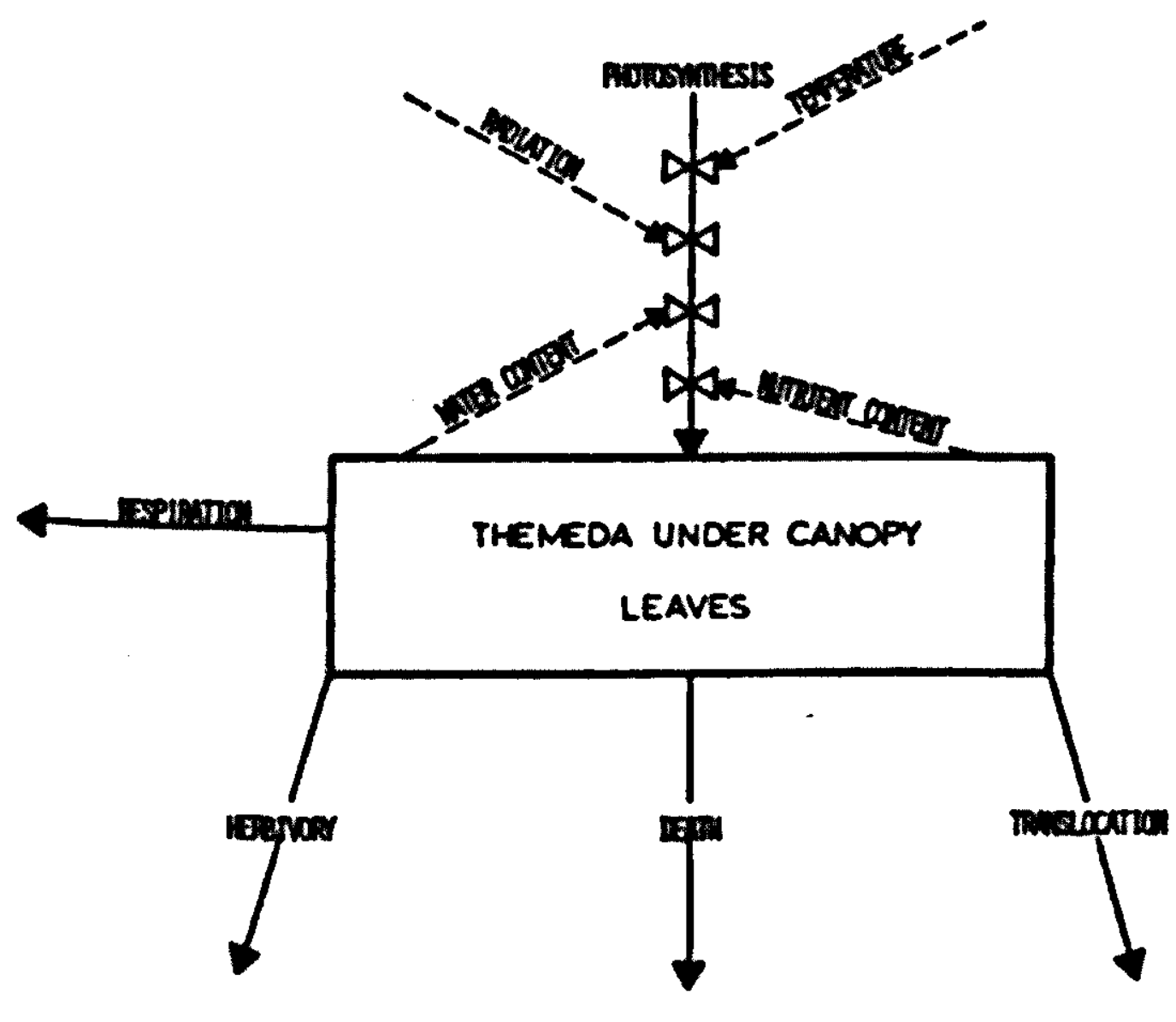

Fig. 5 
The irradiation and temperature are affected by the density of the overhead canopy, which must consequently now be included as a new state variable in the overall system. Internal water status and nutrient status are also new requirements for state variables within the Themedaunder-canopy sub-system, which will call for additional links with the other organ sub-sub-systems within this sub-system.

If we now turn to these other organ sub-sub-systems, we find that modelling of photosynthesis is required for the inflorescences too, that the factors affecting the rate of photosynthesis are the same, and that the function expressing this dependence is also the same, though the constants are different. This similarity between these groups of organs does not, however, extend to all processes. Respiration may be treated similarly; the same may be true of translocation, with a difference in sign; but 'death' is different, this resulting in transfers in one case to dead leaves, in the other to seeds.

If we now broaden our focus again to include Heteropogon under the tree canopy, we find a division into organ sub-sub-systems exactly parallel with those of Themeda is called for (Fig. 6).

Photosynthesis in both cases depends in the same way on the same factors, and the differences are solely in the values of the constants.

If we broaden our focus still more, to include the areas between tree canopies, we find that the structures within these major sub-systems are identical in their subdivision, their processes, their factor dependence, the functional form expressing the rates, and down to the very values of the constants in these expressions. Thus, though the grass sub-system has been decomposed into twenty sub-sub-systems, the modelling work is not multiplied by a factor of twenty. Thanks to the crossclassification, only five different types of sub-systems need to be considered, and the same sub-models can be applied, with appropriate inputs, to each sub-system within a type. Moreover, models of particular processes are even more generally applicable. By classifying the relevant constants of the system in parallel with the appropriate classifications of the state variables, modelling effort for this highly complex system may be greatly reduced. And, where particular processes apply only to certain classes within a classification (e.g., roots do not photosynthesize), these peculiarities may be incorporated in the model by a system of switches.

The process of photosynthesis in Themeda leaves, on which our 


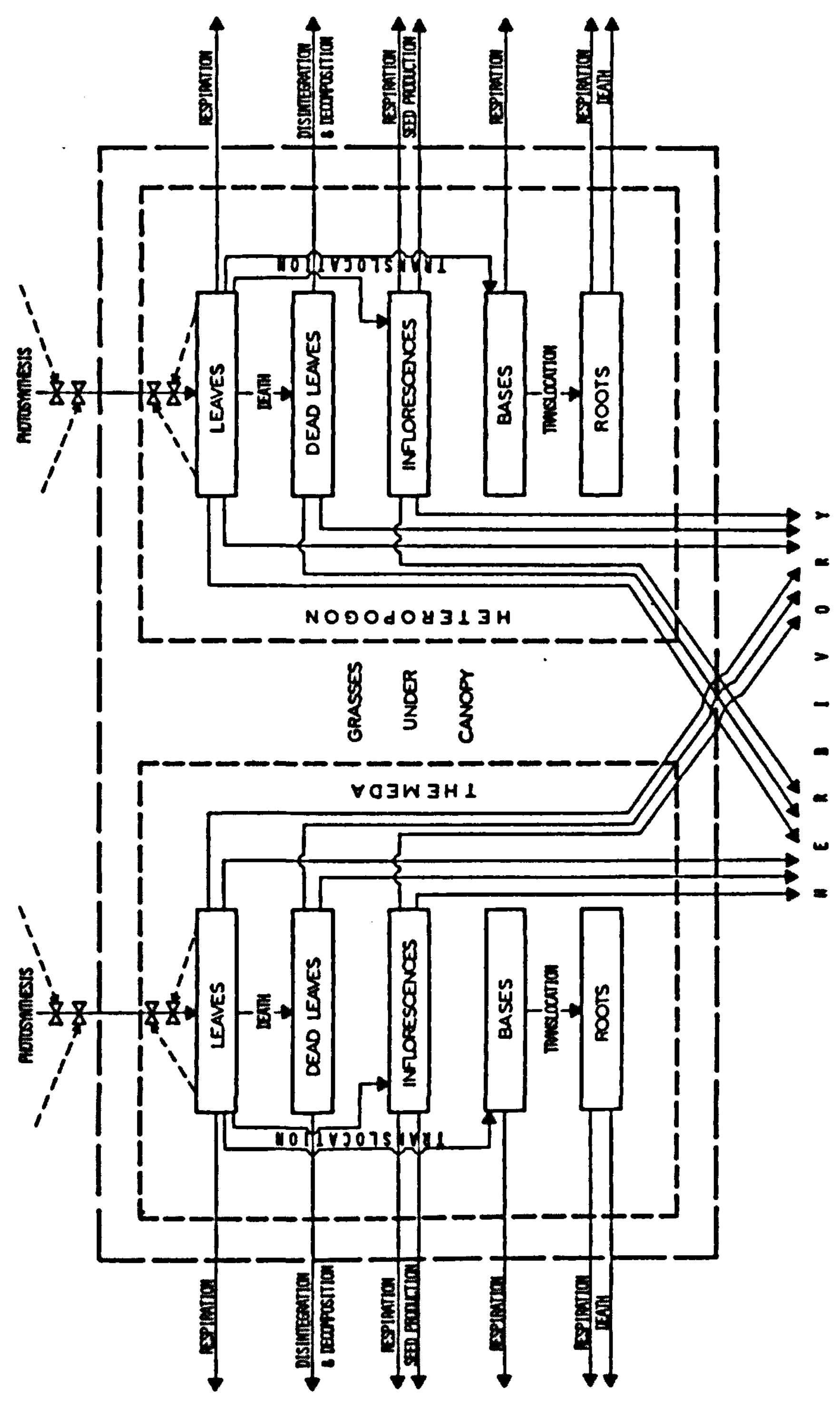

$\frac{1}{i}$ 
attention was concentrated, could be handled in a variety of ways. A possible sub-set of influencing factors has been mentioned; but this list could clearly be expanded (with the expectation of more precise estimation) or reduced (if less precision is acceptable, or if availability of data dictates it). But also, with the particular list of four influencing variables mentioned, options are available. One could use an arbitrary polynomial to relate photosynthesis rate to these variables, or one could use a functional form which more accurately reflects the known biological features of the process. Or one could develop a sub-model which was more than a "black-box", and actually included, say, changes in stomatal aperture, or the process of acclimatization. All these would be legitimate alternatives for sub-models of the process of photosynthesis. And, if the data required are available, it may be worth building them all. The most complex sub-model, that incorporating the most advanced biological knowledge, is not necessarily the best for a particular purpose. And if the whole model has been constructed on the hierarchical principle, with interchangeable modules, this can easily be tested by exercising it with the rest of the model unchanged and the various treatments of photosynthesis replacing one another. Since the whole model is directed towards prediction of an objective function - in this case, the mean rate of gain in weight by the cattle comparison of its performance using alternative photosynthesis modules should be based on this prediction, and on its agreement with observed values. Where the domain of the model includes a variety of systems, or a system under a variety of conditions, the comparisons should in principle include several of these cases, and the performance of the model would be assessed over this whole range. Particularly if errors in the estimation of parameters are taken into account, it may be found that one of the less sophisticated sub-models is at present giving more reliable predictions; and tests of sensitivity of the objective function to these parameters may show that improved estimation would not be worth the effort.

Tests of alternative modules may also be performed elsewhere in the hierarchy. Instead of the sub-models at the leaf level, one may perhaps be considering sub-models at the plant species level. Here, too, the input of energy by photosynthesis could be treated in various ways, without considering the subdivision of the plant into organs. And these alternative modules at the higher hierarchical level could be tested in the same way as those for photosynthesis of leaves considered sepa- 
rately. Moreover, comparisons can be made between different hierarchical levels. The highly decomposed model with sub-models for separate organs may be compared with that in which decomposition does not proceed below the plant level.

The question may be asked: "If data for a model of higher resolution are available, of what interest is one of lower resolution?" One answer is that errors in parameter estimation may make the latter preferable for estimating the objective function. Another is the practical one of computer time. It may be that the cost of running a high-resolution or high-precision model would be prohibitive, and that some compromise with a model in principle less satisfactory must be accepted. But all these alternatives may readily be explored and pursued, if the model has been constructed on the hierarchical and modular principle. Though this illustration has, at each hierarchical level, been limited to one sub-system, or one process, it can of course be extended throughout the system, so that (for instance) the cattle sub-system and the wallaby sub-system will have almost identical internal structure.

It seems likely that the principles outlined here of hierarchical organization, modular structure, and cross-classification will be widely applicable wherever ecosystem modelling progresses beyond the lowresolution stage. 


\title{
Evaluation of models
}

\author{
H. van Keulen
}

\section{Introduction}

In the increasing stream of publications on the use of computer modelling and simulation as tools for ecological research, relatively little attention is paid to the evaluation of the models presented. Models originating from the technical sciences are in general based on detailed knowledge of the theory of the underlying processes, whose mathematical description is exact. Hence such models hardly require experimental verification to prove their validity.

In the biological sciences and certainly in ecology, we are, however, dealing with dynamic systems that are not man-made and in many areas our understanding of the basic principles is fragmentary if present at all. Models of biological systems are therefore often not more than a subjective expression of our opinion about its structure and behaviour. Complex models, when properly formulated, do represent a consistent argument based on these opinions; but that is still no guarantee of their validity.

It should be recognized, of course, that the validity of a model is primarily determined by its purpose. The model of a system does not exist, as there may be several models of one system, all perfectly valid, but aiming at different goals. A model of an aeroplane, developed for the purpose of flight control gives satisfactory results without taking into account detailed aerodynamics. However, when a model is built to decide on the design of the machine, aerodynamic laws cannot be neglected.

In general a model, like any theory, aims at summarizing and predicting. Thorough proof must be given that existing historical data can be satisfactorily explained by the model before sufficient confidence can be placed in the predictive results. Verification of the model is therefore an important part of the simulation. Results of carefully designed experiments with computer models based on the purpose of the model, should be tested at all stages with the results obtained from experiments with the real system. 


\section{Evaluation at different levels}

\section{a. Postulates}

Whenever the modeling approach is used to investigate a problem, a number of decisions must be taken. The first and most basic problem is the choice of the postulates on which the model is to be based. This involves the decision on the boundaries of the system to be studied, determining which processes are included in the model and which are introduced as forcing functions. The choice is not always obvious. For example, if one is interested in the dry matter production of a maize crop, the macro-weather may be considered as an external variable which is not affected by the standing vegetation. When, however, the influence of a pollutant from a nearby chemical plant on the yield is the main interest, aerodynamic differences caused by the presence of vegetative surfaces may be of decisive influence on the effect of the macro-weather on the fate of the pollutant. The main criterion must be the purpose of the simulation, which should not be too ambitious to keep the model verifiable. The model should be designed in such a way that it yields the kind, the quantity and the quality of data necessary to draw conclusions relevant to its purpose. Hence the system should be chosen in such a way, that the inputs and outputs at the boundaries can be measured. Also for the decision on the distinction between different subsystems each subsystem must be defined such, that it may be subject to isolated experimentation, with measurable inputs and outputs. In whatever way the postulates are chosen or implicitly included in the model by intuitive incorporation or omission of certain processes or interactions, at some point in the evaluation phase we must return to them and check how adequate they are and in which way they influence the results. Although this may seem obvious, the spectacular impact of the results of Meadows' (1972) world model showed that the implied postulates were not explicitly recognized.

\section{b. Processes incorporated in the model}

Once the decision about the postulates and the boundaries is taken, a set of mathematical equations, each one describing a relevant physical, physiological or ecological process or part of a process, is combined to form the model. All mathematical relations must be subject to evaluation. In general the processes are studied under controlled conditions 
to establish the relation between external or internal state variables and the dependent rates. Often the technique to obtain maximum information from such experiments is the application of stepwise changes in state variables and recording the dynamics of the response. Such experiments serve as validation tests for independent submodels. Such submodels may then be used in full in the final model when the dynamics of the processes are of interest or the results of the submodel are entered through analytical expressions or tabulated functions. This implies a hierarchical approach to modelling, which can help to make complexity manageable. An alternative to the use of dynamic submodels to obtain quantitative mathematical relations, is the determination of a number of equilibrium situations, which may be described by an analytical expression, like the photosynthesis-light response curve of individual leaves in a crop growth model. Such relations can only be applied, however, if instantaneous adaptation to changing conditions may be assumed, i.e. when the effects of time-lags can be neglected.

Compound relationships are also obtained by the use of a 'black box' approach. This is done when the underlying processes are not known, and inputs and outputs of a specific component of the model are then connected by a special programming technique, which 'mimics' their measured relation. In this way no information is obtained on the causal relationship between the variables and it is dangerous to use them for predictive purposes, because under different circumstances different reactions may occur. It should, however, be realized that every relation on a level higher than that of atoms and molecules is a 'black box' to some extent, but the use of this technique becomes increasingly dangerous when applied on higher levels. Ultimately it turns the model from a explanatory model into a descriptive one which cannot be used for extrapolation at all.

An example of a reasonable use of this way of working is given by Janssen (1974) in his model of germination of winter annuals, where changes on the biochemical level are 'mimicked'.

All three methods described can be evaluated either by statistical methods or by judging the accuracy of the relations from independent knowledge of the measuring methods. Often, however, no quantitative data are available at all and relations are introduced based on intelligent guesses'. This may not be disturbing when it concerns minor details of a model but when important relations are based upon this 
principle, model validation becomes a recreative pastime and the investigator should consider going back to experiments with the real system in order to establish the relevant relations. At best, results obtained from such models may then serve as a guideline in designing proper experiments.

An additional problem arises from the parametrization of the functional relationships. In plant production models often the quantitative reactions of plants grown under different conditions show large differences, though the processes are the same. In general, studies at the process level yield most information in the evaluation phase of modelling, especially when simulation is aimed at gaining more insight into the relevance of various factors.

\section{c. Evaluation of output and model behaviour}

Testing of the whole model may still be done at two levels: gross output of the model, like yield in crop growth models, may be tested, or we may test the internal behaviour of the subsystems, comprising the model. Testing the gross output is in general not very enlightening, especially with crop growth models. On the one hand the experimental data available are subject to sampling errors, which are seldom smaller than $10 \%$. This implies that the error in the measured growth rates is of the order of $20 \%$, so that, when statistical analysis is applied, 'reasonable agreement' is easily obtained. On the other hand, such models contain so many feedback relations that internal compensation may lead to levelling out of deviations caused by the introduction of erroneous relations.

When, however, only gross output data are amenable to testing, as is often the case in models used in ecology, proper evaluation should contain two phases: (Wigan, 1972) calibration and validation. The calibration procedure is best described by the term curve fitting. One set of data is used to adapt, within reasonable limits, weak or unknown parameters or relations, so as to reach the best overall agreement between simulated and observed results. Even the most simple ecological model, however, contains already such a large number of parameters that such a procedure often requires an unrealistic amount of experimental data.

In the final stage of validation still other sets of completely independent data must be used to show that the model yields proper results under different conditions. Many of the ecological models developed at 
present do not permit this full procedure because of lack of data. This implies that all or part of the same data are used in both the calibration and validation phase so that all that can be evaluated is the extent to which the model regenerates its own inputs. Such techniques are widely accepted in econometric sciences and are completely based upon successive application of statistical methods to obtain goodness of fit. This may be called identification, rather than validation and it is questionable whether in such cases simulation has any advantage over multiple regression techniques. The most that can be concluded from such models is that historical events under a given set of conditions may be described by the generated set of equations but no insight into the dynamics of the processes is gained.

Even when in the model the processes are described completely on the basis of physical or physiological principles and the validation experiments are carried out by the same team working in the modelling part, it is difficult to completely separate the two. Unintentionally observations from the experiments play a role in the decisions about the relations that enter the model. Therefore data that were available during development of the model give a better comparison with the simulated results than independent data that were collected later on (van Keulen, 1975). This also shows that the risk of circular reasoning is very high when partly empirical or semi-empirical relations obtained in validation experiments are used in the model. Hence when results from simulation and real system conflict with each other, no attempt at parameter adaptation should be made but the individual processes should be re-examined and improved at the weakest points. This is done more directly when the internal behaviour of the subsystems is used for validation. Although this may be a huge task in more complex models it is the only way to develop simulation models that are not only convincing in their summarizing behaviour, but have also predictive value and can be used to extrapolate knowledge from known situations to new areas or circumstances. A good example of this technique is the use of enclosure studies in which the processes of photosynthesis, respiration and transpiration are subject to direct validation (van Keulen \& Louwerse, 1974). Comparison of measured and simulated dynamic behaviour of these processes under different conditions may lead to redesigning of the model, which in turn is a guide line for the design of new experiments (de Wit, 1970). Such an intimate relation between modelling and experimentation will generally not lead to the 
rapid production of a great number of models, but will certainly increase confidence in the results that are obtained.

\section{Internal evaluation}

So far we have been considering the validity of the model as a representation of reality. There are, however, in the validation phase of modelling some other pitfalls that should receive proper attention. Before any comparison with the real world makes sense, the modeller must be sure of the internal consistency of his model.

There is firstly the problem of dimension inconsistency but, although this may create difficulties, the occurrence of such errors generally shows up in the early stages of model development. It would, however, be very helpful if the problem-oriented computer languages contained a dimension check routine. A more serious problem is that of the correct computer implementation: errors during formulation of ideas, during programming, and mistakes introduced during the writing and punching procedures. Especially in more complex models, which may consist of over 1000 statements, such errors are easily made and difficult to detect. Especially errors made during the formation of the ideas, may escape detection because the normal safeguard of independent implementation by more than one person is impossible. The best solution is running the model in limit situations, where its behaviour is known. Such a test does not completely prove that these errors are absent and so far there is no technique to avoid them completely.

\section{Sensitivity analysis}

A widely accepted technique in the process of model evaluation, applied specifically in situations where accurate input data are missing, is sensitivity analysis. It is most conveniently defined as a test on the relative influence of changes in input data and parameters on the relevant outputs of the model. This technique may be especially helpful when it must be decided which subsystems should receive most attention in the experimental field. Relations with the strongest impact on the final result must be studied thoroughly, while those which hardly influence the outcome may be introduced as intelligent guesses. There is, however, a dangerous aspect in the technique: the structure and the functional relationships of the model are taken for granted, so that 
when conceptional errors are present, the importance of certain relations may not be visible at all.

Research efforts may then be directed into the wrong field and important parameters may be completely neglected. It is therefore necessary to evaluate sensitivity analysis in the light of all assumptions that were made during the development of the model. In many cases it is more significant to study the sensitivity of the model's results to different postulates, than to different parameter values.

\section{Conclusions}

As is clear from the foregoing, proper validation of simulation models is an extremely difficult and time-consuming procedure. It is, however, an essential procedure, as this phase of the modelling process must prove the validity of the opinions on which the model is based. It will also lead to the design of relevant experiments and thus to increasing understanding of the system in which we are interested. One may, however, put the question how useful even thoroughly validated models of ecosystems are for predictive purposes. When a perfect simulation model is to be used for predictive purposes, it is still necessary to initialize it properly to obtain the desired answers. The determination of the initial state of such a system is, however, likely to disturb it to such an extent that completely different behaviour is the result. Hence if each ecosystem is unique, as is often stated, we will never be able to find experimental data to test the results of our model. This may lead to the conclusion that only systems which show a repetitive behaviour are amenable to simulation. This is generally the case with systems that are controlled by a negative feedback.

And that is hardly an encouraging thought at a time where ecologists claim or are asked for qualified opinions about explosive situations.

\section{References}

Janssen, J. M. G., 1974. Simulation of germination of winter annuals in relation to microclimate and microdistribution. Oecologia (Berl) 14: 197-228.

Keulen, H. van \& W. Louwerse, 1974. Simulation models for plant production. In: Proceedings of the WMO symposium 'On agrometeorology of the wheat crop', Braunschweig (in press). 
Keulen, H. van, 1975. Simulation of water use and herbage growth in arid regions. Pudoc, Wageningen. (Simulation Monographs).

Meadows, D. L., 1972. The limits to growth. Universe Books, New York. Wigan, M. R., 1972. The fitting, calibration and validation of simulation models. Simulation 18 (5): 188-192.

Wit, C. T. de, 1970. Dynamic concepts in biology. In: Prediction and measurement of photosynthetic productivity. Proceedings of the IBP/PP Technical Meeting, Třeboň. Pudoc, Wageningen. 


\section{Management of ecosystems: information supplied by simulation models}

Donald A. Jameson

\section{Summary}

Although prediction of ecosystem response, in the strict sense of the term, is difficult because of the highly probabilistic events involved, it is, nevertheless, a feasible problem to estimate the probabilities of particular responses occurring. These probabilities usually cannot be determined from actual field data because of the large data sets which would be required, but can be estimated from results of simulation models. Management models which use mean values and variances of ecosystem parameters can then be used to make better management decisions.

\section{Introduction}

In assessing the applicability of ecosystem studies to grassland resource decision-making, we are faced with the paradox that: a) there has not yet been a case where a decision involving grassland resources has been specifically based on ecosystem study results. This is not surprising, of course, since summary reports based on the research program efforts of 1967-74 have not yet been completed. The other side of the paradox is: b) that methods for approaching the problems of grassland resource decision-making have been presented to international and various national audiences several times.

Procedures for treating grassland resource decision-making primarily utilize optimization models. Professional journal articles include those by Woodworth (1973); D'Aquino (1974); and Bartlett, Evans, and Bement (1974). The procedures are also covered in book form (Jameson, D'Aquino, and Bartlett, 1974).

On the other hand, ecologists typically do not arrange their information in the same format as do resource decision-makers. Scientists are more likely to use simulation models such as those utilized by Forrester (1968). Nevertheless, simulation models directed toward applied questions have been prepared (e.g., Smith and Williams, 1973). 
It is generally the case, however, that resource managers have not used simulation models, nor do the thoughts of many managers appear to be well represented by such models. The different conceptual structure of managers as compared to that of scientists has led to the frequent accusation by scientists that managers do not have specific questions that are researchable. Researchers, on the other hand, often appear to have a conceptual structure of problems which leads to simulation models, but generally have not utilized such models to improve the organization of research results about a particular question. Thus, managers have previously accused the researchers of taking too long to come up with relevant results, and generally not dealing with relevant questions.

Most of these accusations are, of course, true, but the utilization of appropriate modelling procedures for managerial and scientific questions should greatly reduce this discrepancy.

Unfortunately, many scientists have thought that detailed biological studies conducted by biome programs would lead directly to management recommendations. We find, however, that no such studies, no matter how detailed they may be, lead to a 'better' solution. Contrary to the belief of many ecologists, 'good' and 'bad' are not ecological properties. Research results and modelling efforts of scientists can, however, greatly facilitate answering of if-then questions of managers. It appears that there are three major attributes of biome type research which are relevant to grassland resource decisions:

1 Biome research has led to entirely new approaches in ecological research. Previous ecological research has very often described conditions at a particular time and place. In the modelling vocabulary, these have been 'state variable' measurements. The numerical value of such state variables depends on the unique combination of circumstances of that particular time and place, and very often is not generalizable to broader situations.

On the other hand, biome programs have emphasized process studies which determine the rates or changes per unit of time. These rates or results of process studies can then be incorporated into models which are much less situation-specific than state variable measurements, and consequently can provide general indications of results for a wide variety of situations. We are now very nearly able, for example, to simulate grassland systems for practically any climatic situation (Fig. 1). Thus, the advantage to the resource decision- 


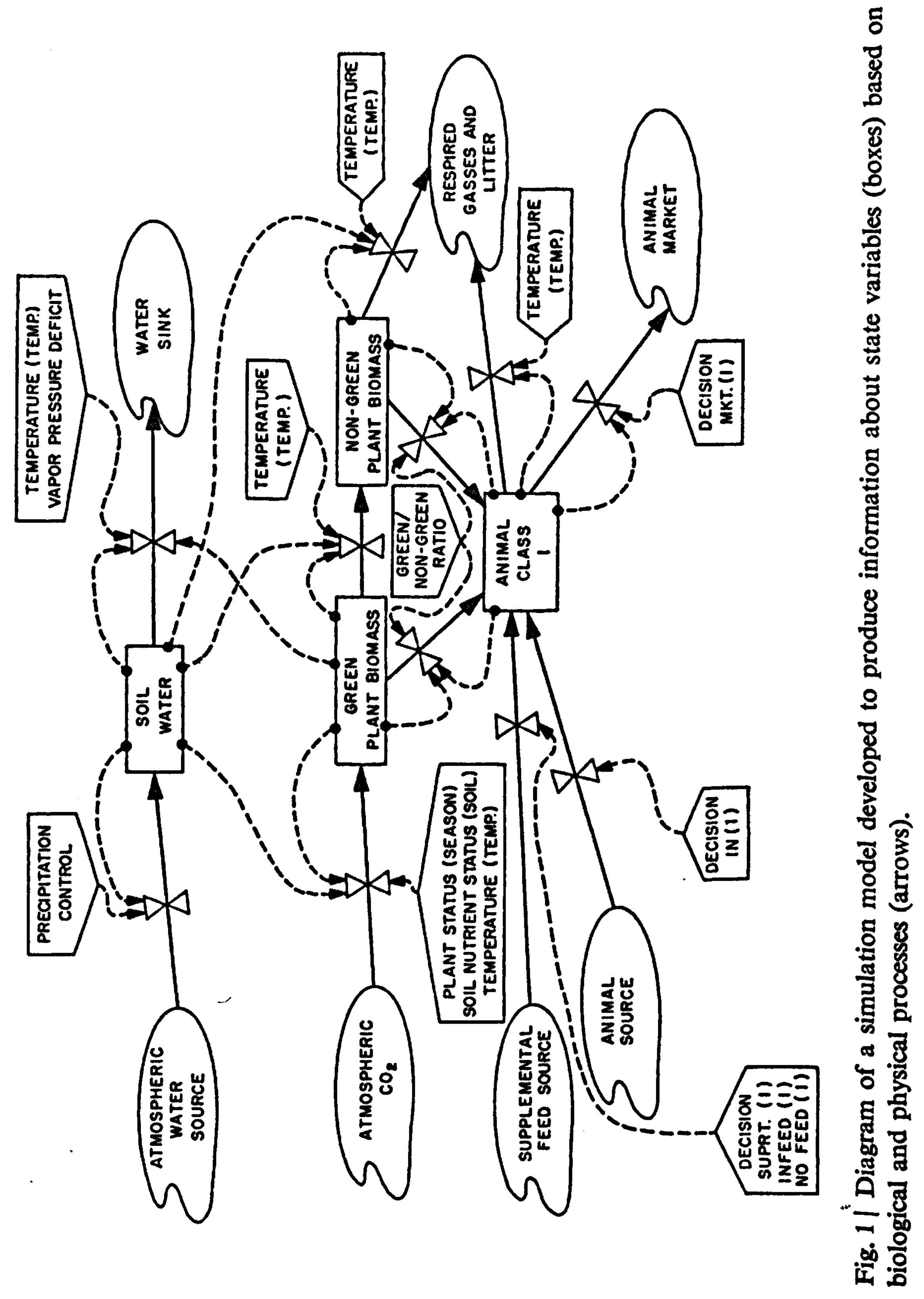


maker from biome results is that ecosystem and modelling approaches may lead to better research and thus, eventually, but nevertheless indirectly, to better management.

2 A second major contribution of biome results is the clarification and emphasis of filtering or stability aspects of ecosystems. Filtering is used here in the sense that the output of a stage of a system is less variable than the input. Ecosystems in the grassland management context are driven by highly variable precipitation, temperature, and other climatic events. The first stage in reducing some of the variation is soil water, which is much less variable than precipitation. Subsequent filtering stages include live plants, dead plants, primary consumers (such as cattle), offspring of primary consumers (calves) and, with economic systems, can include stabilizing components such as monetary reserves. From this very practical example, we can see that the ecological system acts as a filter mechanism which needs several stages (6-10) to result in a satisfactory economic stability for managerial purposes. An economy based on plants (e.g., wheat production) will be much less stable than one based on grazing animals for example, and will require greater monetary reserves. Note that the definition of stability in this case is economic rather than ecological. Too few stages yield unsatisfactory stability, i.e., instability; additional stages may not be necessary for stability considerations but may add greatly to the difficulty of research.

3 A third major contribution of the biome approach is that it provides us with methods of getting specific information which cannot be readily obtained experimentally. Biome models based on synthesis of process studies information can be used to generate approximate data. Although these synthetic data will likely be less accurate than state variable measurements, which would have been collected for a particular situation, they are also much cheaper and quicker to obtain, and thus have a higher probability of having a real impact on managerialdecisions. For example, managers usually need to know seasonal values of standing crop of herbage as influenced by varying management practices. Biome-type models provide a ready way of generating such values even though they would be somewhat difficult to obtain experimentally (Fig. 2). These estimates from simulation models can be used in deterministic management models such as linear programming. The 


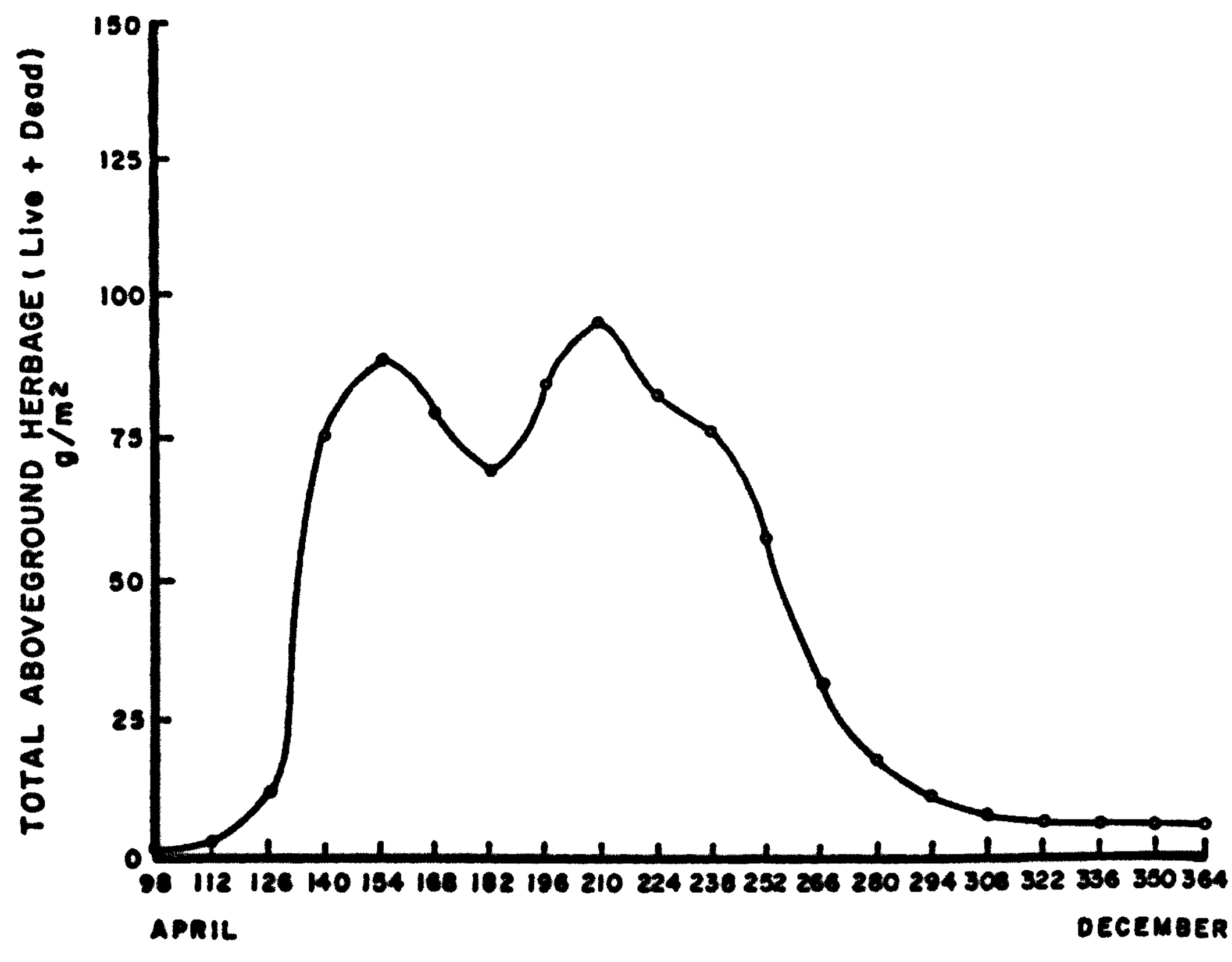

DAY OF THE YEAR

Fig. 2| Three year average of total standing forage crop (live and dead) derived from the simulation model of Figure 1.

serialized model developed by Bartlett, Evans, and Bement (1974) builds upon a linear programming model, but allows for seasonal growth of vegetation and buying and selling of livestock. This is accomplished by the discrete continuity equation (1):

$$
s c_{l}+g_{t}-c_{l}=s c_{i+1}
$$

where $s c_{l}$ is standing crop of forage at the start of period $i, g_{t}$ is forage growth during period $i$, and $c_{t}$ is forage grazed during period $i$. By placing the forage growth factor $\left(g_{l}\right)$ on the right-hand side, equation (1) becomes (2):

$$
-s c_{i}+s c_{i+1}+c_{l}=g_{t}
$$

It is apparent that each of the terms of equations (1) and (2) can be derived from Fig. 2.

Equation (1) can also be adapted for flow of livestock through the year. 
The livestock flow equation (3) becomes:

$$
h_{l}+b_{l}-s_{l}=h_{l+1}
$$

where $h_{i}$ is size of the herd at the start of period $i, b_{i}$ is the number of animals bought at the start of period $i$, and $s_{i}$ is the number of animals sold at the end of period $i$.

In other examples, some particular decision procedures require an estimate of uncertainty about standing crop and forage. A model appropriately constructed can provide the necessary variance and covariance approximations by running the model through several years. Even though we may assume, for simplicity, that we have perfect knowledge about the coefficients in such a model, probabilistic driving variables such as precipitation and temperature give highly variable results (Fig. 3). Note that with the use of such models we are able to

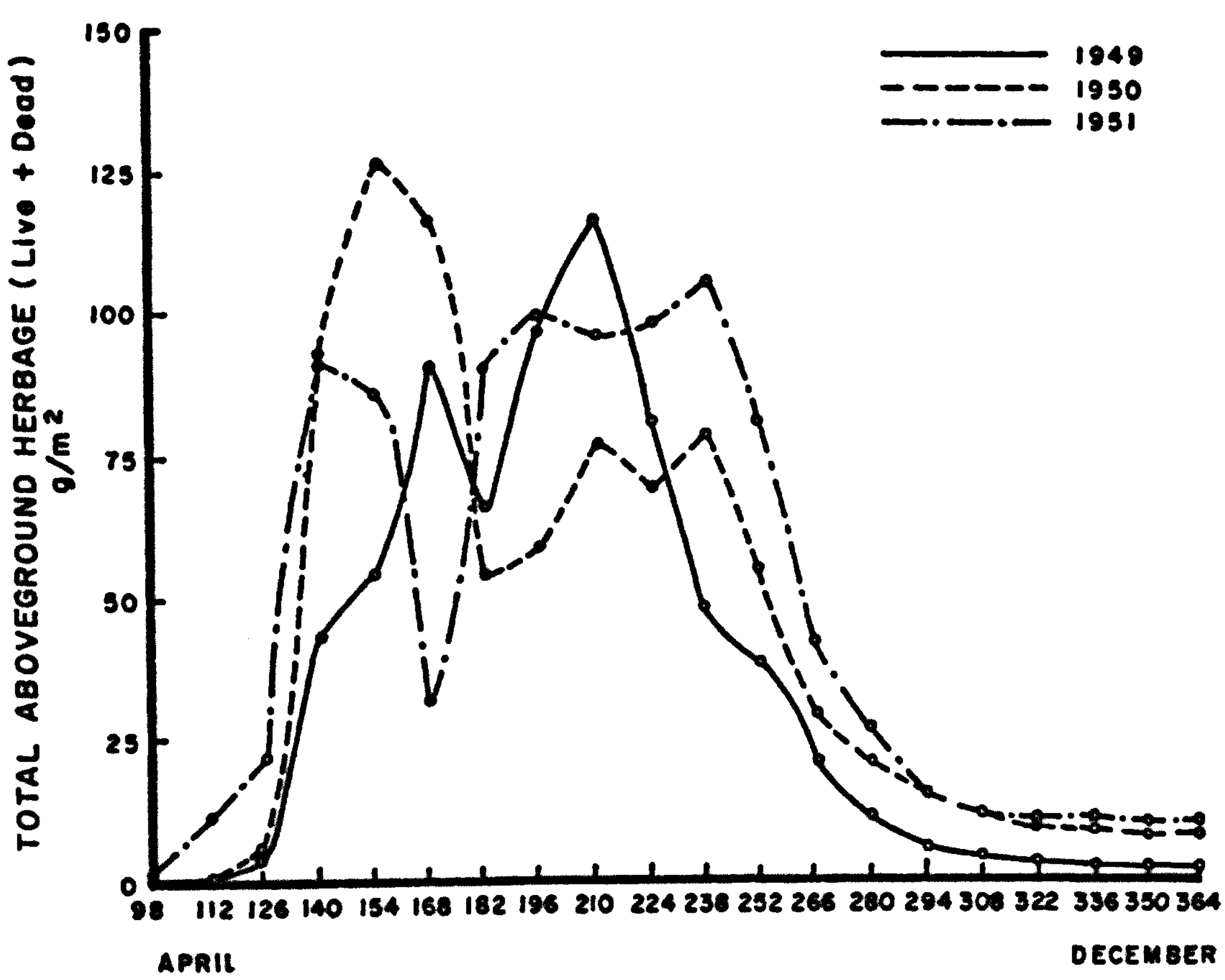

DAY OF THE YEAR

Fig. 3 | Individual year results of total standing forage crop (live and dead). 
generate results for years and places other than those for which data were obtained for model development.

To be realistic, climatic elements in grassland management cannot be assumed to be known with certainty. It is these elements that present problems of risk and uncertainty involved in making decisions about resource use. A mathematical approach which can handle some of the uncertain events and allocate resources in an optimal way is known as chance-constrained programming. This type of model makes possible investigation of risk and uncertainty associated with resource management decision-making. Because grassland managers must often stock their land before they are sure of available forage, they are in essence assuming an ecological risk of overutilizing the forage resource or an economic risk of underutilization. Thus, the amount of available forage is an uncertain event with which managers must contend. The chanceconstrained approach to decision-making may be used when such uncertain events occur, provided that meaningful estimates of standing crop variances are available. Such estimates can be obtained from simulation models; obtaining the same estimates by direct measurements could be costly and time consuming. Methods of treating such probabilistic problems are too lengthy to be included in this paper; fuller treatments of the subject are given in Hunter (1974) and Jameson, D'Aquino, and Bartlett (1974).

\section{Conclusion}

We have previously had much difficulty getting enough information to make good grassland resource decisions. We are now on a threshold where biological data can be generated synthetically by the use of appropriate models. Such models will also provide a clear identification of research priorities so that research can be more specifically directed to critical problem areas.

With the output of such models, coupled with better inventory methods which have become available through such accomplishments as remote sensing, the apparent lack of biological information will no longer be the limiting factor in resource decisions. A new set of limiting factors, therefore, will come into play. It appears that these will fall into two categories: (i) management models needed to better evaluate alternative plans and practices must be developed to better utilize the information made available by biome-type research models, and (ii) 
social constraints will more clearly become the limiting factors in resource decisions. The previous lack of biological information has obscured the necessity of appropriately including such social values in the decision paradigm.

\section{Acknowledgments}

This research was supported by the National Science Foundation (RANN) Grant No. GI-33370. In addition to those listed in the references, the contributions of Bradley J. Gilbert and George S. Innis are gratefully acknowledged.

\section{References}

Bartlett, E. T., Gary R. Evans \& R. E. Bement, 1974. A serial optimization model for ranch management. J. Range Manage. 27: 233-239.

D'Aquino, Sandy A., 1974. A case study for optimal allocation of range resources. J. Range Manage. 27: 228-233.

Forrester, Jay W., 1968. Principles of systems. Wright-Allen Press, Cambridge, Mass.

Hunter, Dennis H., 1974. Optimum resource allocation through chanceconstrained programming. M.S. Thesis, Colo. State Univ., Fort Collins. Jameson, Donald A., Sandy A. D'Aquino \& E. T. Bartlett, 1974. Economics and management planning of range ecosystems. A. A. Balkema, Rotterdam. 245 pp.

Smith, Richard C. G. \& William A. Williams, 1973. Model development for a deferred-grazing system. J. Range Manage. 26: 454-460.

Woodworth, Bruce M., 1973. Optimizing the calf mix on range lands with linear programming. J. Range Manage. 26: 176-178. 


\section{The origin and structure of American arid-zone ecosystems. The producers: interactions between environment, form, and function}

Philip C. Miller and Harold A. Mooney

\section{Introduction}

The concept of subdividing the vegetation of the world into categories based on the form of the plants is old, appearing in Greek literature. Early attempts classified vegetation on the basis of a static concept of vegetation form (Humboldt, 1806), but after Darwin, classification systems included a concept of the biological significance of the different life forms (Grisebach, 1872; Warming, 1895; Schimper, 1898; Drude, 1913; Raunkiaer, 1934). Clements (1916), Tansley (1935), and Braun-Blanquet (1951) began their vegetation classification schemes with divisions based on the form of the vegetation which was assumed to be causally related to climate. The functional factorial approach of Jenny (1941) and Major (1951) generalized that any ecosystem or vegetation property depends on climate, relief, parent material, floral or faunal history, and time.

Ascertaining the essential relationships in the interactions between climate and vegetation form and function is a vital area of ecological research. This analysis can proceed by selecting two geographic areas with broadly similar climates and broadly similar vegetation forms. The degree of similarity and dissimilarity in the vegetation of the two areas can be assessed, and existing concepts of the interrelations between primary production, microclimate, and plant growth used to explain both the similarity and dissimilarity of vegetation form and function. The working hypothesis, in functional factorial notation, is that given similar climates, similar vegetation will occur, if topography, parent material, and recent disturbance (time) are matched, regardless of floral and faunal history. This convergence of form from different genetic stock will occur either through the evolution of genotypes or through the selection of species, and should be especially apparent in those characteristics which are important in maintaining carbon balance, reproduction, and survival. Mooney \& Dunn (1970), Mooney et al. (1973), and Mooney (1973) formulated qualitative models of the diverse factors leading to the convergence of form and function, 
including patterns of allocation of carbon to productive, supportive, root, and reproductive systems. The carbon costs of allocation to these systems involved costs of construction, maintenance, and protection against herbivory. The carbon gain was through an allocation scheme such that photosynthesis by the productive system was least hampered by light, water, or mineral limitation in any climatic and edaphic situation.

There now exists a body of mathematical, physical, and physiological analyses synthesizing some of the details of the climate-microclimatestand structure-water-primary production system which can be used to analyse some of the interrelations between the climate and the form and function of the vegetation (Monsi \& Saeki, 1953; Davidson \& Phillip, 1958; Raschke, 1960; Gaastra, 1962; Gates, 1962, 1965, 1968; Denmead, 1964; de Wit, 1965; Monteith, 1965; Anderson 1966; Duncan et al., 1967; Waggoner \& Reifsnyder, 1968; Chartier 1969; Miller 1969, 1972, 1973; Waggoner, 1969; Waggoner et al., 1969; Slatyer, 1970, Lemon et al., 1971, 1973; Lommen et al., 1971; Miller \& Tieszen, 1972; Stewart \& Lemon, 1972). If the essential aspects of the interrelations are encoded, the models should assign different relative importances to plant properties in different climates, which should correspond with the observed different life forms in different parts of the world. On the other hand, the models should assign similar relative importances to plant properties in different geographic regions which have similar climates. The plant properties of greater importance to the carbon balance should be those which show the greatest convergence of form, and plant properties of lesser importance should show the least convergence. A correspondence between the prediction based on simulation experiments and field observations will increase our confidence in both. A lack of correspondence should cause a revision of our concepts.

\section{Mediterranean scrub areas of the world}

The Mediterranean scrub areas of the world are examples of areas with similar climates and similar vegetation, but with different genetic histories. Such areas occur around the Mediterranean Sea, on the southwest coast of South Africa, in southern Australia, in southern California, and in central Chile (Fig. 1). Aschmann (1973) defined the Mediterranean climate as having one month with an average temper- 


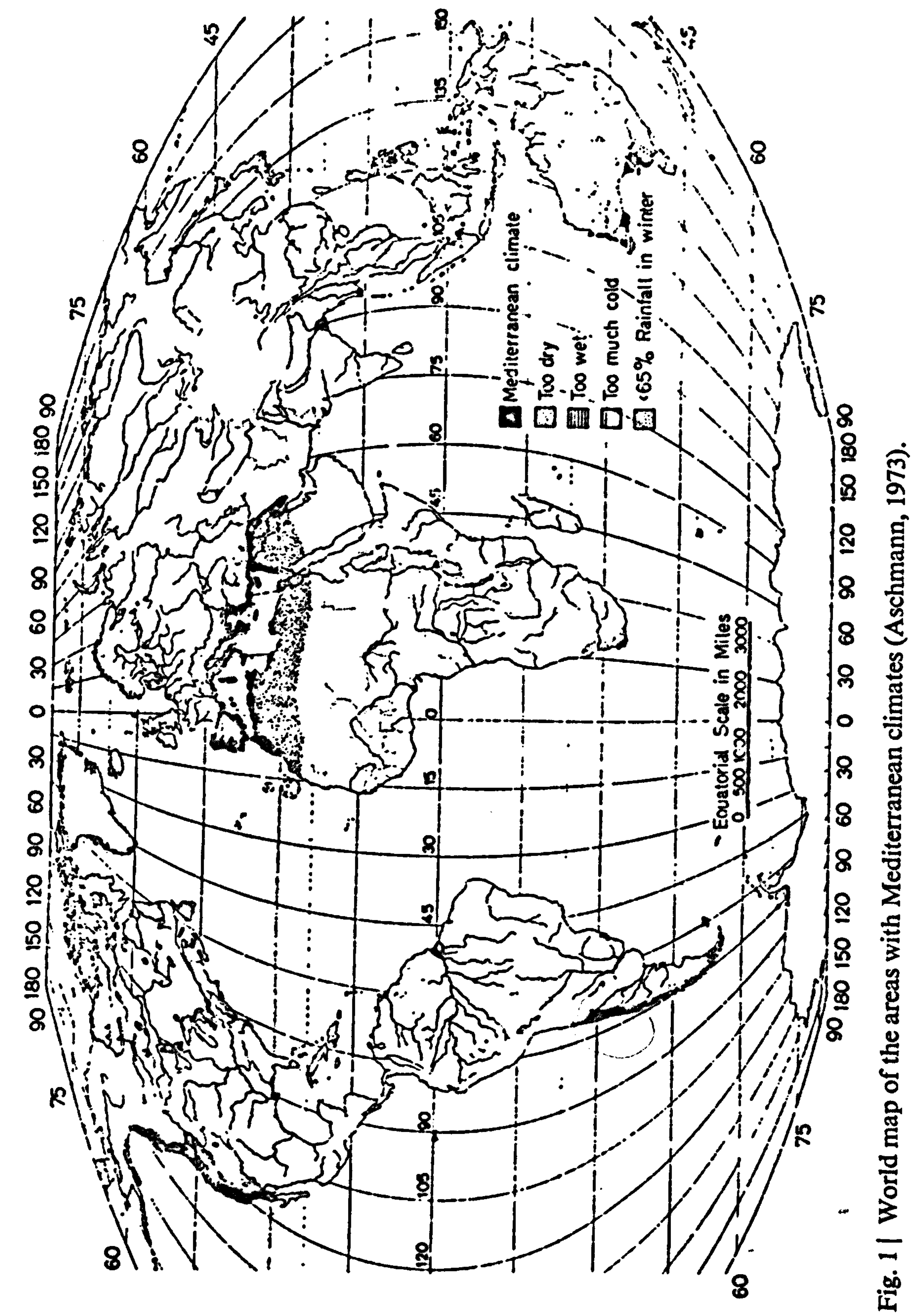


ature below $15^{\circ} \mathrm{C}$, but not so cold that more than $3 \%$ of the hours of the year are below $0^{\circ} \mathrm{C}$. The arid boundary has $275 \mathrm{~mm}$ of precipitation for cool coastal stations and $350 \mathrm{~mm}$ for warm interior stations. The humid boundary has $900 \mathrm{~mm}$ of precipitation per year. At least $65 \%$ of the yearly precipitation must fall in the winter six months, November through April in the northern hemisphere and May through October in the southern hemisphere.

\section{Mediterranean scrub areas of California and Chile}

The Mediterranean scrub areas of California and Chile are centered around $32.5^{\circ}$ latitude. At these latitudes, climatic and vegetational differences occur between countries and within each country, providing some variation to test the predictions. Solar radiation in the summer tends to be slightly less in southern California than in Chile, and in the winter slightly more in California than in Chile because the earth is closer to the sun on December 21 than on June 21 (Fig. 4). Solar radiation in the summer of 1973 was about $60 \mathrm{cal} \mathrm{cm}^{-2}$ day $^{-1}$ less and in the winter about $30 \mathrm{cal} \mathrm{cm}^{-2}$ day $^{-1}$ more in southern California than in Chile. In both countries solar radiation at the coast is about $100 \mathrm{cal} \mathrm{cm}^{-2} \mathrm{day}^{-1}$ less than in the interior because of fog and cloudiness.

Air temperatures are about $2{ }^{\circ} \mathrm{C}$ warmer and more variable diurnally and seasonally in California than in Chile (Fig. 2). California experiences hot, dry air masses from the inland deserts, especially in the fall, and also some summer precipitation from tropical storms. The coastal climates in both countries are warmer in winter and cooler in summer, and have less precipitation, than the interior climates.

Diurnal variations in air temperature of $20^{\circ} \mathrm{C}$ were common at the inland site in California, but variations were rarely greater than $10^{\circ} \mathrm{C}$ at the inland site in Chile. Air temperatures in the summer were between 10 and $35^{\circ} \mathrm{C}$ in California and 10 and $30^{\circ} \mathrm{C}$ in Chile. Air temperatures in the winter were between -2 and $+15^{\circ} \mathrm{C}$ in California and 5 and $17^{\circ} \mathrm{C}$ in Chile. Soil temperatures at $2 \mathrm{~cm}$ depth reached $55^{\circ} \mathrm{C}$ repeatedly from April to August during a dry year and $37^{\circ} \mathrm{C}$ during a wet year at the inland sites in California, while at the inland site in Chile they reached $43^{\circ} \mathrm{C}$. Minimum soil temperatures at $2 \mathrm{~cm}$ were colder in California than in Chile. 
CALIFORNIA
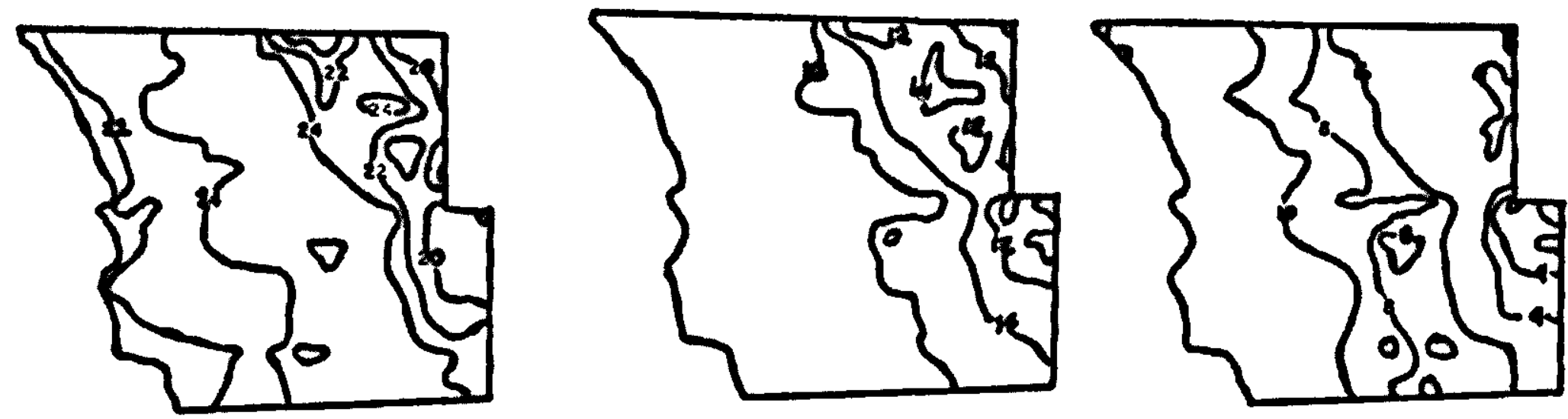

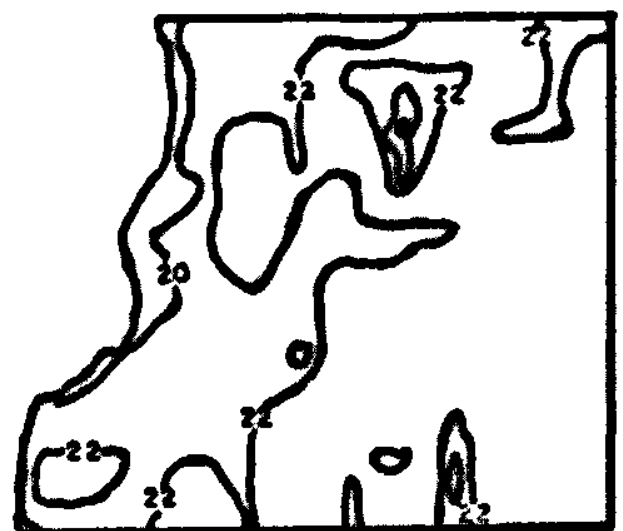

MEAN MAX. TEMP. annual
CHILE

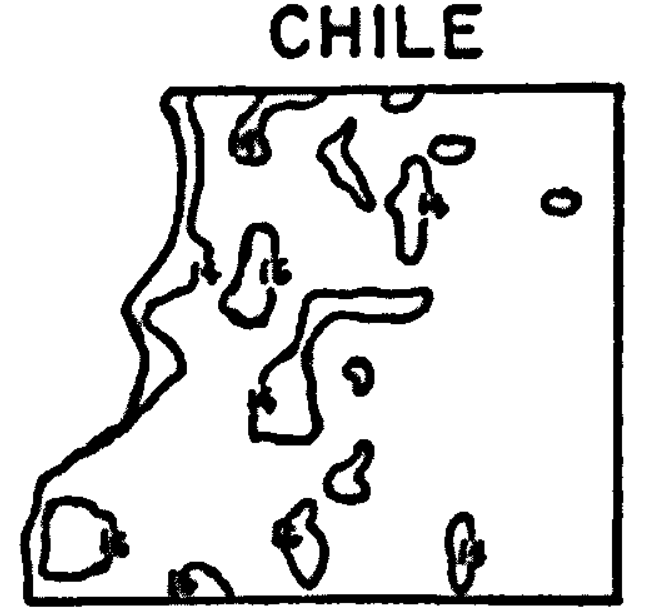

MEAN TEMP. annual

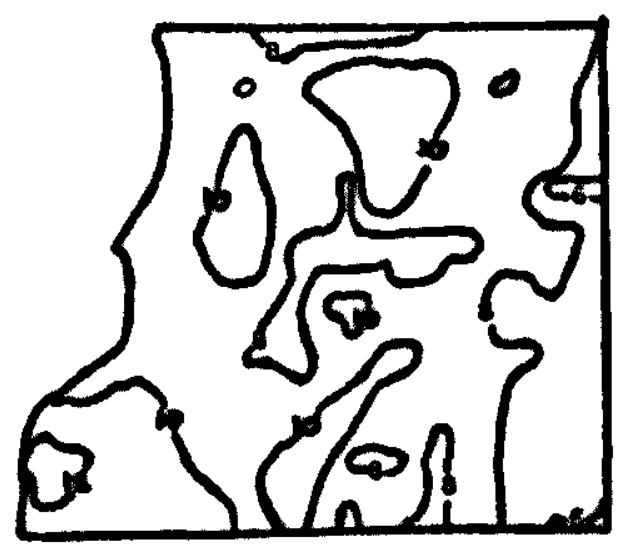

MEAN MIN. TEMP. annual

Fig. 2 Isopleths of annual mean maximum, mean, and mean minimum temperature for southern California (between lat. $32^{\circ} 32^{\prime}$ and $33^{\circ} 25^{\prime}$ ) and central Chile (between lat. $32^{\circ} 30^{\prime}$ and $33^{\circ} 15^{\prime}$ ). Elevation range is from sea level to $2000 \mathrm{~m}$ (Hynum, 1974).

Precipitation is about $500 \mathrm{~mm}$ per year in both countries where the evergreen shrubs predominate. It increases to $650-750 \mathrm{~mm}$ at higher elevations and decreases to $250-350 \mathrm{~mm}$ along the coast (Fig. 3). Soil moisture is high throughout the soil profile in winter and spring. As the soil dries out in the spring, surface layers dry first. At San Dimas in southern California soil moisture was above the wilting point from December to June throughout the profile and above the wilting point all year at about $1.2 \mathrm{~m}$ (Mooney et al., 1973). At the inland site in California soil moisture below $30 \mathrm{~cm}$ depth was above -10 bars throughout the year on ridgetop sites and below -10 bars in the summer on pole facing slopes. Soils dried earlier in the spring at the coast than at the inland site. A more complete description of the data is given in Hynum (1974).

Drier conditions along the coast are also indicated in measurements 


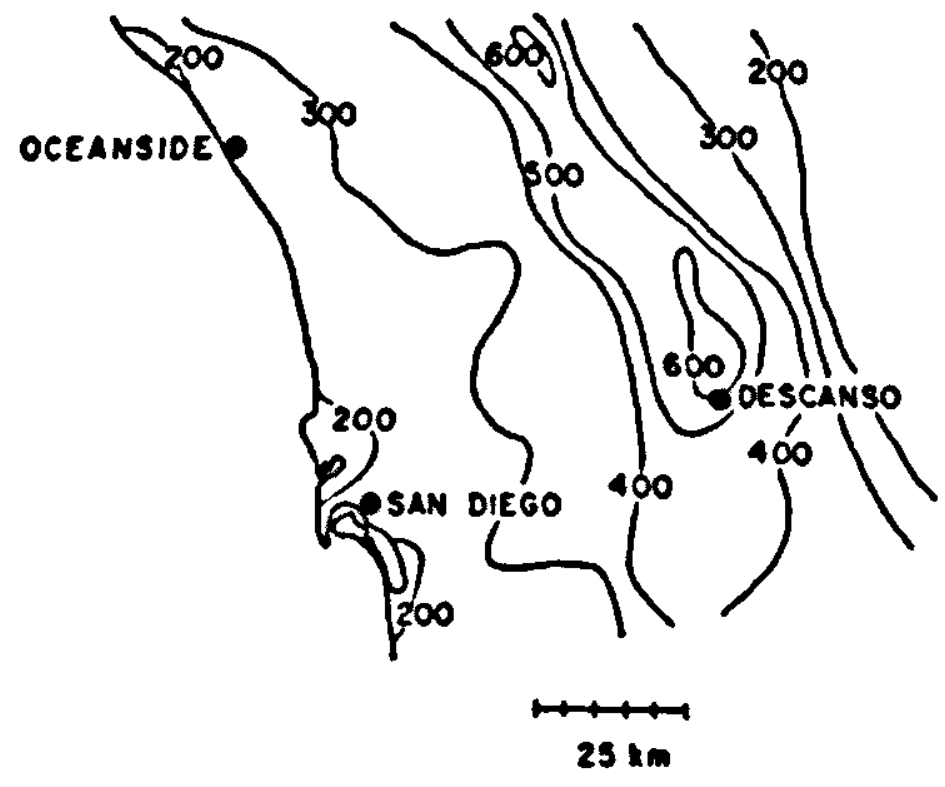

CALIFORNIA

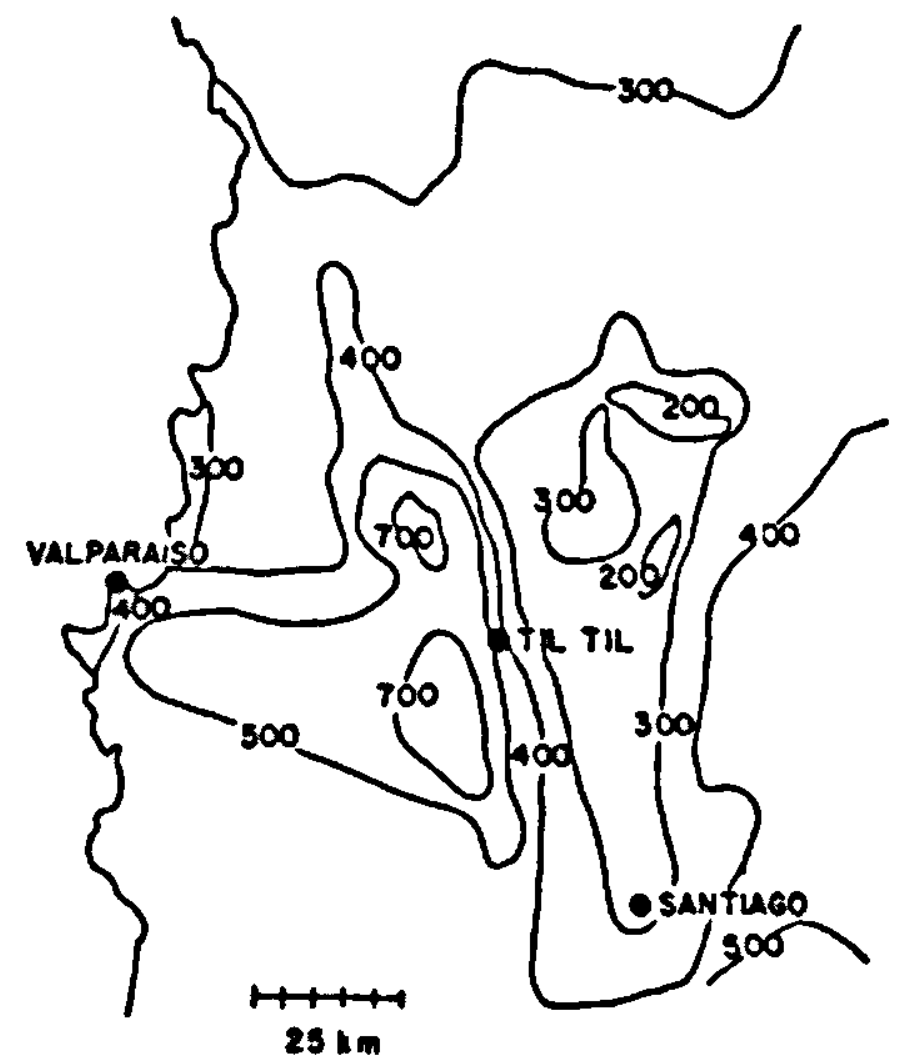

CHILE

Fig. 3| Isopleths of annual precipitation in the region around $32.5^{\circ}$ lat. in California and Chile. Data were obtained from 164 stations in Chile and 128 stations in California from Anuaries Meteorologicos de Chile and the San Diego County Department of Sanitation and Flood Control Hydrology, and fall within the periods 1931-1973 in Chile and 1950-1973 in San Diego.

of plant water potential and leaf resistance to water loss. Dawn xylem water potentials of Heteromeles arbutifolia, a characteristic California chaparral shrub occurring at both the coastal and inland sites, were below -20 bars for about 4.5 months (June to mid-November) at the coast and for 2 months (mid-August to mid-November) at the inland site. Potentials were lower than -35 bars for 1.5 months (September to mid-November) at both sites. Midday water potentials were lower than -35 bars for 3.5 months (late July to mid-November) at both sites. Along the coast leaf resistances in June were low in the morning and high through the rest of the day, but in August to mid-November resistances were high in the morning and through the rest of the day. At the inland site, resistances were low throughout the day in June and July, but low only in the morning in early August. Resistances were high throughout the day from late August until mid-November. Thus, the period of water stress as measured by the leaf resistance was about one month longer at the coast than inland, or as measured by the xylem water potential was about two months longer. It is 


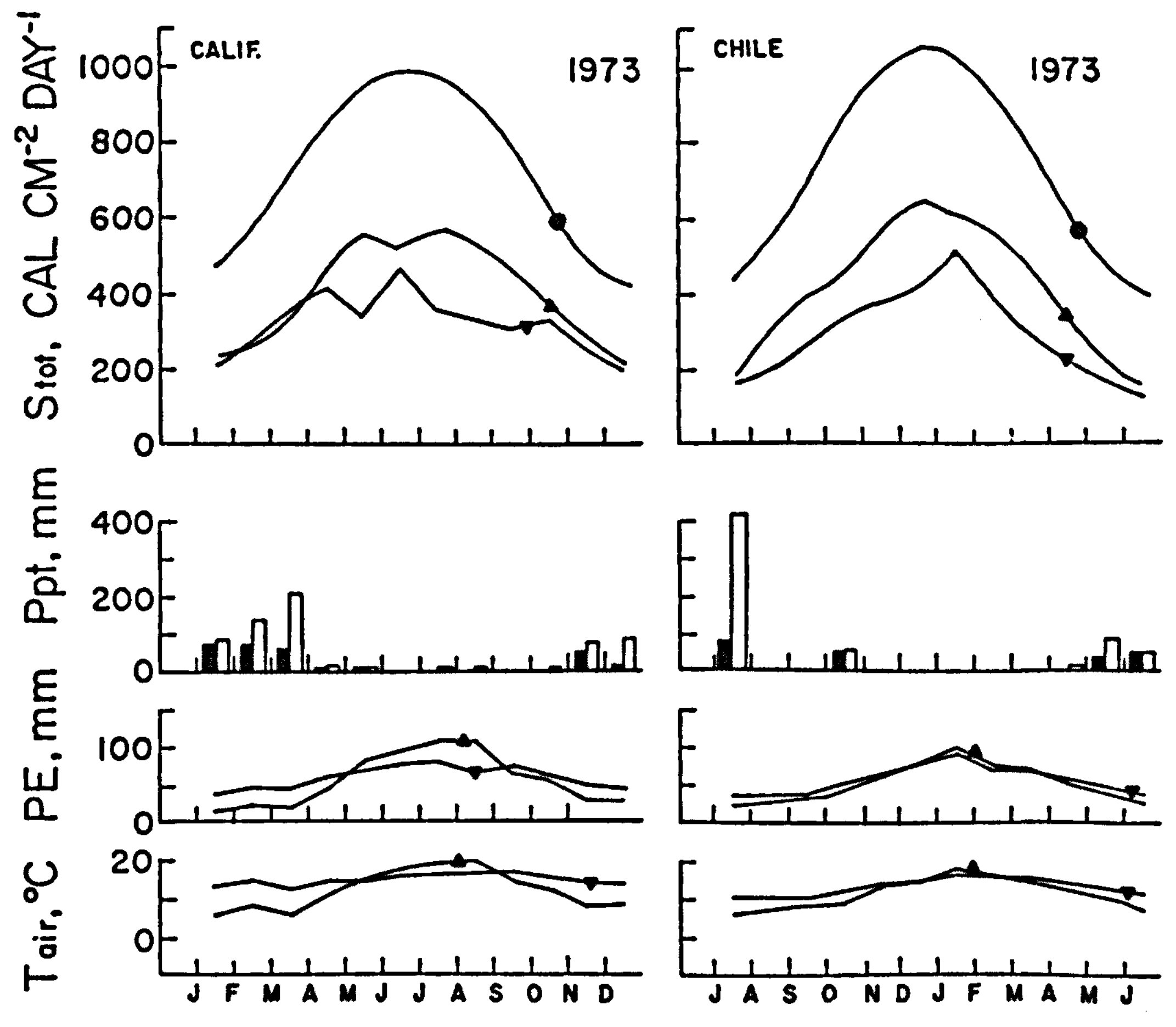

Fig. 4| Seasonal courses of potential solar radiation at the top of the atmosphere $(\bullet)$, measured solar radiation at the inland sites $(\Delta)$, measured solar radiation at the coastal sites $(\nabla)$, precipitation at the inland (clear block) and coastal (dark block) sites, potential evapotranspiration inland ( $\Lambda$ ) and coastal $(\boldsymbol{\nabla})$, and mean air temperature inland $(\boldsymbol{\Lambda})$ and coastal $(\boldsymbol{\nabla})$ for 1973 in California and Chile.

expected that photosynthesis was suppressed by the high leaf resistances for about 90 days in the interior and 150 days at the coast. In both countries the vegetation of the interior consists of evergreen, sclerophyllous shrubs with broad leaves $0.2-3.0 \mathrm{~cm}$ wide (Mooney et al., 1970; Parsons, 1973). Towards the coast in both countries, deciduous soft leaved shrubs with leaves $0.2-2.0 \mathrm{~cm}$ wide, and succulents, become more common (Mooney et al., 1973; Parsons, 1973). Mooney\& Parsons (1973) suggested that along an aridity gradient from dry to 
wet, plant communities are arranged thus: coastal sage, chamise chaparral, mixed chaparral, oak woodland, and riparian woodland. Towards increasing aridity succulents become increasingly common. With increasing elevation and colder temperatures, the winter deciduous form becomes more abundant (Parsons, 1973) (Fig. 5). Carter (1973) showed a higher percentage of perennial herbs in Chile and a higher percentage of annuals in California. The significance of these patterns of vegetation and the associated climate can be explained by simulation models of photosynthesis and plant water relations.

CALIF.

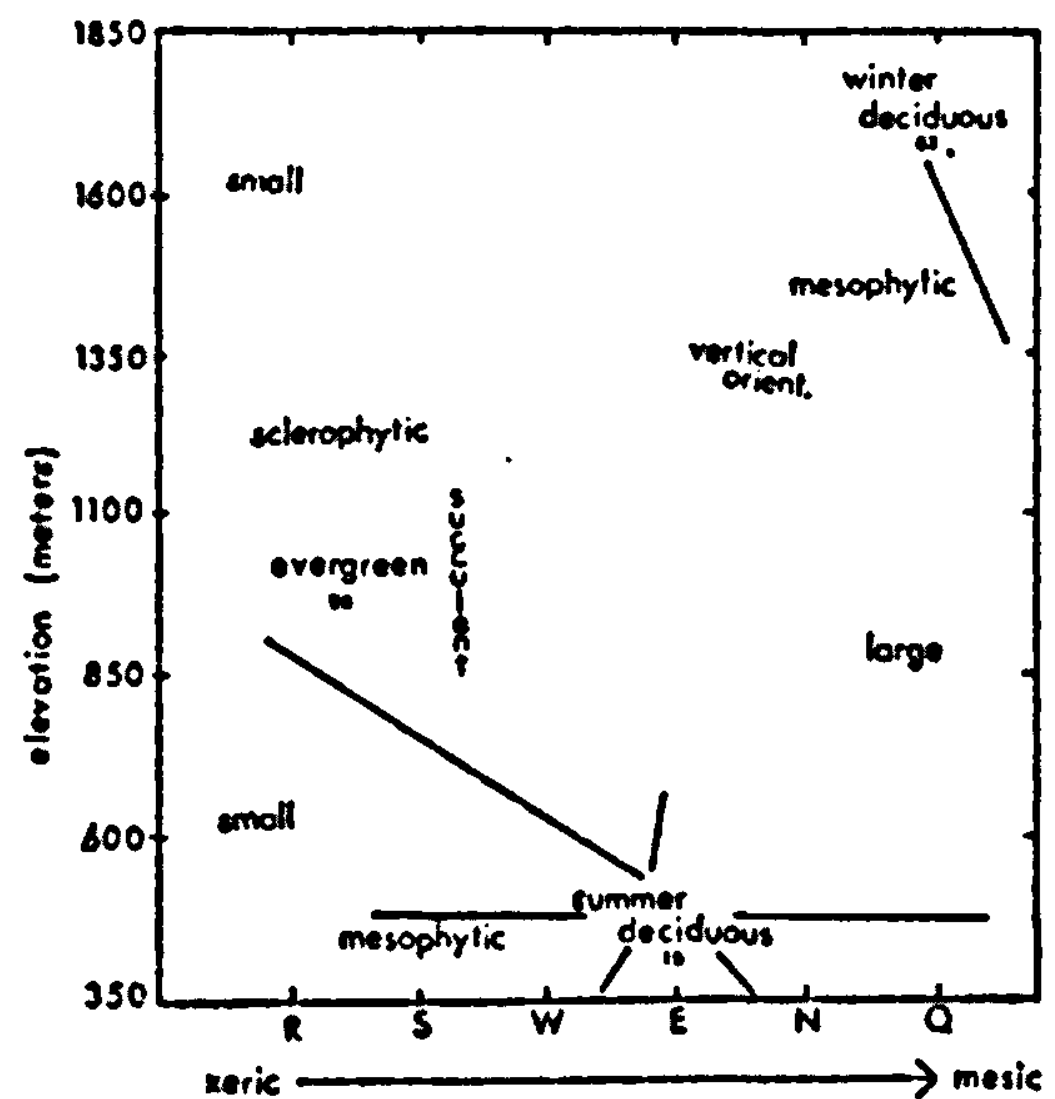

CHILE

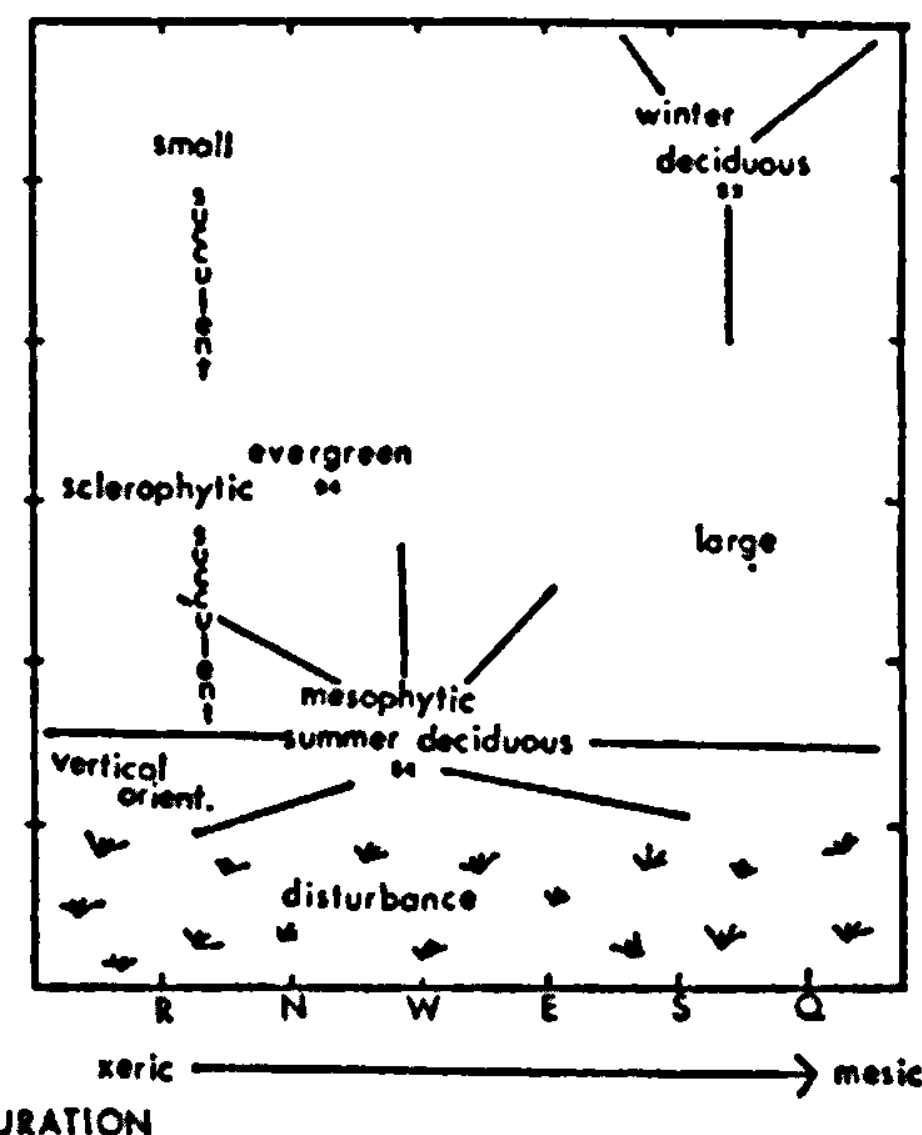

LEAF DURATION

Fig. 5| Distribution of characteristics of plant species along altitudinal and moisture gradients in California and Chile (Parsons, 1973). $R=$ ridge, $\mathrm{S}=$ south facing exposure, $\mathrm{W}=$ west facing exposure, $\mathrm{E}=$ east facing exposure, $\mathrm{N}=$ north facing exposure, $\mathrm{Q}=$ quebrada (= ravine).

\section{Simulation results}

Simulations of the seasonal course of canopy photosynthesis and water relations were run using physiological data for Heteromeles (Harrison, 1971; Poole, 1974), for which the most complete set of physiological data on the Californian and Chilean shrubs exist, and soil water potential data from California. The simulations used horizontal topo- 
graphic positions and a canopy with a leaf area index of 0.5 in both countries. This leaf area index was estimated from the percent cover on ridgetops at both interior research sites and gave realistic surface soil temperatures and temperature profiles in the simulations. The actual leaf area index is somewhat higher, but is effectively reduced by the clustering of the leaves.

The independent variables were the climates of California and Chile measured through 1973 at the inland research stations. The average daily courses of total and diffuse solar radiation, infrared radiation from the sky, wind, air temperature above the canopy, soil temperatures at $30 \mathrm{~cm}$, vapor density above the canopy, and the average soil water potential in the profile for each month for each country were used as input data. From these daily courses of vertical profiles of total, diffuse, reflected and absorbed solar radiation, downward and upward infrared radiation, wind, air, and leaf temperatures, soil temperatures, vapor densities, leaf water potentials, leaf resistances to water loss, transpiration, water uptake from the soil, and photosynthesis were calculated. Output was compared against data on the microclimate, soil moisture, and plant water relations. The model proceeds in five minute time steps through the day.

\section{Evergreenness and annual course of photosynthesis}

The results of the simulation showed that stand net photosynthesis is positive throughout the year at the inland sites but is highest in spring and low in the summer, fall, and winter (Fig. 6). Water-use efficiency (mg organic matter produced per $\mathrm{g}$ water transpired) is high in the spring and fall, and low in winter in both countries. In the summer water-use efficiency is low in California and high in Chile. Solar radiation absorbed by leaves is high in the summer and low in the winter. By the time fall and winter rains begin, absorbed solar radiation is low. The spring season has both available moisture and high solar radiation. Maximum and minimum air temperatures through the canopy show warmer daytime air temperatures and cooler nighttime temperatures in California than in Chile. Leaf temperatures departed more from air temperatures in California than in Chile, both during the day and the night. Soil surface temperatures were similar in both countries. The unusually wet spring in California in 1973 is noticeable in depressed temperatures in March. The calculated values for stand 

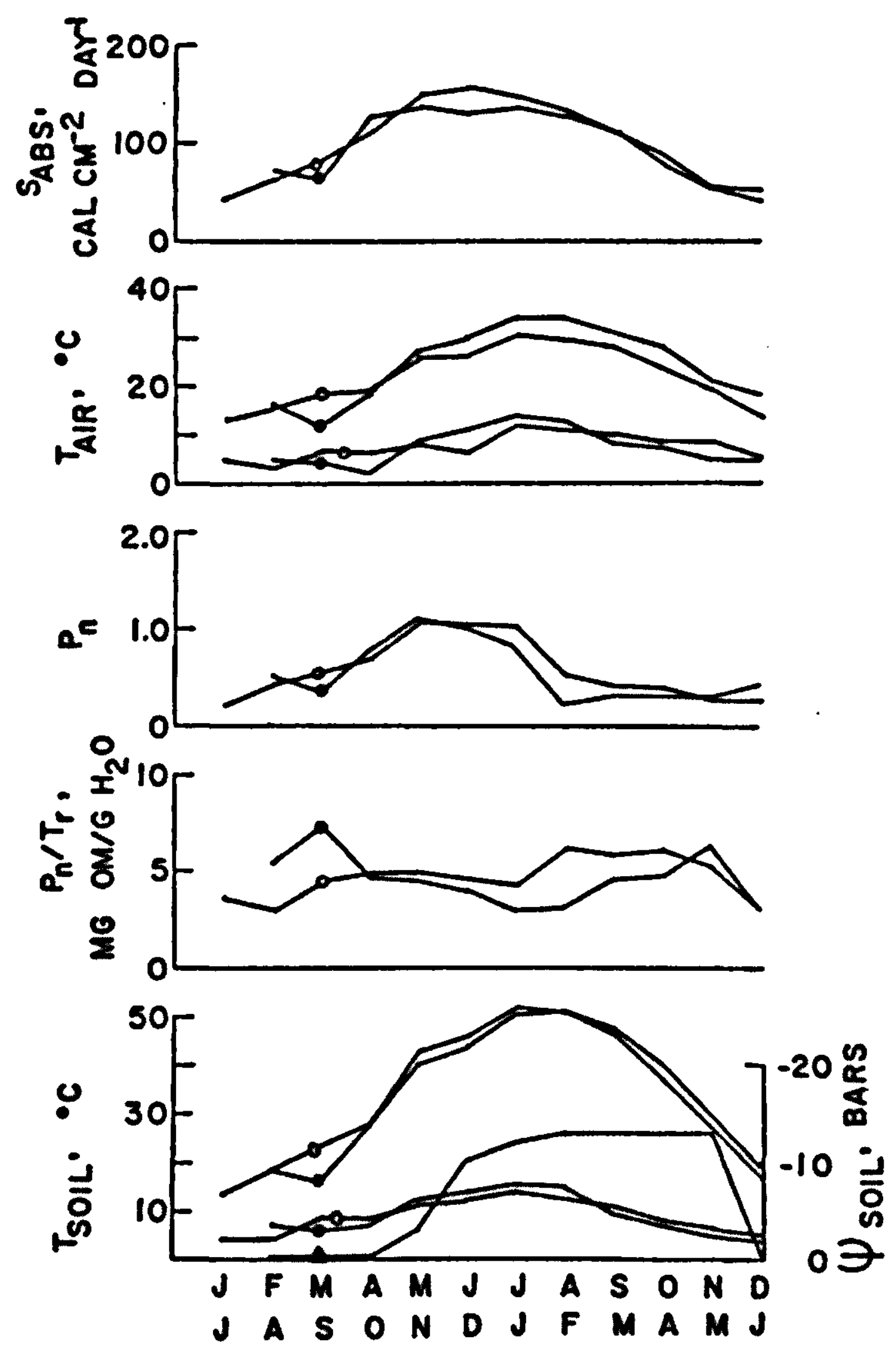

Fig. 6| Simulated seasonal courses of absorbed solar radiation, maximum and minimum air temperatures, net photosynthesis, water-use efficiency (mg organic matter produced/g water transpired), maximum and minimum surface temperatures for California $(\bullet)$ and Chile $(0)$ and soil water potentials for Chile, based on physical data on Heteromeles and climatological data for the inland research stations in 1973.

production are similar to those estimated by Specht (1969).

Evergreenness should confer an advantage in a climate where photosynthesis is possible throughout the year. The relative advantage of the evergreen life form compared with the drought deciduous life form may be clarified with some crude bookkeeping. The density of new leaves of 
Heteromeles arbutifolia was $1.3 \mathrm{~g}$ d.w. (dry weight) $\mathrm{dm}^{-2}$ and of old leaves, $2.0 \mathrm{~g}$ d.w. $\mathrm{dm}^{-2}$ (Mooney et al., 1973). The leaf densities of evergreen shrubs in Chile and California were similar (1.0-2.7 $\left.\mathrm{g} \mathrm{d} \mathrm{w} . \mathrm{dm}^{-2}\right)$ and about twice that of drought deciduous shrubs $\left(0.5-1.4 \mathrm{~g} \mathrm{~d} . \mathrm{w} . \mathrm{d} \mathrm{m}^{-2}\right)$. The respiratory cost of producing this leaf biomass will be $30-50 \%$ of the leaf weight, depending on the biochemical composition of the leaves (Penning de Vries, 1972). The construction costs of $\mathrm{a} \mathrm{dm}^{-2}$ of an average evergreen leaf $\left(2.0 \mathrm{~g} \mathrm{~d} . \mathrm{w} . \mathrm{dm}^{-2}\right)$ would then be about $2.7-3.0 \mathrm{~g}$ d.w. $\mathrm{dm}^{-2}$. If the maintenance respiration cost is $1.5 \%$ of the dry weight per day (McCree \& Troughton, 1966), the cost of maintaining $\mathrm{a} \mathrm{dm}^{2}$ of leaf for 90-100 days will equal the cost of constructing a new $\mathrm{dm}^{2}$ of leaf. The evergreen form should be more favored than the drought deciduous form in areas where photosynthesis is negligible because of soil drought or cold temperatures for a period of less than 90-100 days and less favored in areas of drought or cold temperatures lasting more than 90-100 days. The lengths of the soil drought at the coast and inland sites correspond with the greater incidence of deciduous shrubs at the coast than inland. At $2000 \mathrm{~m}$, where the deciduous form appears again, cold temperatures may limit production for about three months.

The photosynthetic efficiency of different life forms has been summarized by Sestak et al., (1971), Mooney (1972), and Tieszen \& Wieland (1974). The photosynthetic efficiency of evergreen shrubs is about half that of deciduous shrubs or annuals. For California and Chilean shrubs the maximum photosynthetic rate of evergreen shrubs was $10.2 \mathrm{mg} \mathrm{CO} \mathrm{cm}^{-2} \mathrm{~h}^{-1}$ (range 4.5-16.0) and of drought deciduous shrubs, $24.5 \mathrm{mg} \mathrm{CO}_{2} \mathrm{~cm}^{-2} \mathrm{~h}^{-1}$ (range 15-42) (Harrison, unpublished; A. Gigon, unpublished; Dunn, 1970). Photosynthesis in the field will be reduced by lower solar radiation, temperatures above or below optimal, or when water stress forces stomatal closure during the day. If the photosynthetic return from a dm${ }^{2}$ of leaf is about $10 \mathrm{mg} \mathrm{CO}_{2}$ $\mathrm{dm}^{-2} \mathrm{~h}^{-1}$ for an evergreen and $25 \mathrm{mg} \mathrm{CO}_{2} \mathrm{dm}^{-2} \mathrm{~h}^{-1}$ for a drought deciduous shrub and assuming $0.614 \mathrm{~g}$ d.w. per $\mathrm{g} \mathrm{CO}_{2}$, it would take about 480 hours (60-80 days at 6-8 hours per day) to regain the cost of construction of one $\mathrm{dm}^{2}$ of leaf for an evergreen and 192 hours (24-32 days) for a drought deciduous shrub. The evergreen shrub requires a productive period of about 2.3 months and a deciduous shrub a period of about one month to regain the cost of leaf growth. Photosynthesis beyond these periods can contribute to the cost of root 
maintenance and to reproduction. If the photosynthetic period is less than these periods, both life forms are disadvantaged and succulents may become more prevalent.

\section{Vertical placement of productive tissue}

The simulated seasonal course of absorbed solar radiation profiles indicates solar radiation limitation of photosynthesis at the bottom of the canopy throughout the year, but especially in winter (Fig. 7). Net daily production was positive at all levels in the canopy in all months, but at the bottom of the canopy production was limited by the low radiation. The levels of absorbed solar radiation found at the top of the canopy in winter are found at the bottom of the canopy in spring and summer. The Californian profiles show less seasonal variation than the Chilean profiles, because of the different levels of incoming solar radiation in the two countries. The profiles depend upon the incoming solar radiation and the interception of solar radiation by the canopy, which increases in the winter because of the lower solar altitudes. Profiles of leaf temperatures at noon show the hottest leaves within the canopy, because of higher air temperatures and lower wind speeds near the ground (Fig. 7). Leaf temperatures in California are higher than those in Chile, and are over $30^{\circ} \mathrm{C}$ at the bottom of the canopy in spring and fall and are over $30^{\circ} \mathrm{C}$ throughout the canopy in the summer. Californian leaf temperatures are about $35^{\circ} \mathrm{C}$ at the bottom of the canopy in summer. Chilean leaf temperatures are above $30^{\circ} \mathrm{C}$ only
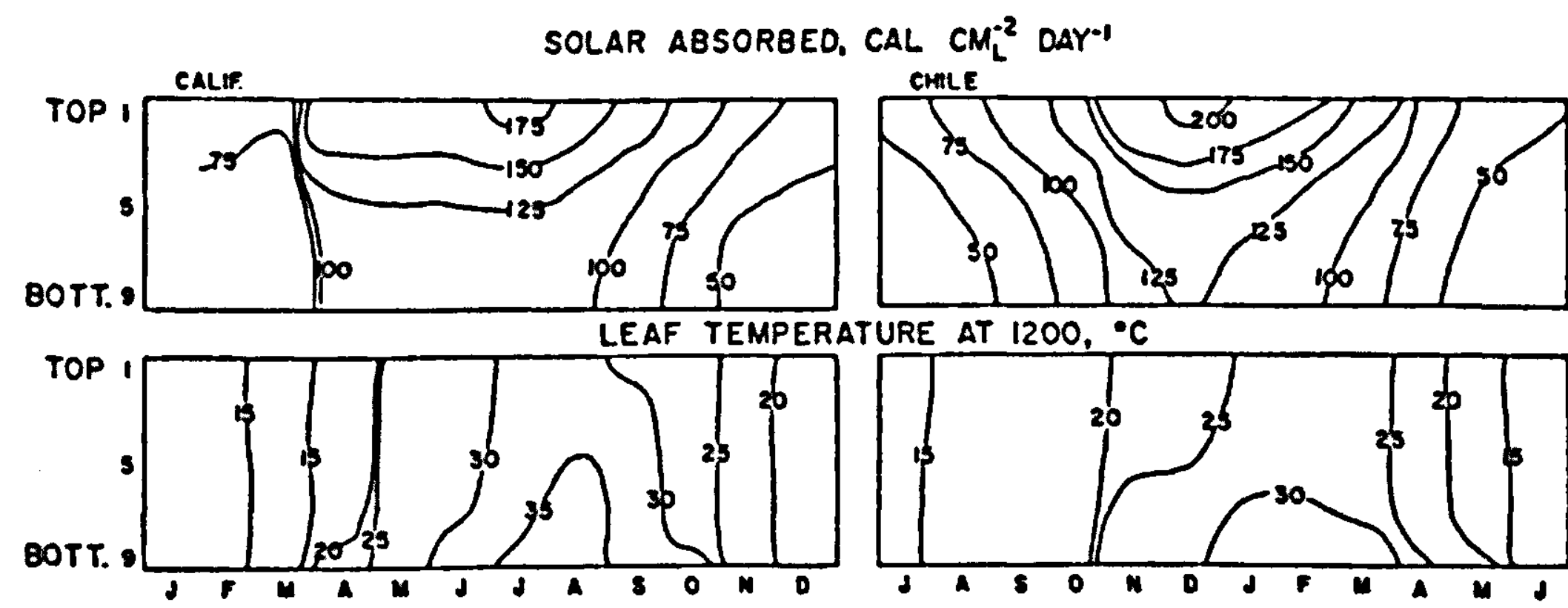

Fig. 7| Simulated seasonal courses of the profiles of absorbed solar radiation and noon leaf temperatures through the canopy in California and Chile from 1973. March 1973 was unusually cold in California. 
at the bottom of the canopy in summer. The profiles show the greatest differentiation from top to bottom in summer and least in winter.

Photosynthesis and growth depend on the temperatures and water status of the leaf. The relationship between photosynthesis and temperature usually shows a broad temperature range within which photosynthesis is near maximal, decreasing at temperatures lower or higher than an optimum temperature. In southern California the optimum temperature for photosynthesis of Heteromeles arbutifolia was about $25^{\circ} \mathrm{C}$ (Harrison, 1971), but varies with species and acclimation history (Mooney \& Harrison, 1970).

The simulated seasonal course of the vertical profiles of primary production and water-use efficiency (Fig. 8) show the effects of limitation by solar radiation and temperatures. In this figure the profiles for each month have been standardized by dividing the photosynthesis rate or water-use efficiency at each level by the mean photosynthesis rate (in $\mathrm{mg} \mathrm{CO} \mathrm{Cm}^{-2}$ leaf day ${ }^{-1}$ ) or water-use efficiency for the profile to eliminate month to month variation. In the winter, temperatures are suboptimal and solar radiation is low within the canopies, and maximum daily photosynthesis is at the top of the canopies. Water-use efficiencies are high at the top and bottom of the canopies. In the spring, temperatures are nearly optimal in both countries, but cooler in Chile. Solar radiation levels are higher throughout the canopies and photosynthesis is similar throughout the canopy profiles. Water-use efficiency is highest at the bottom. In the summer, temperatures are above optimal in California and slightly above optimal in Chile. Solar radiation levels are high throughout the canopy, but the temperature profiles are such that maximum photosynthesis and water-use efficiencies are at the top of the canopies. In the fall, temperatures return to optimal and suboptimal but solar radiation is decreased. Maximum photosynthesis and water efficiencies are slightly higher at the top of the canopies.

The profile of soil water potential through the season for California shows water available throughout the soil profile in the winter and early spring. By late spring and through the summer, moisture is unavailable at the surface but is available deeper in the soil. When precipitation begins in the late fall and winter, solar radiation and temperatures are low.

The annual course of the productive structure of the vegetation follows the pattern of having the productive structures located in the profiles 
where maximum photosynthesis and water-use efficiency occur. In the spring, herbs tap the shallow soil moisture and are close to the ground while surface temperatures are optimum for photosynthesis, and die
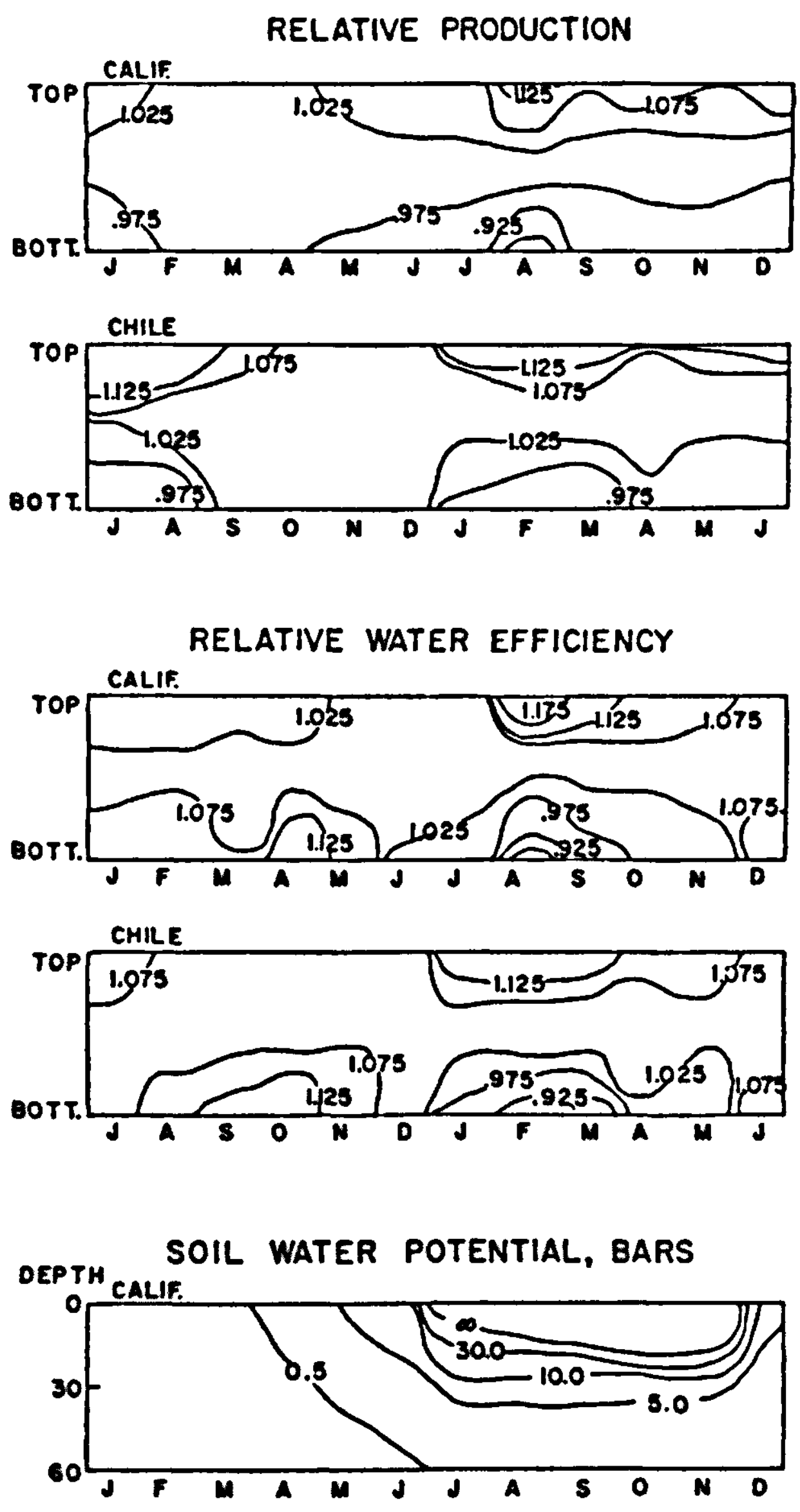

Fig. 8| Simulated seasonal courses of relative production (photosynthesis in $\mathrm{mg} \mathrm{CO} \mathrm{Cm}^{-2} \mathrm{~h}^{-1}$ at each level divided by the mean photosynthesis rate for the profile) and or relative water-use efficiency (water-use efficiency at each level divided by the mean water-use efficiency for the profile) at different levels in the canopy for California and Chile, and of the profile of soil water potentials in California, using 1973 data. 
or become dormant in the summer when the surface moisture is gone and the surface temperatures are above optimum. In the spring and summer, shrubs tap the deeper soil moisture and are high off the hot ground where temperatures are cooler. In order to obtain deep soil moisture throughout the year the plants need deep roots, and to utilize this moisture efficiently the photosynthetic and transpiring tissue is placed off the ground surface in a shrub form, which increases photosynthesis and water-use efficiency.

\section{Leaf width and inclination}

Leaf temperatures depend upon all the factors which effect the processes of energy exchange, such as solar and infrared radiation, wind, air temperature, and the vapor density of the air, and upon leaf properties such as orientation to the sun, width, mutual shading, absorptance, and resistance to water loss (Gates, 1962; 1965; 1968). The convectional exchange of heat tends to maintain leaf temperatures at air temperature. A departure of leaf from air temperature is caused by a positive or negative radiation balance or by transpiration and the departure increases as leaf width increases. The photosynthesis rate may be increased or decreased by this additional temperature, over air temperatures, during the day depending upon the temperature of the leaf in relation to the optimum temperature for photosynthesis. Transpiration will tend to be increased by higher leaf temperatures. In the winter, when leaf temperatures are below the optimum temperature for photosynthesis, wider leaves will have higher leaf temperatures during the day and may have higher photosynthetic rates. Transpiration will tend to increase. In the simulations the total effect of increasing leaf width was to increase production slightly and to increase the water-use efficiency. In the summer when leaf temperatures are above optimum temperature for photosynthesis, wider leaves may have higher temperatures and lower photosynthesis rates. Transpiration will tend to increase. In the simulations the overall effect was to decrease production, more so in California than in Chile, and decrease water-use efficiency. Thus the simulations indicated that winter active plants should have broad leaves to increase photosynthesis slightly and water-use efficiency, and summer active plants, especially in California, should have narrow leaves (Fig. 9). California, compared with Chile, should have plants with narrower leaves and of a more consistent 

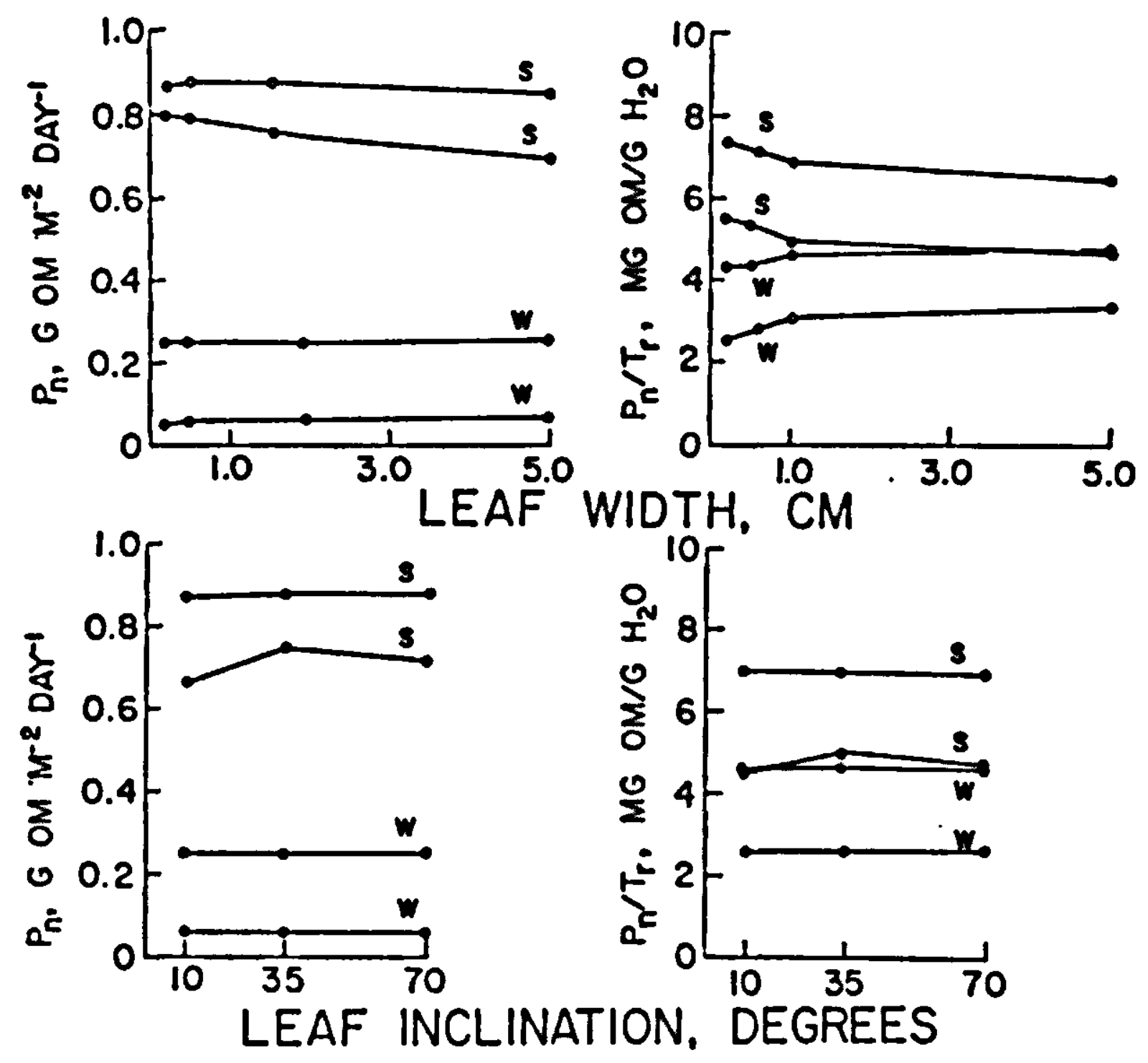

Fig. 9| Simulated effect of leaf width and leaf inclination on net canopy photosynthesis and water efficiency in summer and winter in California $(\bullet)$ and Chile ( 0 ).

size, since production is more sensitive to leaf size in California. Measurements of leaf size support these predictions (Table 1).

In the simulations leaf inclination was related to production and wateruse efficiency only in the summer in California. Summer active plants in California should increase production and water-use efficiency by moderately inclined leaves, such that the interception of radiation is minimized. Winter active plants in California and the Chilean plants could show a diversity of leaf inclinations (Fig. 9). These trends are partially supported by available data on leaf inclination (Table 2), although the predominant plant on ridgetops in California, Adenostoma fasciculatum, was classed as having all leaf inclinations and the mutual shading caused by the clustering of leaves next to the stem may override the advantage of leaf inclinations.

Thus, deep rooted summer active shrubs can increase photosynthesis by decreasing leaf width, a trend more important in California than in 
Table 1 Relative percent cover of woody plants with their given leaf size in California and Chile (Carter, unpublished; Parsons, 1973).

\begin{tabular}{llr}
\hline $\begin{array}{l}\text { Leaf size } \\
\left(\mathrm{mm}^{2}\right)\end{array}$ & \multicolumn{2}{c}{ Relative percent cover } \\
\cline { 2 - 3 } & California & Chile \\
\hline$>18,225$ & 0.4 & 1.9 \\
to 18,225 & 2.6 & 0.0 \\
to 2,025 & 1.0 & 28.6 \\
to 1,125 & 8.0 & 21.8 \\
to 225 & 36.1 & 34.9 \\
to 25 & 51.9 & 12.5 \\
Plants without leaves & 0.0 & 1.9 \\
\hline
\end{tabular}

Table 2 Relative percent cover of woody plants with leaves predominantly horizontal, at $45^{\circ}$, and vertical. Plants without leaves or with leaves of all inclinations are excluded (Carter, unpublished; Parsons, 1973).

Leaf angle

Relative percent cover

California Chile

Vertical

24.0

28.6

$45^{\circ}$

74.6

67.6

Horizontal

1.5

3.9 
Chile. Winter active shrubs or herbs will increase photosynthesis by increasing leaf width. The seasonal course of leaf resistances of Rhus, compared with Adenostoma (Poole, 1974), indicate that Rhus is active in winter and early spring and Adenostoma is active throughout the year. Rhus has wide leaves for a chaparral plant and Adenostoma narrow. In addition, the growth form of Adenostoma maximized convectional heat exchange, while $R$ hus appears not as effective in this process. The wider leaves of Rhus may condense more water from saturated air at night than the narrow leaves of Adenostoma, since the wider leaves will depart more below air temperatures at night. Before the November rain, water potentials and leaf resistances recovered from the summer drought earlier in Rhus than in Adenostoma, a possible response to this condensation.

\section{Conclusions}

The Mediterranean scrub regions of California and Chile occur in a climate with winter rain and summer drought and mild winter temperatures and are comprised predominantly of evergreen sclerophyllous shrubs. Within these regions gradients occur in both countries; the coast is drier than the inland and has a higher frequency of drought deciduous shrubs. Minor climatic differences occur between countries; California is hotter in summer and cooler in winter than Chile. Minor vegetational differences occur; California tends to have a greater frequency of narrow, steeply inclined leaves than Chile. The evergreen form occurs where the carbon cost of maintaining leaves through periods of low photosynthesis is lower than the cost of producing new leaves. The deciduous form occurs where the carbon cost of maintaining leaves is higher than the cost of producing new leaves. The shrub form, which is associated with the utilization of deep soil water in the summer, places the photosynthetic tissue above the hot soil surface increasing photosynthesis and water-use efficiency. The herb form, associated with the utilization of shallow soil water in the spring, places leaves near the soil surface when surface temperatures are moderate, increasing photosynthesis and water-use efficiency at this time. The narrow, steeply inclined leaves of hot summer active shrubs increase photosynthesis and water-use efficiency. Leaf width and inclination are less important in plants active in the spring and in cool summers and are more variable in these plants. Thus, the evolution 
of vegetation form and function in the Mediterranean climate in California and Chile has resulted in a yearly course of productive structure which coincides with a pattern for maximum production and maximum water-use efficiency.

\section{References}

Anderson, M. C., 1966. Stand structure and light penetration. 2. A theoretical analysis. J. appl. Ecol. 3: 41-54.

Aschmann, H., 1973. Distribution and peculiarity of Mediterranean ecosystems. In: F. di Castri \& H. A. Mooney [eds.] Mediterranean type ecosystems. Springer-Verlag, New York, p. 11-19.

Braun-Blanquet, J., 1951. Pflanzensoziologie, Grundlage der Vegetation spunde. Springer-Verlag, Vienna.

Carter, S., 1973. Observations on the role of the herbaceous vegetation in the Chilean matorral. U.S. IBP, Origin and Structure of Ecosystems Tech. Rep. 73-6.

Chartier, P., 1969. A model of $\mathrm{CO}_{2}$ assimilation in the leaf. In: Prediction and measurement of photosynthetic productivity. Proc. IBP/PP meeting, Trebon, p. 307-315.

Clements, F. E., 1916. Plant succession. Carnegie Institution, Washington, D.C.

Davidson, J. L. \& J. R. Phillip, 1958. Light and pasture growth. In: Climatology and microclimatology. UNESCO, Paris, p. 181-187.

Denmead, O. T., 1964. Evaporation sources and apparent diffusivities in a forest canopy. J. appl. Meteorol. 3: 383-389.

Drude, O., 1913. Die Okologie der Pflanzen. Die Wissenschaft, Bd 50, Braunschweig.

Duncan, W. G., R. W. Loomis, W. A. Williams \& R. Hanau, 1967. A model for simulating photosynthesis in plant communities. Hilgardia 38: 181-205.

Dunn, E. L., 1970. Seasonal patterns of carbon dioxide metabolism in evergreen sclerophylls in California and Chile. Ph.D. dissertation. Univ. of California, Los Angeles.

Gaastra, P., 1962. Photosynthesis of leaves and field crops. Neth. J. Agric. Sci. 10: 311-324.

Gates, D. M., 1962. Energy exchange in the biosphere. Harper and Row, New York. 151 p.

Gates, D. M., 1965. Energy, plants, and ecology. Ecology 46: 1-13. 
Gates, D. M., 1968. Transpiration and leaf temperature. Annu. Rev. Plant Physiol. 19: 211-238.

Grisebach, A., 1872. Die Vegetation der Erde nach ihrer klimatischen Anordnung, W. Englemann, Leipzig, p. 603-635.

Harrison, A. T., 1971. Temperature related effects on photosynthesis in Heteromeles arbutifolia M. Roem, Ph.D. dissertation. Stanford Univ., Palo Alto, Calif.

Humboldt, A. von, 1806. Ideen zur einer Physiognomik der Gewachse Tubingen.

Jenny, H., 1941. Factors of soil formation. McGraw-Hill Book Company, New York.

Lemon, E., D. W. Stewart \& R. W. Shawcroft, 1971. The sun's work in a cornfield. Science (Wash. D.C.) 174: 371-378.

Lommen, P. W., C. R. Schwintzer, C. S. Yocum \& D. M. Gates, 1971. A model describing photosynthesis in terms of gas diffusion and enzyme kinetics. Planta (Berl.) 98: 195-220.

McCree, K. J. \& J. H. Troughton, 1966. Prediction of growth rate at different light levels from measured photosynthesis and respiration rates. Plant Physiol. 41: 599-566.

Major, J., 1951. A functional, factorial approach to plant ecology. Ecology 32: $392-412$.

Miller, P. C., 1969. Comparison of models of direct solar radiation in vegetation canopies with observations in three forest stands. Ecology 50: 878-885.

Miller, P. C., 1972. Bioclimate, leaf temperature, and primary production in red mangrove canopies in south Florida. Ecology 53: 22-45.

Miller, P. C., 1973. A model of temperatures, transpiration rates and photosynthesis of sunlit and shaded leaves in vegetation canopies. In: Plant response to climatic factors. Proc. Uppsala Symp., UNESCO, Paris, 1970, p. 427-434.

Miller, P. C. \& L. L. Tieszen, 1972. A preliminary model of processes affecting primary production in the arctic tundra. Arct. Alp. Res. 4: 1-18. Monsi, M. \& T. Saeki, 1953. Uber den Lichtfaktor in den Pflanzengesellschaften und seine Bedeutung für die Stoffproduktion. Jap. J. Bot.14: 22-52.

Monteith, J. L., 1965. Light distribution and photosynthesis in field crops. Ann. Bot. N. S. 29: 17-37.

Mooney, H. A., 1972. The carbon balance of plants. Annu. Rev. Ecol. Syst. 3: 315-346. 
Mooney, H. A., 1973. Plant forms in relation to environment. U.S. IBP, Origin and Structure of Ecosystems Tech. Rep. 73-4.

Mooney, H. A. \& E. L. Dunn, 1970. Convergent evolution of Mediterranean-climate evergreen sclerophyll shrubs. Evolution 24: 292-303. Mooney, H. A., E. L. Dunn, F. Shropshire \& L. Song, 1970. Vegetation comparisons between the Mediterranean climate areas of California and Chile. Flora (Jena) 159: 480-496.

Mooney, H. A., S. L. Gulmon, D. J. Parsons \& A. T. Harrison, 1974. Morphological changes within the chaparral vegetation type as related to elevation. Madroño 22: 281-285.

Mooney, H. A. \& A. T. Harrison, 1970. The influence of conditioning temperature on subsequent temperature-related photosynthetic capacity of higher plants. In: Prediction and measurement of photosynthetic productivity. Proc. IBP/PP meeting, Trebon, p. 411-417.

Mooney, H. A. \& D. J. Parsons, 1973. Structure and function of the California chaparral - A model from San Dimas. In: F. di Castri and H. A. Mooney [ed.] Mediterranean type ecosystems. Springer-Verlag, New York, p. 83-112.

Mooney, H. A., D. J. Parsons \& J. Kummerow, 1973. Plant development in Mediterranean climate. U.S. IBP, Origin and Structure of Ecosystems Tech. Rep. 73-6.

Parsons, D. J., 1973. A comparative study of vegetation structure in the Mediterranean scrub communities of California and Chile. Ph.D. dissertation. Stanford Univ., Palo Alto, Calif.

Penning de Vries, F. W. T., 1972. Respiration and growth. In: Cockskull et al. [ed.] Crop processes in controlled environments. Academic Press, London, p. 327-347.

Poole, D. K., 1974. Water relations of selected species of chaparral and coastal sage plants. Masters thesis. San Diego State Univ., San Diego, Calif.

Raschke, K., 1960. Heat transfer between the plant and the environment. Annu. Rev. Plant Physiol. 11: 111-126.

Raunkiaer, C., 1934. The life forms of plants and statistical plant geography. Clarendon Press, Oxford.

Schimper, A. F. W., 1898. Pflanzengeographie auf physiologischer Grundlage, Jena.

Sestak, Z., J. Catsky \& P. Jarvis, 1971. Plant photosynthetic production. Manual of methods. W. Junk, the Hague. 818 p. 
Slatyer, R. O., 1970. Comparative photosynthesis, growth and transpiration of two species of Atriplex. Planta (Berl.) 93: 175-189.

Specht, R. L., 1969. A comparison of the sclerophyllous vegetation in France, California, and southern Australia. Aust. J. Bot. 17: 293-308.

Stewart, D. W. \& E. R. Lemon, 1972. The energy budget at the earth's surface: A simulation of net photosynthesis of field corn. ECOM Atmospheric Sciences Lab., Fort Huachuca, Ariz., Int. Rep. 69-3.

Tansley, A. G., 1935. The use and abuse of vegetational concepts and terms. Ecology 16: 284-307.

Tieszen, L. L. \& N. K. Wieland, 1974. Physiological ecology of arctic and alpine photosynthesis and respiration. In: F. J. Vernberg [ed.] Physiological adaptation to the environment. InText Publishers Group, New York \& London. (in press).

Waggoner, E. W., G. M. Furnival \& W. E. Reifsnyder, 1969. Simulation of the microclimate in a forest. For. Sci. 15: 37-45.

Waggoner, P. E., 1969. Predicting the effect upon net photosynthesis of changes in leaf metabolism and physics. Crop Sci. 9: 315-321.

Waggoner, P. E. \& W. E. Reifsnyder, 1968. Simulation of the temperature, humidity and evapotranspiration profiles in a leaf canopy. J. Appl. Meteorol. 7: 400-409.

Warming, E., 1895. Plantesamfund. Grundtraek auf den okologiske Plantegeografi. Kjobenhavn.

Wit, C. T. de, 1965. Photosynthesis of leaf canopies. Agric. Res. Rep. (Wageningen) 663. 


\title{
A critical appraisal of some grassland models
}

\author{
N. G. Seligman
}

Grassland and ecosystem models have been proliferating since the beginning of the IBP in 1968. From a rather ambitious beginning, total ecosystem and even less comprehensive grassland models have become increasingly complex so that the task of comprehending someone else's models has become a formidable, if not an impossible task. True, the actual intellectual exercise in ecological holism has increased awareness of certain aspects of grassland systems that would otherwise have been ignored (Noy-Meir, 1975a). This is useful in itself but is essentially a spin-off that hardly justifies the scale of effort involved in the more complex ecosystem models. Many reported modelling efforts conclude with a declaration that the results are reasonable but the model needs further development; and that there are large gaps in our knowledge of the processes that make the systems run (Patten, 1971). Many are sitting ducks for withering criticism like that of Passioura (1973).

And yet, the enthusiasm that produced many of these complex abstractions of grassland systems cannot be dismissed as misguided preoccupation with computerized science fiction because the challenge is real and the approach is intuitively promising. How else will the burgeoning explosion of research results in biology, and grassland science in particular, be marshalled into a usable, integrated form, meaningful beyond the restrictions of the individual analytical disciplines? There certainly is an overshoot of complexity and an undershoot of sound conceptualization, but many of these "first generation' ecosystem-like models can be seen as exploratory exercises that are more like tests of a new methodology than applications of it. Now, after the international flurry of modelling activity has thrown up a growing pride of models on grassland and related systems, is it not time to have a closer look at some of them in order to see what has been achieved that is already of general interest and what pitfalls should be avoided? A comprehensive and balanced review, "especially of the larger models, is called for, but will not be attempted here. The comparative study presented instead is intended as no more than an 
introduction to a critical appraisal of grassland modelling that should become a permanent feature of such activity. The more pointed the criticism the greater the chance that the quality and status of grassland models will rise to a level that will make possible undisputed contributions to the understanding and management of grassland, and gain the grudging respect of anti-modellers.

\section{What justification is there for grassland models?}

Biological system models are said to be a means of hypothesis testing and as such are a research tool (Patten, 1970). They are also said to be the means whereby basic research results in plant physiology, soil science and agrometeorology are efficiently extrapolated to field conditions (de Wit, 1970). Grassland modellers often claim that, for them, modelling is all of this too, but mainly a management tool (Arnold \& Bennett, 1975). One can object that if crop canopy models have reached a higher level of complexity, often very sophisticated complexity, without yet becoming management tools, how can such a claim be seriously made for a grassland system where the grazing animal and its interaction with the growing pasture add greatly to the potential complexity of the system? The stock rejoinder is that if the farmer relies on available knowledge, experience, intuition and faith to manage the complexities of the system and often does so successfully, surely the application of a much more powerful battery of information and experience in an objective and dynamic reasoning scheme should be even more successful. The implication is that the criterion of scientific rigour has been replaced by one of pragmatic usefulness. Unfortunately hardly any grassland models have shown that they stand by the second criterion, which may be an even sterner master than the first.

It seems therefore, that grassland models today can be justified not on performance but on promise. A slim justification indeed, but the need is so obvious, and the alternatives so few and so demanding, that the promise will have to be proved vain before grassland modelling is given up.

\section{The grassland system}

A representation of the basic elements in a grassland system is given 
in Fig. 1. The elements or state variables that are defined as part of the system interact with each other while the driving variables act unidirectionally on the system. The management variables have a more ambiguous status: they can be fixed and independent of the dynamics of the system or they can be flexible and dependent on information feedback, in which case they would be part of the system.

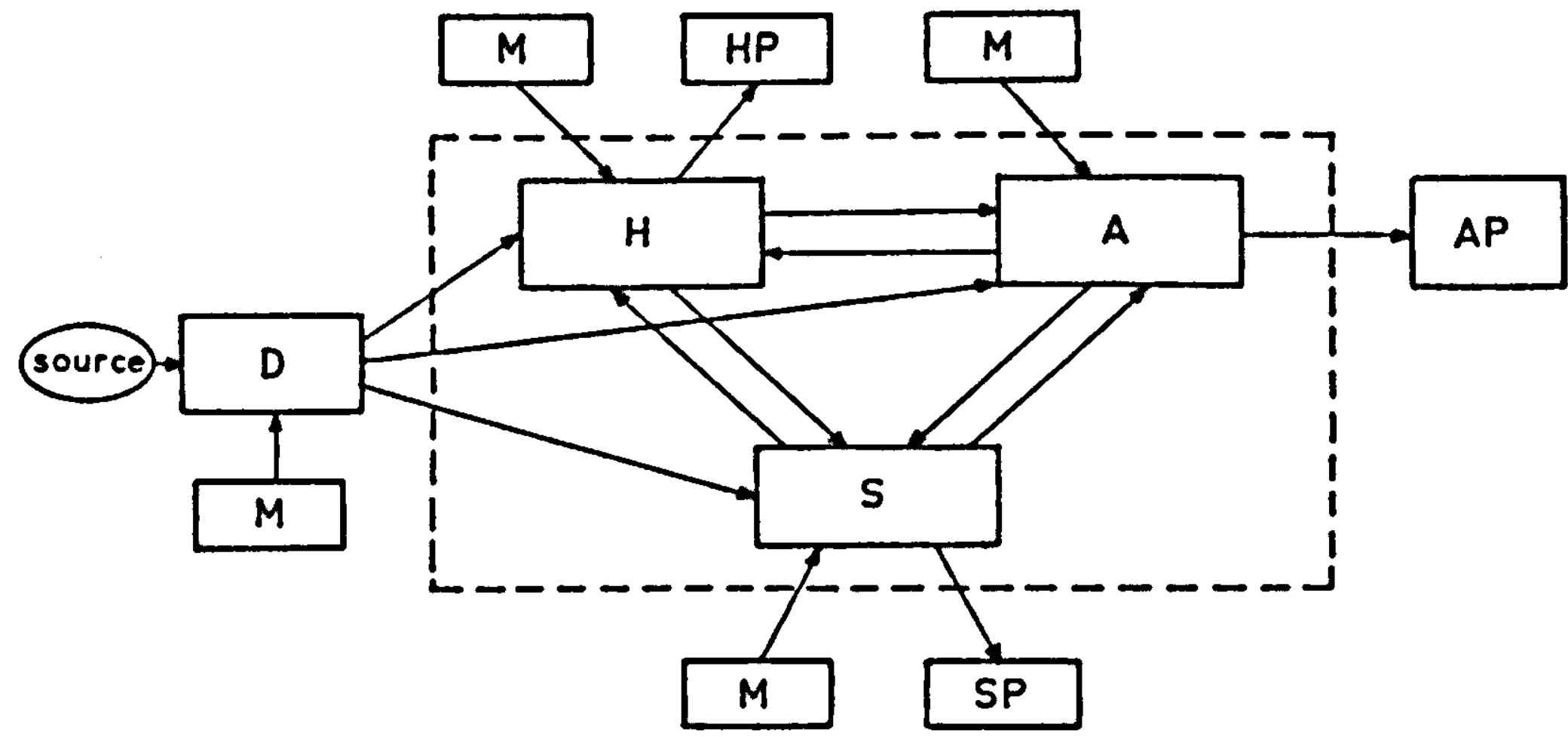

Fig. 1| Some relationships between variables in a grassland system. ( $D=$ driving variable; $M=$ management; $H=$ herbage; $A=$ animal; $\mathrm{S}=$ soil; $\mathrm{HP}=$ herbage output; $\mathrm{AP}=$ animal output; $\mathrm{SP}=$ soil output. system boundary).

Management of the driving variables implies practices like irrigation and windbreaks; management of the herbage includes grazing systems, reseeding, haymaking and artificial forage desiccation; management of the animal includes supplementary feeding and protection from the elements; management of the soil includes chemical fertilization and cultivation. The outputs are obvious, those of soil including runoff, deep drainage and eroded soil. Even in such a highly simplified representation, it is clear that the interactions or feedbacks are numerous and complex. A crop canopy model that assumes moisture and nutrients to be non-limiting (as many do) treats the following relationships defined in Fig. 1:

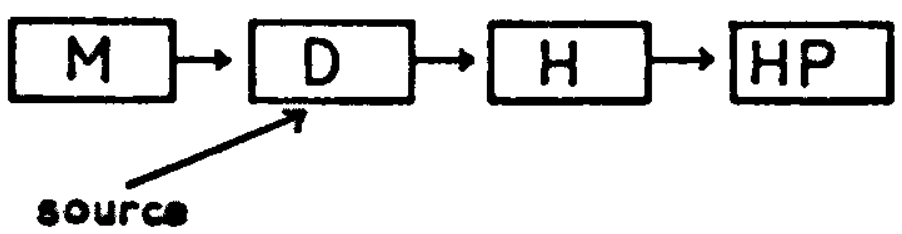


These are 4 links only, compared to 9 when soil is added as a variable and 15 when animals are added. As most serious crop canopy models are already very complex, it is clear, $a$ priori, that a grassland model will have to simplify many of the interrelationships to stay comprehensible and manageable. Simplification in this context means either omitting processes considered secondary or irrelevant to the main objective or reducing the number of component elements of a process and replacing them with a single empirical relationship or table. These elements become forcing functions or 'black boxes' unaffected by feedback from the rest of the system. As 'system' and 'feedback' are, in a sense, almost synonymous this procedure which is basic to biological modelling, reduces the sensitivity, generality, and in some cases, even the validity of a model. The alternative, severe circumscription of the scope of the model, has been chosen by many crop canopy modellers but it is cold comfort for the grassland modellers interested in pasture, animal and management interactions. Noy-Meir (1975c), however, has shown that the comfort may not be so cold, after all. A list of some crop, grassland and ecosystem models selected to represent different levels of complexity and different approaches to the analysis of grassland systems, is given in Table 1. Growth models have received much more attention till now than have grassland models. Some of them are discussed here as background and reference to the discussion on grassland and ecosystem models.

\section{Review of some growth, grassland and ecosystem models}

\section{The BACROS Model}

BACROS, or basic crop simulator (de Wit et al., 1970 and 1976) is a detailed physiological process model that has been developed over a number of years by a continuing process of validation and experimentation. It assumes moisture and nutrients to be non-limiting but radiation and $\mathrm{CO}_{2}$ content of the incoming air to be variable. The model simulates the photosynthesis and distribution of assimilate between shoot, root and respiration of specific crop canopies. It does not simulate morphogenetic change in the plant, so that leaf area must be entered as input. The model has been used mainly to help develop hypotheses about growth processes and direct an integrated research effort. The resolution of the model is very fine, the time constant being of the 


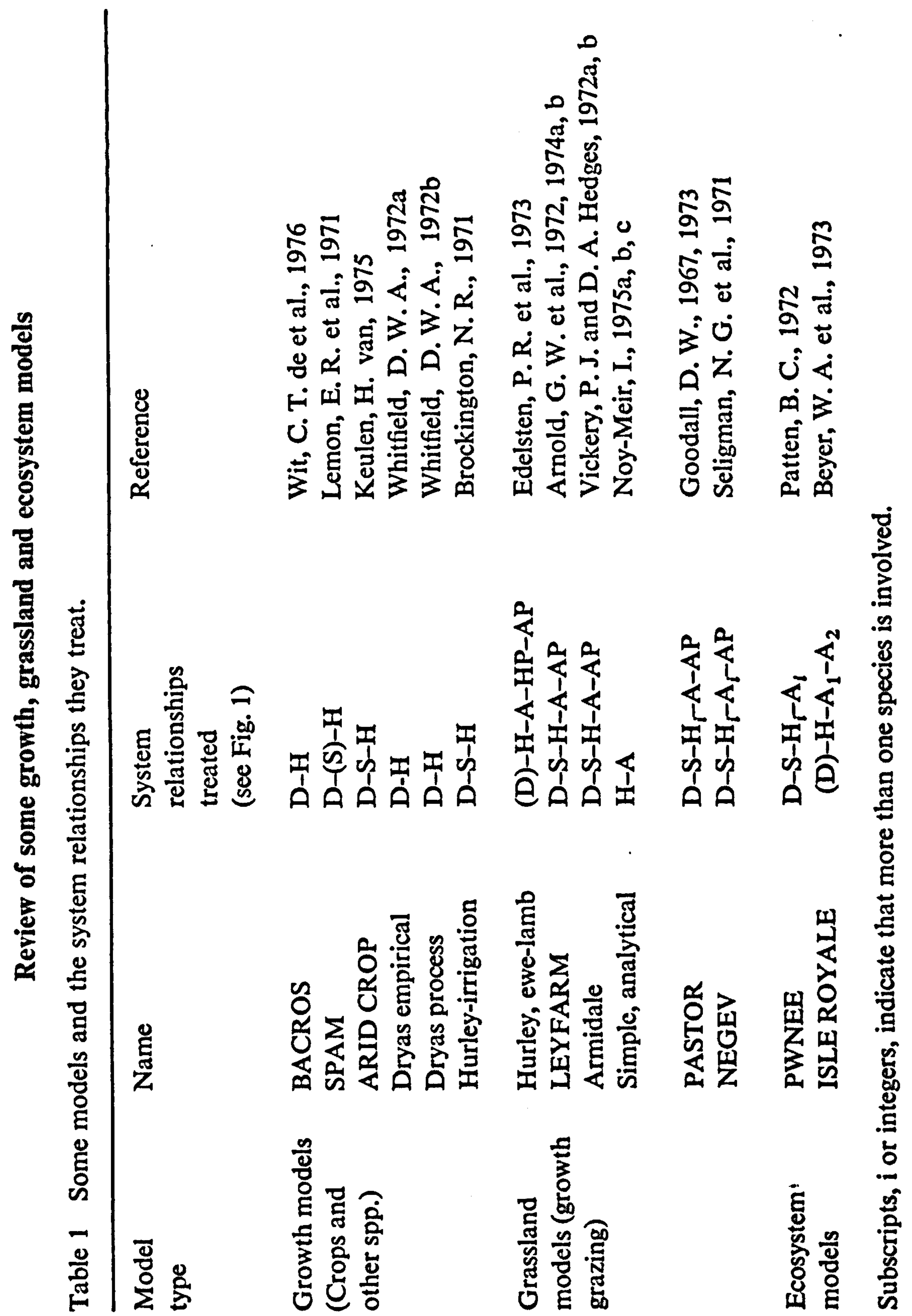


order of a few minutes. The results of the simulation are generally very close to the measured results, in most cases within $\pm 10 \%$ of the actual hourly photosynthesis rate. This model is cited here as an example of the tremendous effort that is needed to obtain accurate results from a basic model of even a limited aspect of crop growth. Even such a model requires an independent determination of a fundamental variable like leaf area. A fixed proportionality between shoot weight and leaf-area does not materially reduce accuracy in many situations, especially as the canopy becomes closed, but can introduce considerable error through positive feedback when leaf-area is low.

\section{The SPAM Model}

SPAM (Soil Plant Atmosphere Model; Lemon et al., 1971; Stewart \& Lemon, 1969) is a similar process model developed specifically for corn but in principle adaptable to other crops too. It does not regard soil moisture as necessarily non-limiting and has photosynthesis dependent on soil moisture too. Essentially it is a micro-meteorological photosynthesis model of the type that is attracting much attention in many parts of the world. It, like BACROS, is an example of the detail and complexity of photosynthetic canopy models. Expanding them on the present level of detail to include morphogenesis, phenology, nonoptimal soil moisture and nutrient conditions will make them so complex that, besides computer limitations, they will be extremely difficult to manipulate and comprehend. At that stage, simulation will become self-defeating in that it will probably create more problems than it will solve. Thus for more comprehensive models, and certainly for grassland models, certain elements of the basic models will have to be reduced or simplified.

\section{The ARID CROP Model}

A possible approach is used in ARID CROP (van Keulen, 1975). This is an application of BACROS to conditions where soil moisture is not necessarily optimal. It draws most attention to the water status of the soil as moisture enters, passes through it and is withdrawn by evaporation and transpiration. In order to exploit the plant physiological depth of BACROS and yet avoid becoming bogged down by its complexity, a simplifying concept was necessary to link the two models. The con- 
cept chosen was first proposed by de Wit (1959) and is based on the observation that growth and transpiration are closely related; $\mathrm{CO}_{2}$ uptake and moisture loss are regulated by the stomata, but moisture loss will also depend on the evaporative conditions. Thus in order to relate moisture loss to $\mathrm{CO}_{2}$ uptake it must be corrected for the current potential evaporation. Thus,

$$
\begin{aligned}
& G=M \frac{E}{E_{0}} \\
& G=\text { growth (or } \mathrm{CO}_{2} \text { uptake) } \\
& E=\text { actual transpiration } \\
& E_{0}=\text { potential transpiration } \\
& M=\text { proportionality or transpiration factor }
\end{aligned}
$$

The value of the transpiration coefficient (M) can be determined by BACROS for a given plant species and given radiation conditions. Thus, this detailed physiological process model enters ARID CROP as a single coefficient. The concept has the added advantage that $M$ is an experimentally verifiable parameter. It can therefore also be used without reference to BACROS. It is now left to determine the actual transpiration, which in fact is what ARID CROP does by simulating the rooting depth of the crop, soil moisture and canopy cover. This approach assumes that there is no feedback from ARID CROP onto $M$ which is dependent solely on the radiation conditions and the species. If $M$ was dependent on soil moisture changes too, its determination would have had to be included in ARID CROP. It is therefore fundamental to this type of solution, that the link variable developed by the basic model does not depend materially on feedback from the applied model. It then becomes a driving variable in the applied models. Such an approach has been called 'hierarchical modelling' (van Keulen, 1975).

ARID CROP has been tested on data from the Northern Negev of Israel (van Keulen, 1975) and has been found accurate, also to within $10 \%$ of the observed final yield. There are, however, deviations during the growing season in that early growth is overestimated and late growth underestimated. This problem will have to be solved before full confidence can be placed in ARID CROP as a source of input to an even more comprehensive model. It runs at present on the 
assumption that nutrients are non-limiting. Development to include the effects of nitrogen limitation is under way.

Here we have an example of development of a grassland model step by step from a basic plant physiological process model to more and more comprehensive applied models.

\section{The Dryas empirical and the Dryas process models}

The two following models (Whitfield, D.W.A., 1972a, b) illustrate an aspect of accuracy and resolution in plant growth models. The first one, an empirical model of growth of the shrub Dryas integrifolia, calculates net assimilation from radiation input and the measured (or interpolated) amount of Dryas photosynthetic tissue. The relationship between net assimilation and radiation is determined for different phenological states and is then used as a set of functions or tables in the model. It is estimated that the seasonal net photosynthesis calculated by the model is accurate to within $5 \%$ of what is measured in the field. The second model, a process model, is still in the development stage but includes a fairly detailed treatment of the energy budget and water relations, photosynthesis and respiration, translocation and allocation of carbohydrates and nitrogen, decomposition of dead leaves and nitrogen cycling. The driving variables, temperature, relative humidity, wind speed and incoming radiation, are entered on an hourly basis. In order to run the model, parameter values are determined by field experiments, taken from literature or guessed. The model result for dry biomass increase agrees with measured data for the beginning of the season but then deviates strongly in the later season. This is ascribed to the "lack of any attempt to represent hormonal control of growth or seasonal variation of such processes as gross photosynthesis". The carbohydrate content of the plant is rather stable in the experimental data, but shows strong seasonal variation in the model results.

The process model is clearly a more sophisticated and thus a more interesting one to the physiologist. Yet the results in terms of biomass increase are much less satisfactory than those of the empirical model. The reason is that the empirical model uses as input, data which are closely related to the final result. The process model uses more plant specific data (parameters, initial values) and more detailed micrometeorological data, but these are also more distantly related to the 
final result. The closer one comes back to the data and looks at leaf temperatures, for instance, the better the approximation to reality. BACROS, which is also a process model, has indeed achieved much closer agreement with observation in many situations, but that only after a much larger effort had been invested in experimental determination of relationship between variables and model development. The point of this discussion is that accuracy and resolution of a model are often inversely related, if by accuracy we mean the agreement between model output and observation and by resolution, the number of simulated processes that separate the input and output variables. Thus, if one is constructing a more complex model it would be sounder to invest the main experimental and modelling effort into those selected processes which are of central interest and rely on actual data or data-hugging simulations for the elements of peripheral interest. The resultant increase in model managability is achieved at a cost of flexibility and generality. In addition it must be clearly established that the data entered are not particularly sensitive to feedback from other parts of the model. Such an approach has been used in the Hurley models.

\section{The Hurley irrigation model}

The Hurley grassland irrigation model (Brockington, 1971) determines the effect of irrigation on dry matter yield of grassland in England. Nutrients, including nitrogen, are assumed to be available in the top layer only. When moisture is depleted from this layer and the sward depends on moisture from the lower soil layers, it is starved of nitrogen even though there may still be some available in the upper soil layer. The emphasis in this study is the effect of moisture depletion in the top layer on potential growth. Thus potential growth, which is defined here as growth when moisture is non-limiting in both soil layers, is entered as a table derived from observed data. Moisture deficiencies in the soil layers are then combined into a water factor which serves as a reduction factor on potential growth. The results of the model agree very well with experimental data in some years so that it was regarded as sufficiently reliable to be used for a series of irrigation strategy studies. Here too, accuracy goes with low resolution. The limitations, however, must be recognized. For instance, if drying of the top layer was accompanied by decrease of the grass cover so that a return to optimal 
soil moisture conditions would not produce potential growth till the cover was restored, then the model results would not apply because potential growth would then become dependent on feedback from the model. Such an effect has been neglected, probably because the problem was not thought to be serious, even though there were discrepancies between the model and observed results in one of the verification years reported that could have been due to just such an effect. The approach in this model is thus highly empirical and as such it is of limited generality. This need not be a serious objection in cases like this because the alternative is to do experiments of a much more limited scope on a site no less specific than the model.

\section{The Hurley ewe-lamb Model}

It becomes more difficult to use such simplifications successfully in cases where the scope or objective of the model is more ambitious. A case in point is the Hurley ewe-lamb model (Edelsten et al., 1973). The structure of the model is given in Fig. 2. Here the emphasis is on the management of the flock of sheep by manipulating the grazing rotation, supplementary feeding and silage cuts from the vegetation.

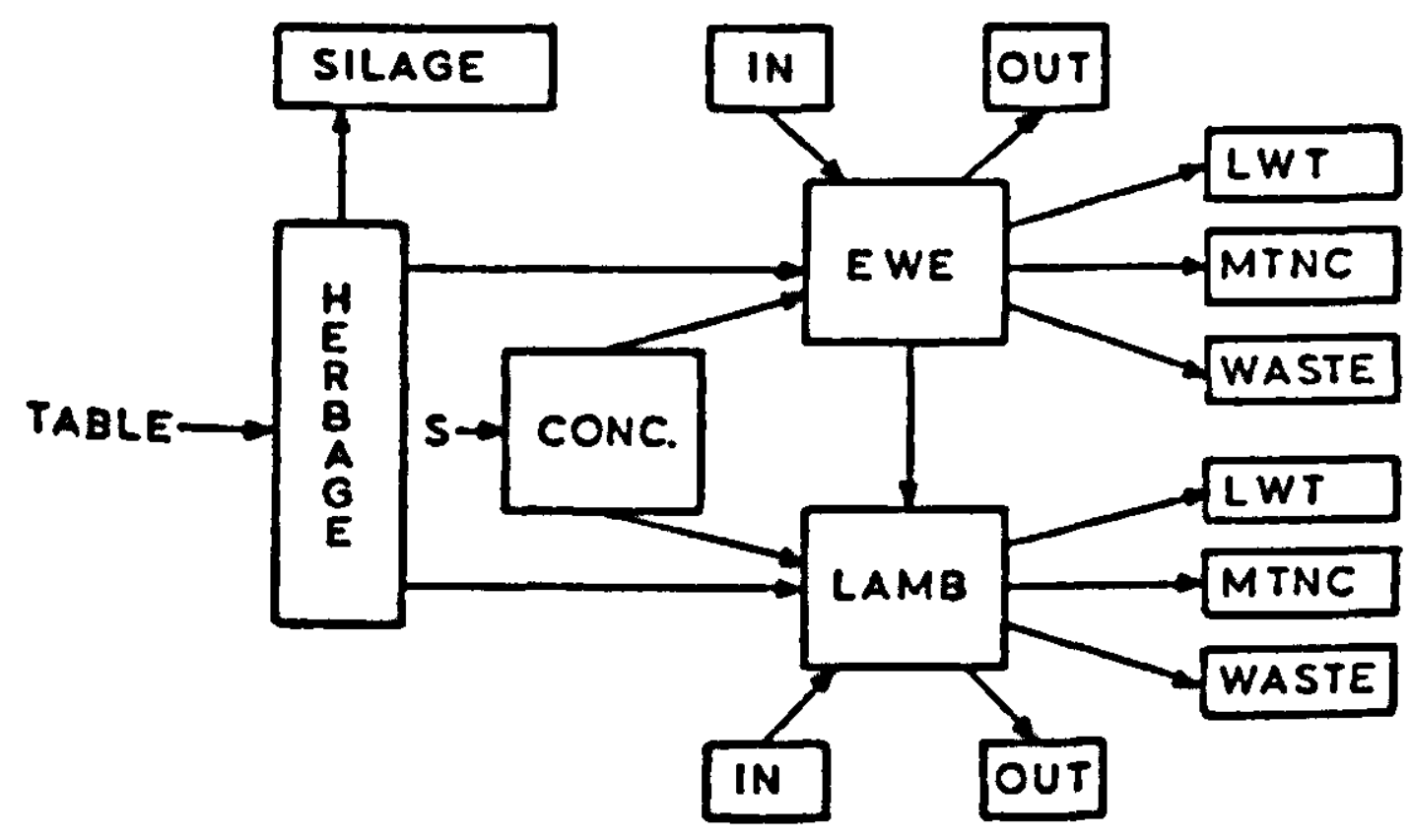

Fig. 2 Structural relationships in the Hurley ewe-lamb model. (After Edelsten et al., 1973).

Growth rate of the vegetation under grazing conditions is entered as a season specific table (Fig. 3) constructed from observed data. When paddocks are not being grazed, growth is calculated by means of an 


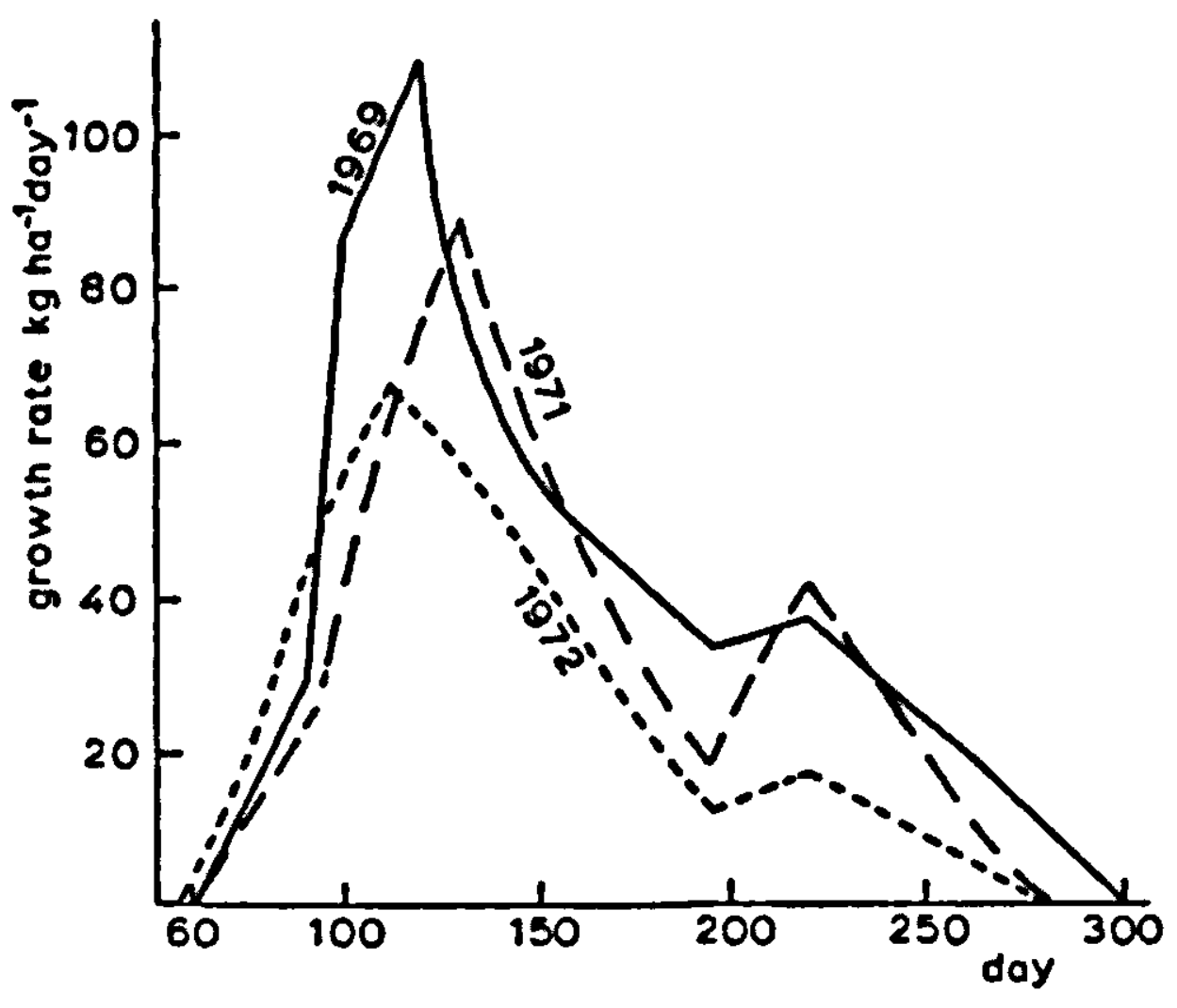

Fig. 3 | Growth rate functions of grazed pasture used in the Hurley ewelamb model. (After Edelsten et al., 1973).

algorithm based on the seasonal rates. It is thus assumed that there is no feedback of grazing effects from the model on herbage growth and that growth undisturbed by grazing is independent of different conditions from year to year. Whatever effect grazing had on growth, it was regarded as constant and independent of the management or stocking densities defined in the model. Such an assumption obviously limits the scope of the model to those cases where this condition holds.

Some results of this model are given in Table 2. The growth rates of the

Table 2 Some results of the Hurley ewe-lamb model.

Experimental

results
Model

results

\begin{tabular}{|c|c|c|c|c|c|c|}
\hline Stocking rates (ewes ha ${ }^{-1}$ ) & 14 & 17 & 20 & 14 & 17 & 20 \\
\hline Ave. growth rate-lambs (g day ${ }^{-1}$ & 189 & 186 & 167 & 212 & 182 & 167 \\
\hline Silage produced (tons $\mathrm{DM} \mathrm{ha}^{-1}$ & 0.96 & 0.96 & 0.96 & 1.5 & 1.5 & 1.5 \\
\hline Concentrates fed $\left(\mathrm{kg} \mathrm{lamb}^{-1}\right)$ & 2.8 & 6.2 & 9.8 & 1.1 & 30.7 & 35.6 \\
\hline
\end{tabular}


lambs are close to observed, especially at the higher stocking densities. This accuracy is built into the model as the management of the herd was set to attain acceptable growth rates. Management included concentrate feeding which is influenced by the amount of feed grazed off the pasture. The amount of concentrate simulated was rather different to that observed; there was also a large discrepancy in the amount of silage harvested.

This model is being developed and the results are from an early version. They do show that some conceptional weaknesses need to be identified and rectified. This will most probably be done as the development of the model progresses. An obvious area of weakness to look at more closely would seem to be the feedback of grazing on herbage growth and the assumptions on which undisturbed growth are based. If the weaknesses can be removed by minor adjustments then possibly the use of the herbage growth tables could still be maintained. If not, then it could well be that a more detailed herbage growth model that could simulate the effect of grazing on growth rates would be required.

\section{The LEYFARM Model}

LEYFARM (Arnold \& Campbell, 1972. Arnold et al., 1974a, b) is a moderately complex, comprehensive model that in its present form, simulates grazed, annual (legume) pasture from seed germination through growth, flowering, seed formation, death, decay and consumption through grazing, to the softening of hard seeds for the next season's germination. The moisture balance in the soil and the grazing animal are simulated in detail. The model is unabashedly empirical and as the objective is to study grazing management, it regards statistical relationships for describing many of the component processes as sufficient at this stage. It makes wide, if not indiscriminate, use of the experimental data available. Considerable attention is given to the seeds which are formed as hard seeds and have to soften before they can germinate. Germination takes place in waves and the separate waves are monitored to form the basis for calculating a mean emergence day (MERGD) and a mean weighted flowering day. These days are used to determine the weight of individual seeds, the yield of seeds and the rate of ageing of the herbage. After germination and establishment, growth is initiated by converting germinated seed into live biomass (weight of seedlings $=0.5 \times$ weight of germinated seed). From 
then on and until all live biomass eventually dies, the pasture grows at a daily growth rate, dies at a daily death rate. The live and dead material are consumed by sheep selectively and the dead material also decays.

Here only the growth of the germinated pasture without grazing will be considered so as to keep the discussion circumscribed and compatible with the foregoing sections.

The daily growth rate (DGR) is determined as follows:

\section{$\mathrm{DGR}=\mathrm{POTGR} \times \mathrm{RADF} \times \mathrm{R} \times \mathrm{AGE} \times \mathrm{TEMP}$}

The potential growth (POTGR) is entered as a function of dry weight of green matter (GRNMAT) in $\mathrm{kg} \mathrm{ha}^{-1}$ (Fig. 4). The form of the function used implies approximately exponential growth till $1000 \mathrm{~kg}$ $\mathrm{ha}^{-1}$ and linear growth thereafter. The maximum growth rate approaches $126 \mathrm{~kg} \mathrm{ha}^{-1} \mathrm{day}^{-1}$. This value is somewhat less than

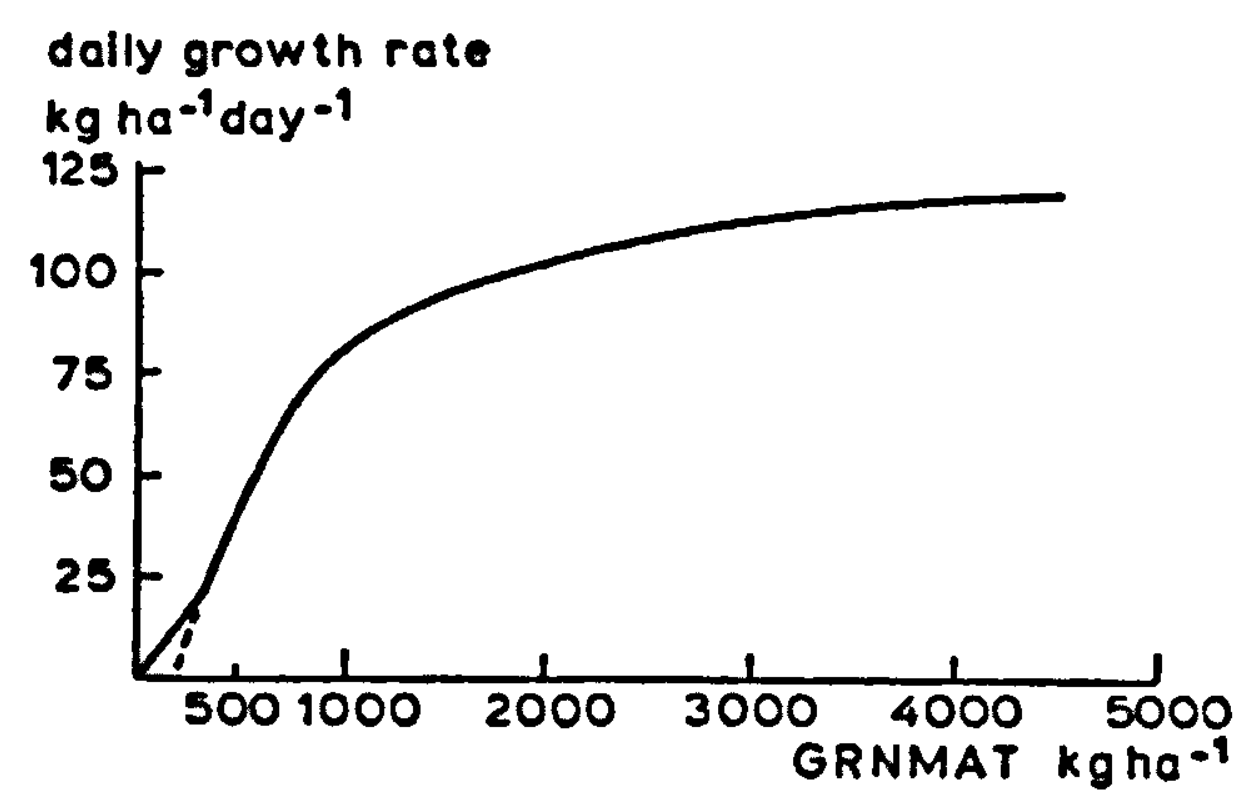

Fig. 4| LEYFARM: Potential daily growth rate as a function of amount of live biomass (GRNMAT). (Derived from Arnold et al., 1974b).

potential growth measured under similar climatic conditions but with a mixed grass-forb sward (van Keulen, 1975). It probably reflects the higher respiration costs involved in producing the high level of protein in plants like the annual legumes modelled in LEYFARM (Penning de Vries, 1973). The linear increase in growth when live biomass is below $500 \mathrm{~kg}$ GRNMAT ha ${ }^{-1}$ implies that growth rate increase per unit GRNMAT (the relative growth rate) is less than it is just above $500 \mathrm{~kg}$ GRNMAT. The reason for such a patchy construction is not clear but is probably related to the data used and could be a rough 
approximation of exponential growth at low GRNMAT values.

The radiation factor (RF) is a function with two variables, radiation (RAD) (cal cm $\mathrm{cday}^{-1}$ ) and GRNMAT (Fig. 5). The dependence on radiation when the canopy is fully developed $\left(7000 \mathrm{~kg} \mathrm{ha}^{-1}\right)$ is linear, a rather rough approximation in semi-arid conditions. $\mathrm{RF}=-0.5$ when $\mathrm{RAD}=0$, implies an excessive dark respiration rate. When GRNMAT is low, growth is virtually independent of radiation, even when $R A D=0$ (Fig. 5). This is not reasonable but may not have had an important effect on the results if low radiation values are rare.

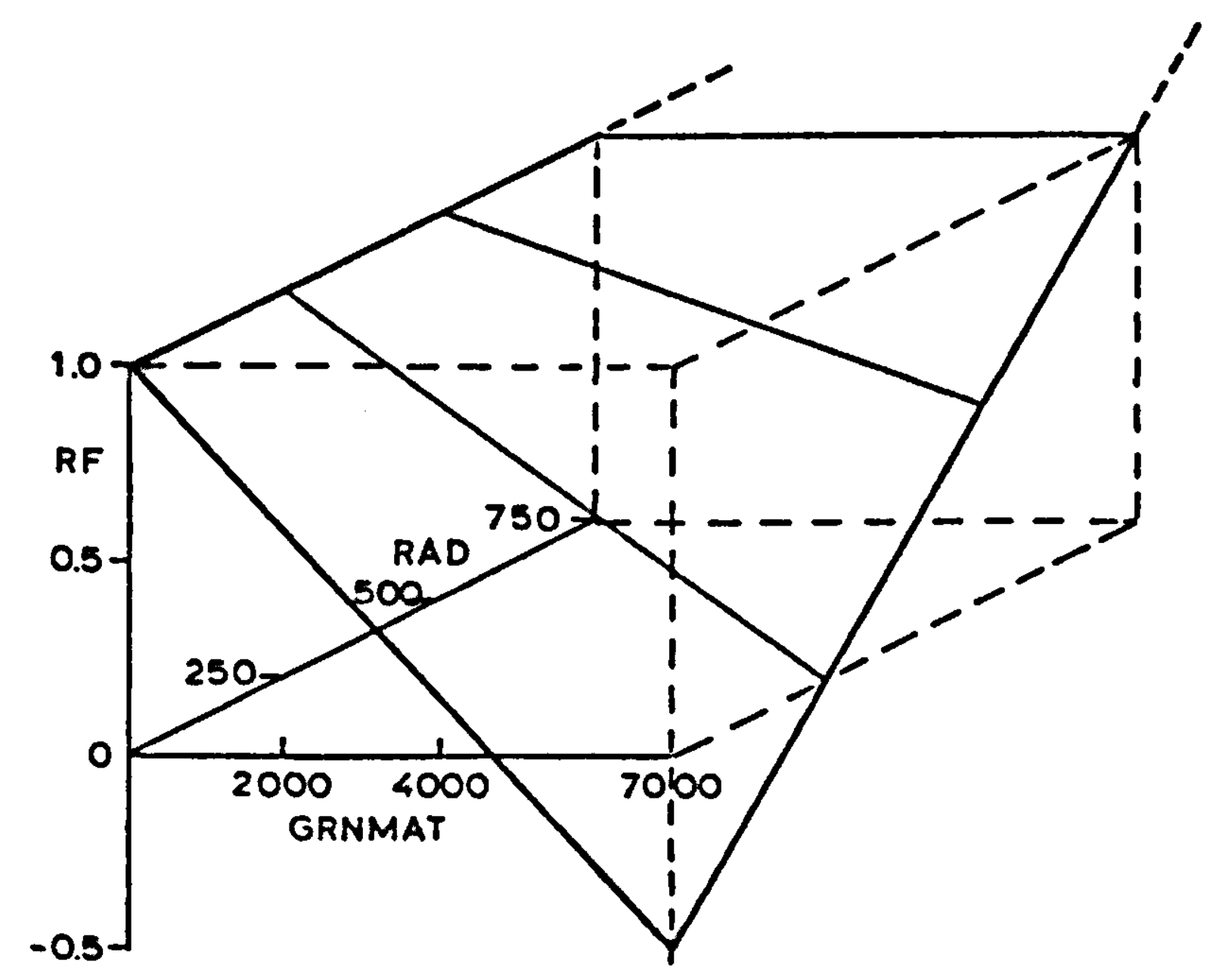

Fig. 5 | LEYFARM: Dependence of radiation factor (RF) on live biomass (GRNMAT) and radiation intensity (RAD in cals $\mathrm{cm}^{-2} \mathrm{day}^{-1}$ ). (Derived from Arnold et al., 1974b).

The effect of soil moisture on growth is mediated by $R=E / E_{0}$, where $\mathrm{E}=$ actual evapotranspiration; $\mathrm{E}_{0}=$ potential evapotranspiration. When LAI is less than $1, \mathrm{E}$ is split into transpiration, $\mathrm{E}_{\mathrm{t}}$, and evaporation from bare soil $E_{b}$. Then,

$$
\mathrm{E}=\mathrm{LAI} \times \mathrm{E}_{\mathrm{t}}+(1-\mathrm{LAI}) \times \mathrm{E}_{\mathrm{b}}, \quad \mathrm{LAI}<1
$$

$$
\text { LAI }=\text { GRNMAT } / 1000
$$

$E_{t}$ and $E_{b}$ are determined by a special soil water sub-routine (Carbon \& Galbraith, 1975). 
When LAI is less than one, the growth reduction factor, $R$, is calculated from the transpiring vegetation only. Thus,

$$
\mathrm{R}=\mathrm{E}_{\mathfrak{t}} /\left(\mathrm{E}_{0} \times \mathrm{LAI}\right), \quad \mathrm{LAI}<1 \text {. }
$$

It may have been simpler and more realistic to relate $R$ to the cover of the vegetation as follows:

$$
\mathrm{R}=\mathrm{E}_{\mathrm{t}} /\left(\mathrm{E}_{0} \times \text { COVER }\right)
$$

COVER $=1-\operatorname{EXP}(-0.5 \times$ LAI) (van Keulen, 1975).

The age factor is dependent on a function of MERGD and number of days after flowering (Fig. 6).

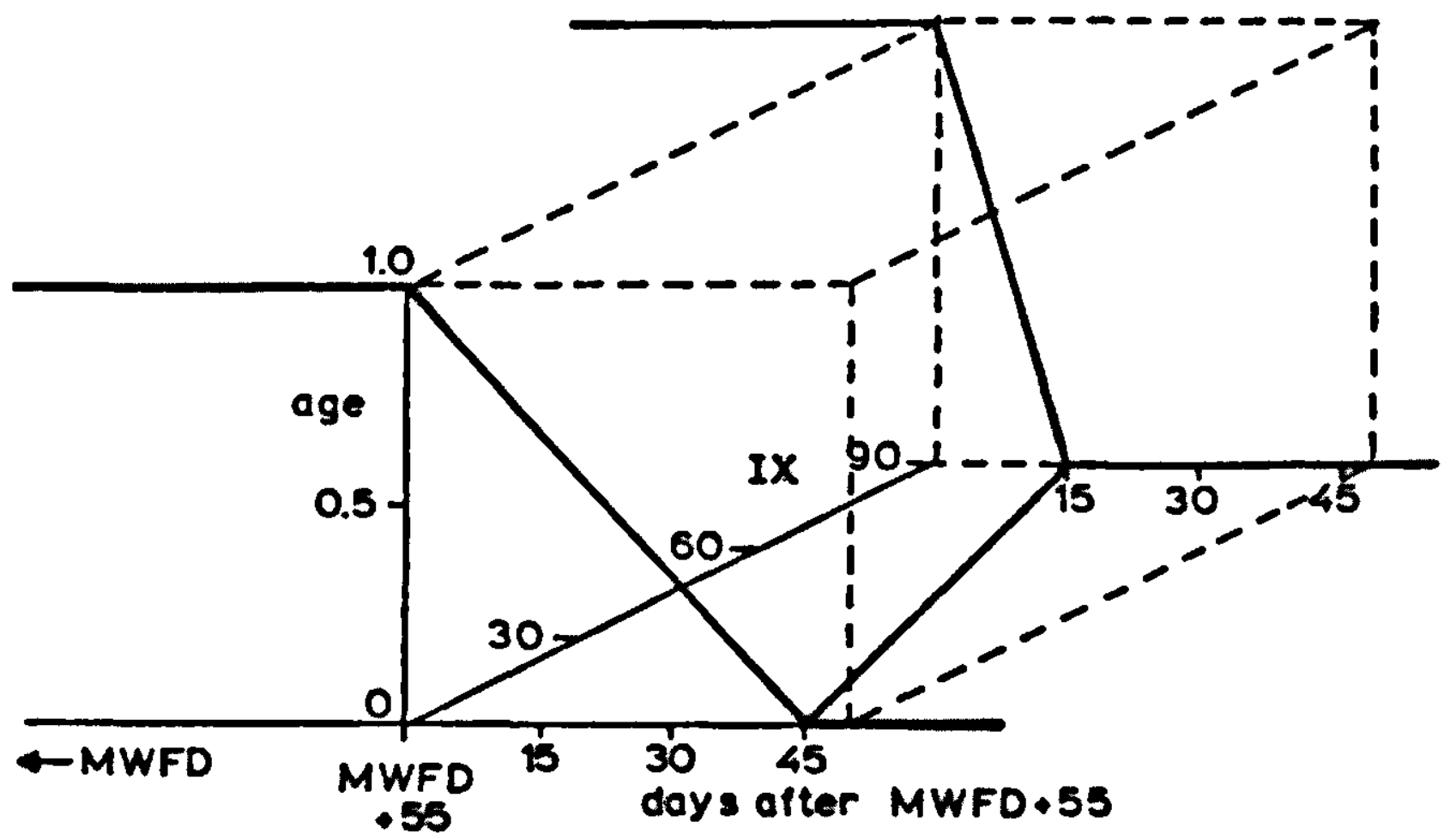

Fig. 6/ LEYFARM: Dependence of ageing factor (AGE) on time of flowering (MWFD) and IX, a function of mean time of seedling emergence (MERGD) where IX $=0<($ MERGD-138) $<90$. (Derived from Arnold et al., 1974b).

IX=MERGD $-138(\equiv 1$ April S.H. $\equiv 1$ October, N.H.) $0<$ IX $<90$.

Till the 55th day after flowering, $A G E=1$. When MERGD $<138$, then $A G E=0$ on the 100th day after flowering; when MERGD $>(138+90)$ then $A G E=0$ on the 70th day after flowering.

Again, the construction is a three-dimensional surface based on direct interpretation of available data. It is, however, a rather cumber- 
some and arbitrary method. Ageing is certainly a complex process, but when more complete information is lacking it would seem that a temperature accumulating treatment would be more appropriate (de Wit \& Goudriaan, 1974, Chap. 6).

The temperature factor is composed of a set of curves, the choice of of which is dependent on GRNMAT and RAD (Fig. 7). When GRNMAT $>1000 \mathrm{~kg} \mathrm{ha}^{-1}$, temperature ceases to influence growth.

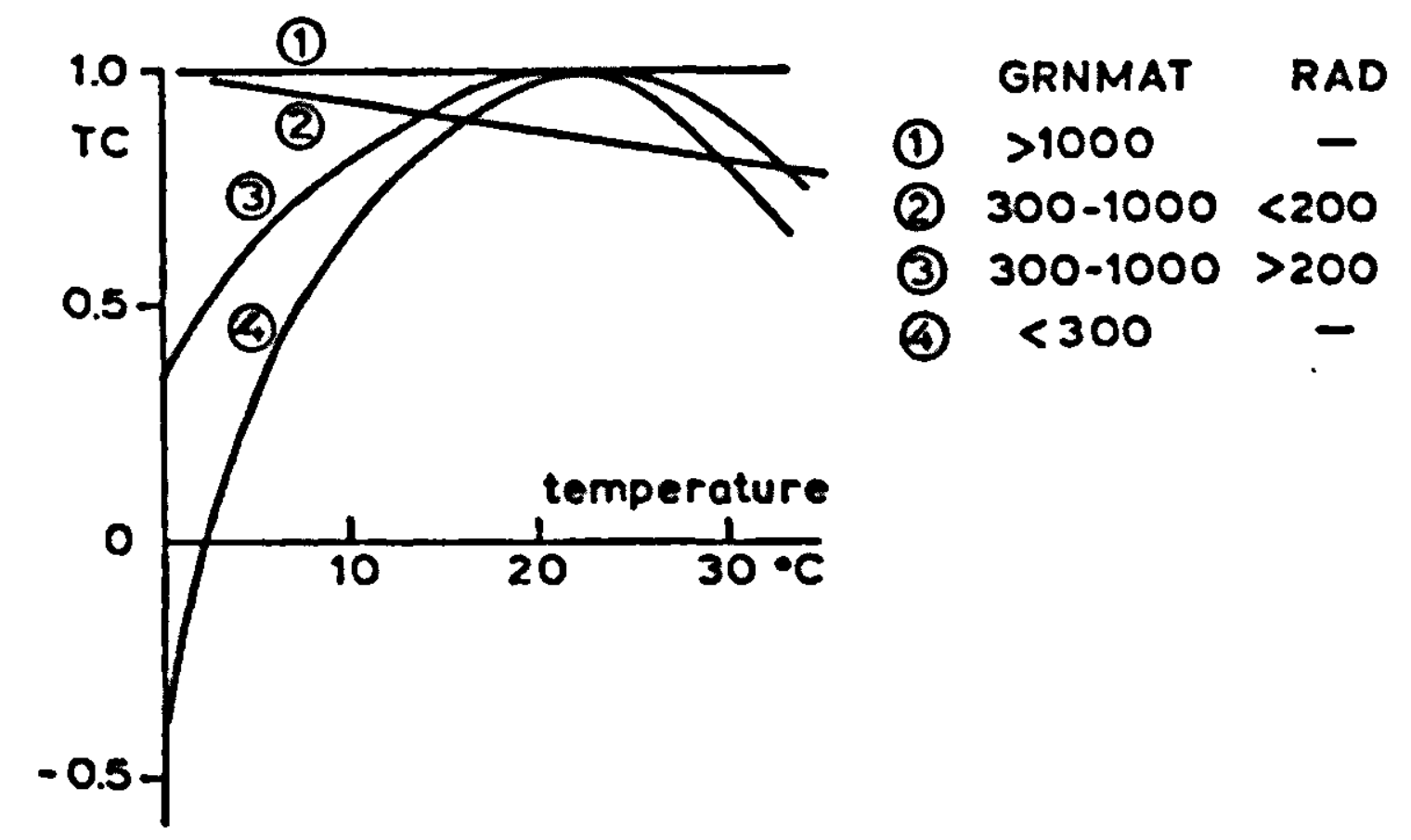

Fig. 7 LEYFARM: Functions used for temperature factor (TC). Derived from Arnold et al., 1974b).

The daily death rate (DDR) of the vegetation is calculated as a basic death rate dependent on the amount of live biomass (LOSS). This is increased as the plant matures (PHEN) and as the soil dries out (DSF):

$$
\begin{aligned}
& \text { DDR }=\text { GRNMAT } \times(\text { LOSS }+ \text { PHEN }+ \text { DSF }) \\
& \text { LOSS }=\left\{\begin{array}{l}
.003, \text { GRNMAT }<3584 \mathrm{~kg} \mathrm{ha}^{-1} \\
0.019, \text { otherwise }
\end{array}\right.
\end{aligned}
$$

PHEN is determined by IX and number of days after MWFD on a three-dimensional surface bounded by 0 and 0.5 (Fig. 8).

$$
\text { DSF }= \begin{cases}.242, & R<0.1 \\ 0, & \text { otherwise }\end{cases}
$$




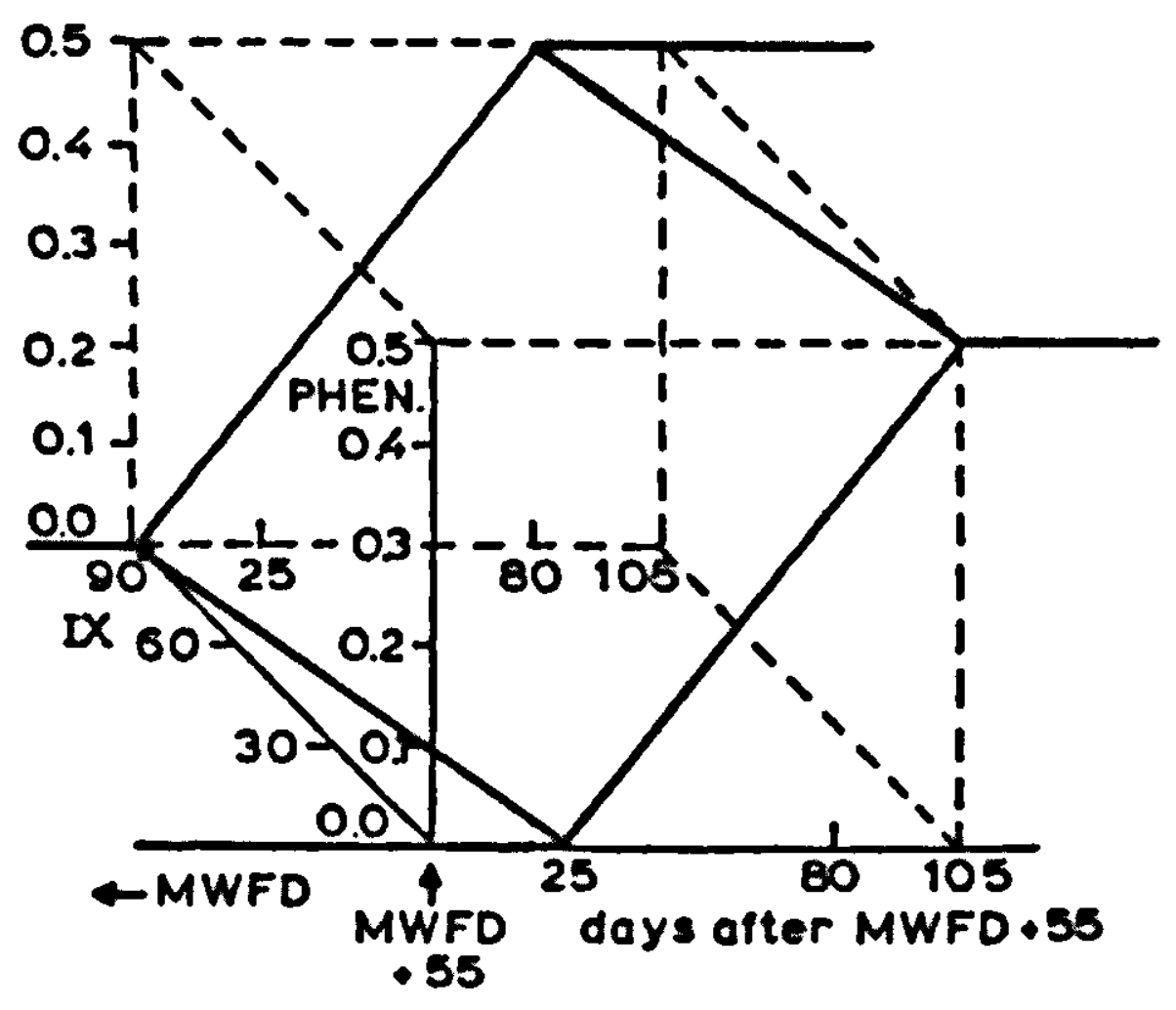

Fig. 8 LEYFARM: Dependence of herbage death due to maturity (PHEN) on time after flowering (MWFD) and on IX, a function of mean time of seedling emergence (MERGD) where IX $=0<($ MERGD-138) $<90$. (Derived from Arnold et al., 1974b).

The effect of the grazing animal on the growth rate of the pasture is assumed to operate solely through the reduction of GRNMAT caused by forage consumption. This assumption is substantiated by experimental data which indicate that potential growth rate is very closely related to the amount of green pasture whether it is being grazed or not (Arnold, 1975; Greenwood et al., 1974). In fact Arnold shows that when GRNMAT $>100 \mathrm{~kg} \mathrm{ha}^{-1}$ the amount of herbage removed by the sheep per day at normal stocking densities is generally much less than $10 \%$ of what is available. The effect on the canopy is thus quantitatively weak. However, at the beginning of the season when there is very little herbage available, then as much as $30 \%$ of what is available can be removed in one day. Arnold maintains that even at such intensities of defoliation the major quantitative effect on growth is directly due to the reduced biomass. Although this is qualitatively a gross over-simplification, much of the data presented supports this view. The matter should be more thoroughly investigated especially for intensive defoliation as it is important to know the limitations of this assumption if it is to become an important means of representing the growth-grazing relationship in a simple and meaningful way. The model produces satisfactory results (Fig. 9), despite the arbitrary 


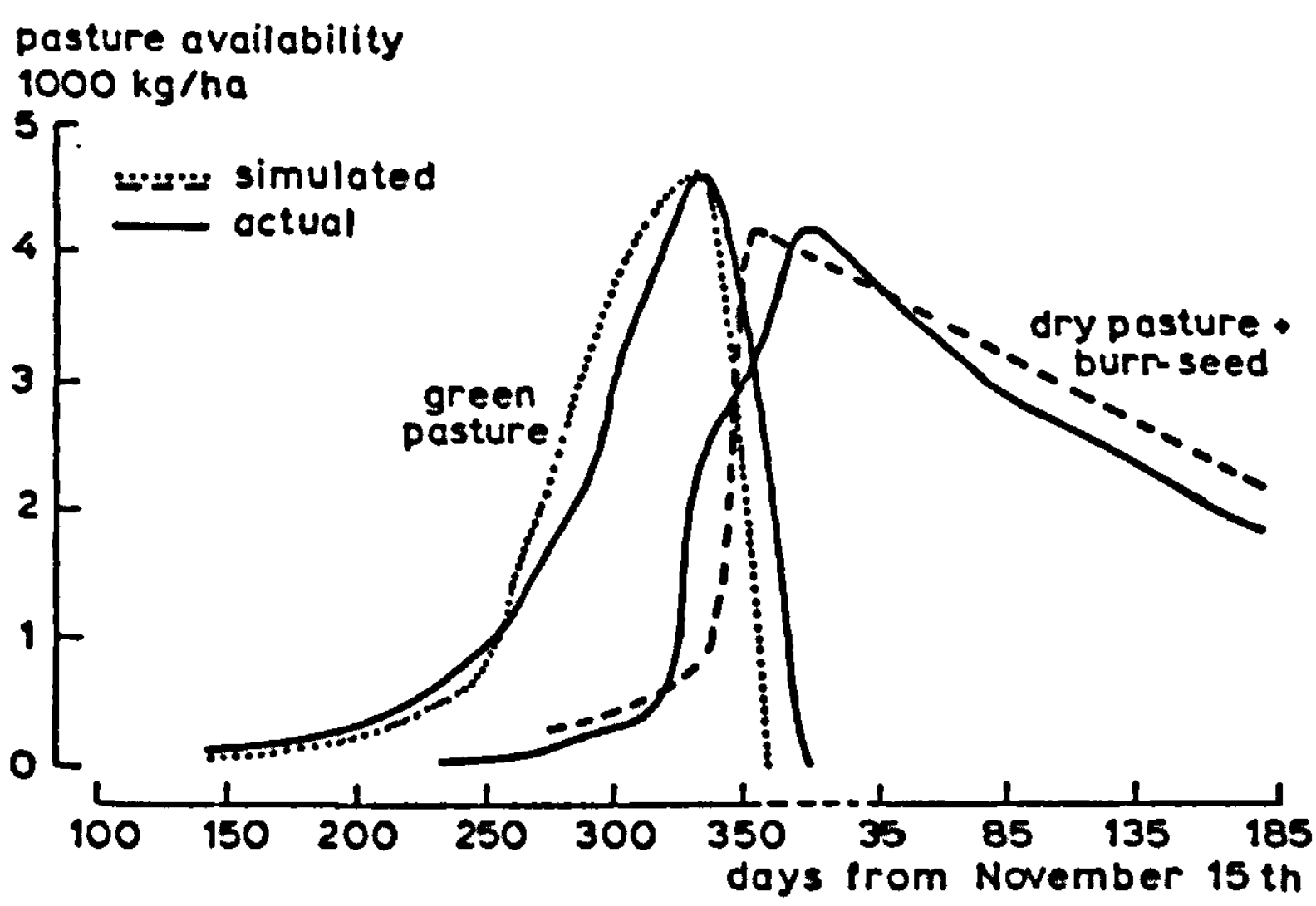

Fig. 9 | LEYFARM: Measured and simulated values for pasture availability when stocking rate is 10 sheep ha ${ }^{-1}$. (Derived from Arnold et al 1974b).,

functions and awkward constructions (or it is because of them!). This proves again that although there are many ways of reaching the top of the hill, some are more devious than others. In the context of LEYFARM a more concise and conceptually sound formulation could be a useful improvement. When so many empirical relationships are employed, a degree of elegance does become important if only to limit the unpredictable and unintended consequences of loose and conceptually weak structures in complex models.

\section{The Armidale Model}

The Armidale model (Vickery \& Hedges, 1972a, b) is of an improved Phalaris tuberosa - Trifolium repens pasture grazed by merino sheep at different stocking densities. The emphasis in the vegetation section is on the growth, forage value and consumption of the pasture. As it is a perennial pasture, germination and seed-formation are neglected. The soil moisture balance is also treated simply: a $75 \mathrm{~mm}$ soil moisture capacity is filled by rain and emptied by transpiration which is $0.8 \times$ (pan evaporation) $\times$ SLMR. The latter term is a reduction factor dependent on soil moisture (Fig. 10). Root distribution is assumed to be always adequate for moisture extraction, - probably a reasonable assumption for the specific conditions, but a possible 


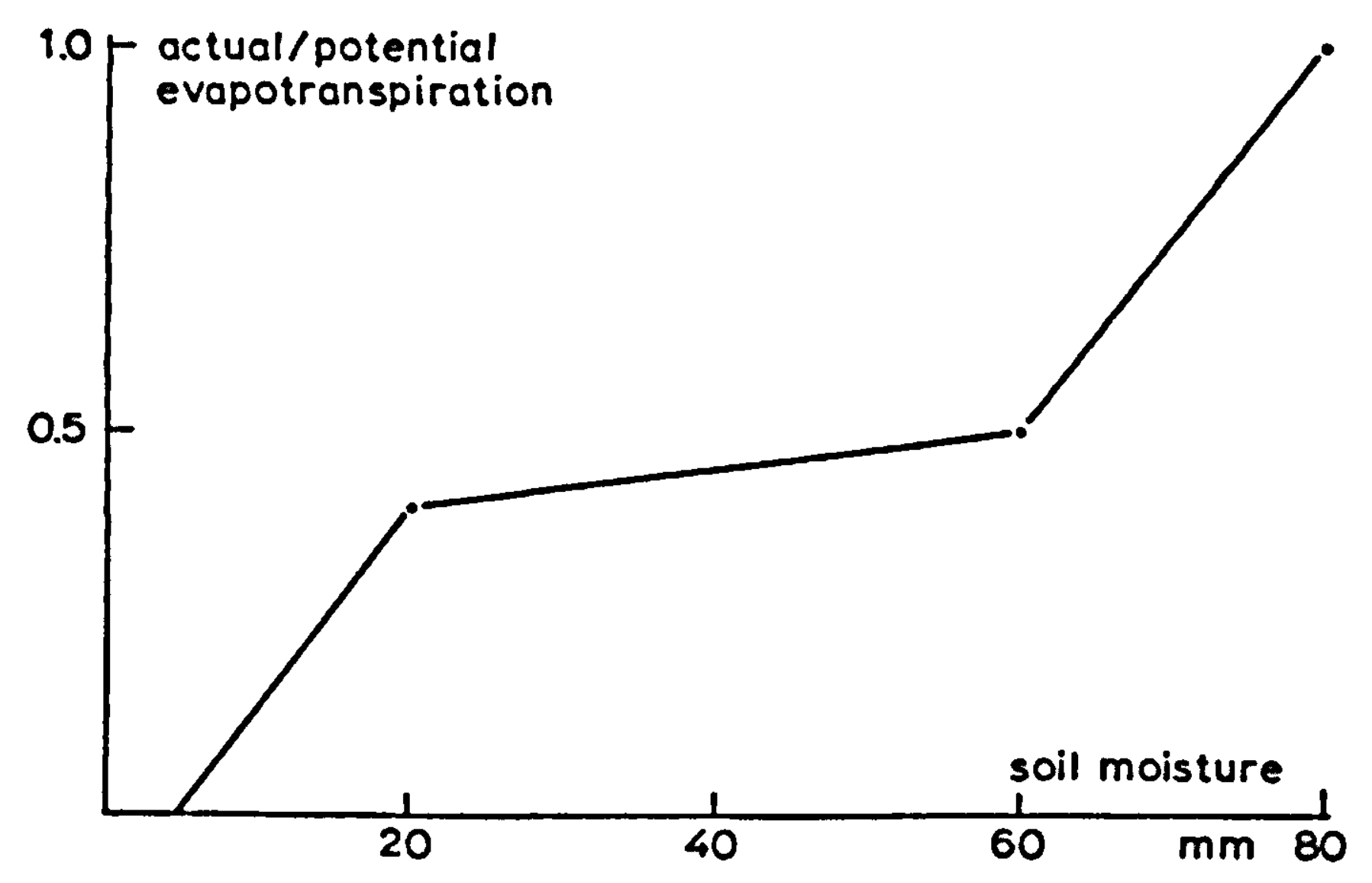

Fig. 10 Armidale: Dependence of evapotranspiration on soil moisture. (From Vickery \& Hedges, 1972a).

source of error. The time unit is one week as is the time step. The relative growth rate (RGR) of the herbage is calculated as a potential rate dependent on soil temperature at a depth of $4 \mathrm{~cm}$. This is adjusted by a series of reduction factors for soil moisture, leaf area, age and a dry soil factor (DRYSOL).

$\mathrm{RGR}=\mathrm{RGRT} \times \mathrm{SMGR} \times \mathrm{PLAI} \times \mathrm{AGE} \times \mathrm{DRYSOL}$

RGRT is the temperature dependent potential growth curve (Fig. 11), whereby there is no growth below $4{ }^{\circ} \mathrm{C}$ and a maximum relative growth rate of $0.5 \mathrm{~kg} \mathrm{~kg}^{-1}$ week ${ }^{-1}$. The soil moisture growth reduction factor (SMGR) given in Fig. 12 is nearly linear between $20 \mathrm{~mm}$ and $75 \mathrm{~mm}$ soil moisture. Below $20 \mathrm{~mm}$ growth almost ceases.

The leaf area reduction factor (PLAI) starts to operate when the green herbage exceeds $2500 \mathrm{~kg} \mathrm{ha}^{-1}$ (dry weight) and reduces growth to 0.1 of potential when it exceeds $5000 \mathrm{~kg} \mathrm{ha}^{-1}$.

The ageing factor (AGE) is dependent on stocking density and time of the year and takes values of 0.75 to 1.5 . It is entered as a table and is based on data by Hutchinson (1969). Thus the growth can be raised above the temperature dependent 'potential' rate. DRYSOL has a value 0.2 and operates for higher stocking densities only during weeks 


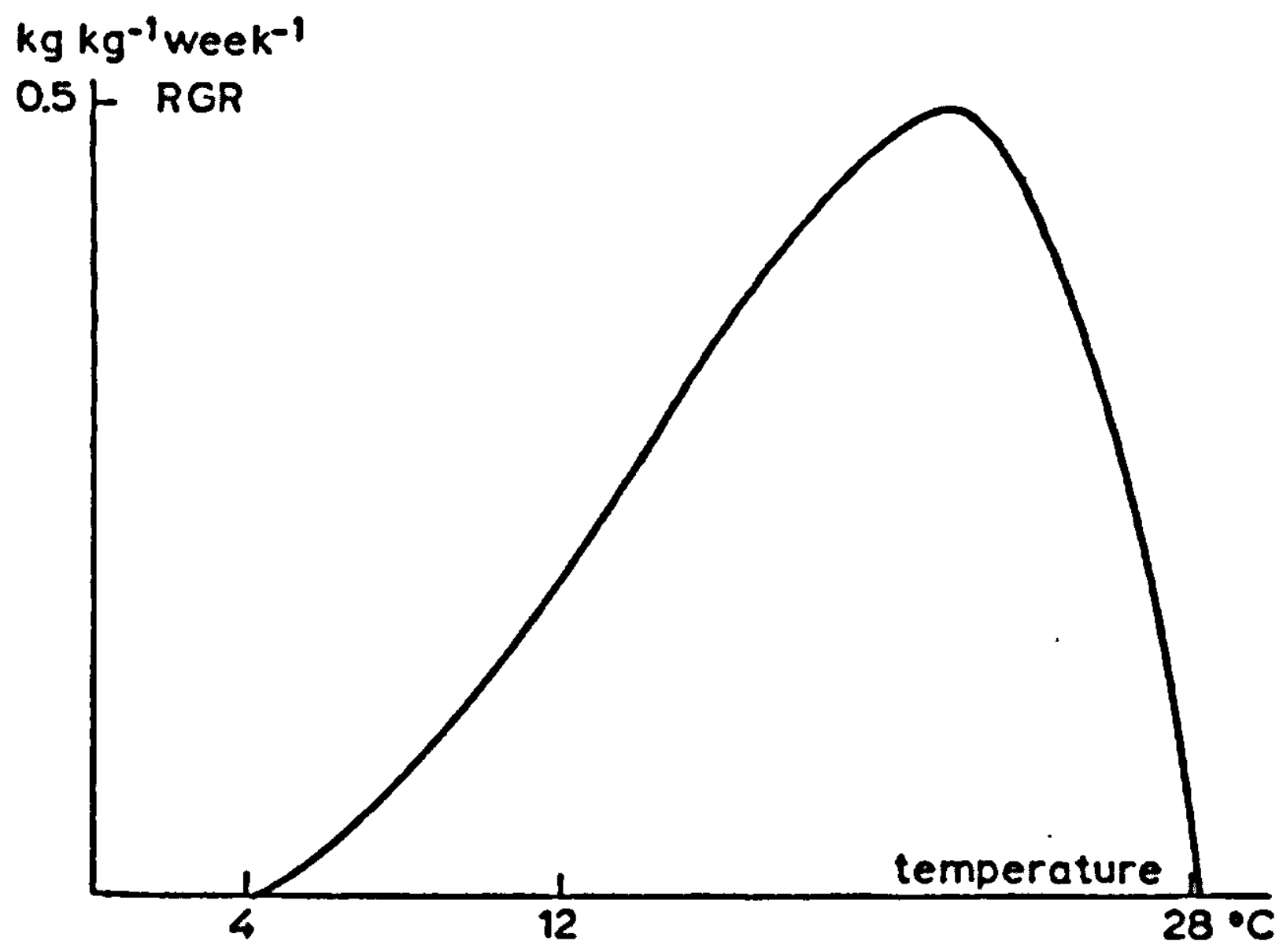

Fig. 11 | Armidale: Dependence of relative growth rate on soil temperature measured at $4 \mathrm{~cm}$ depth. (From Vickery \& Hedges, 1972a).

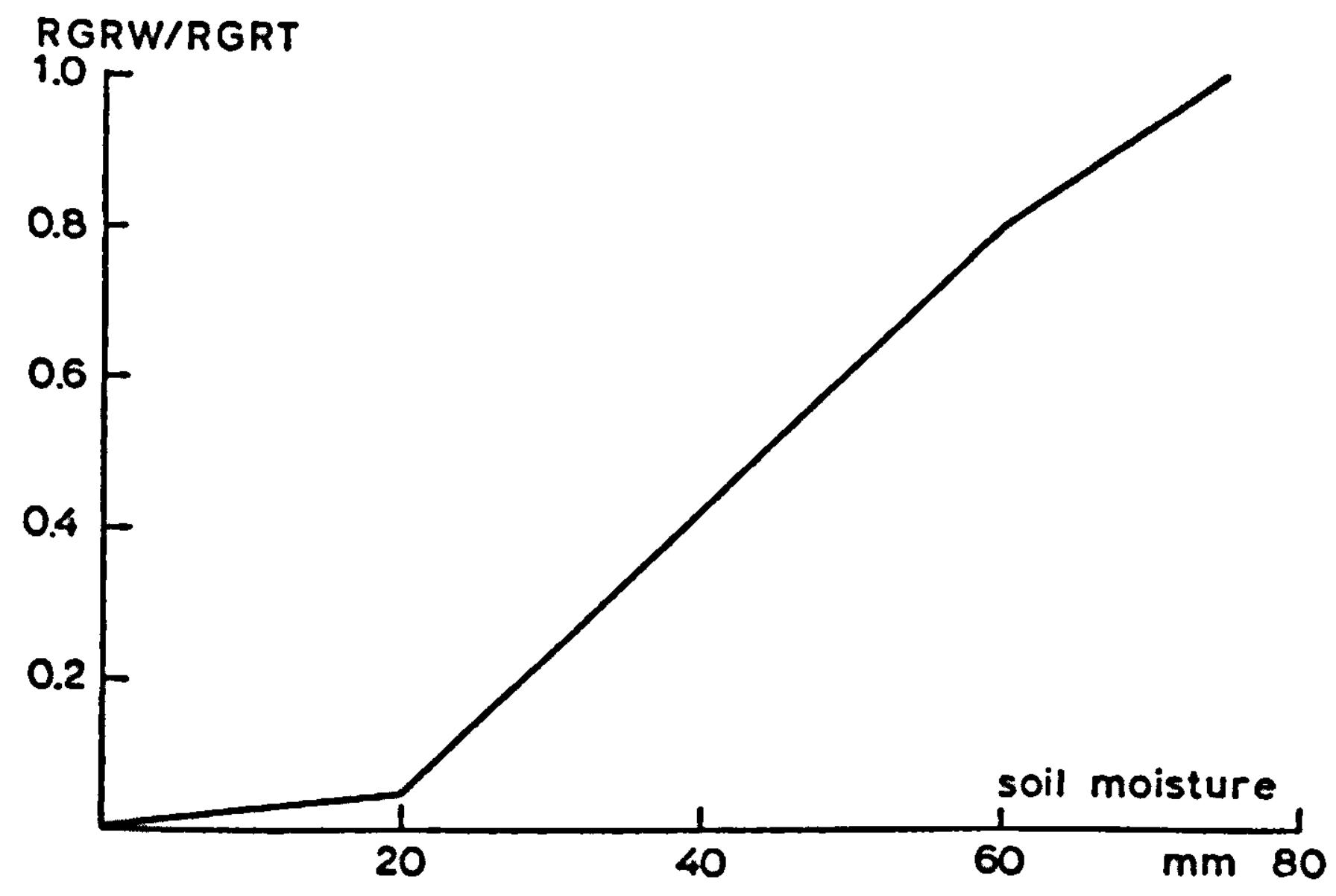

Fig. 12 Armidale: Relationship between soil moisture balance and the ratio RGRW/RGRT where RGRT is the weekly relative growth rate at soil temperature $T$ with soil moisture unlimiting, and RGRW is the relative growth rate at a particular level of soil moisture and the same soil temperature. (From Vickery \& Hedges, 1972a). 
4 and 5 (end January/beginning February). It represents dormancy in Phalaris tuberosa induced by low soil moisture conditions in midsummer. Total weekly growth is then calculated by multiplying RGR with the live shoot biomass plus a fraction of the root biomass. The fraction is a table, dependent on time of the year and has a range from 0.25 to 0.65 . The total growth is limited to a maximum of $1500 \mathrm{~kg} \mathrm{ha}^{-1}$ week ${ }^{-1}$ and is partitioned between roots and tops according to a function dependent on stocking density and time of year. This function is also entered as a table.

The shoot biomass dies according to a rate dependent on time of year which ranges from 0.001 to 0.75 week $^{-1}$. The current value is increased by a factor of 3.5 when soil moisture is less than $20 \mathrm{~mm}$ and concurrently soil temperature is above $19.5^{\circ} \mathrm{C}$. In addition to removal of biomass by grazing there is also consumption by insects. Root biomass dies with a time dependent mortality factor and some of it is consumed by soil fauna.

The growth and death of the pasture vegetation is thus a highly site specific process, fairly rigidly determined by empirical time-dependent functions. Here, as in LEYFARM, grazing affects the pasture only by reducing the live and dead biomass by consumption.

The most distinctive part of this model is probably the approach to determining the forage value of the pasture and the herbage consumption by the sheep. The emphasis is on the ageing of the live and dead biomass. Both are divided into 13 4-week age classes. New growth enters the youngest age class and progresses through the classes, residing in each class for 4 weeks. Live biomass that dies is decremented from the oldest classes and entered into the youngest dead biomass class. This procedure is adopted so as to determine the forage value of the pasture which is here age dependent according to the functions in Fig. 13. It is also used to determine the forage value of the herbage actually consumed by the sheep, as the method allows for selection of young green herbage in preference to old. This is done by accumulating the amount of herbage in the successive age classes and reading off the proportion consumed from each successive class from a curve that relates the proportion of green herbage in the diet to the total amount of green herbage available (Fig. 14). This is admittedly an arbitrary approximation but is used for want of better data on herbage selection.

Despite the fact that herbage is divided into 4-weekly age classes, it 


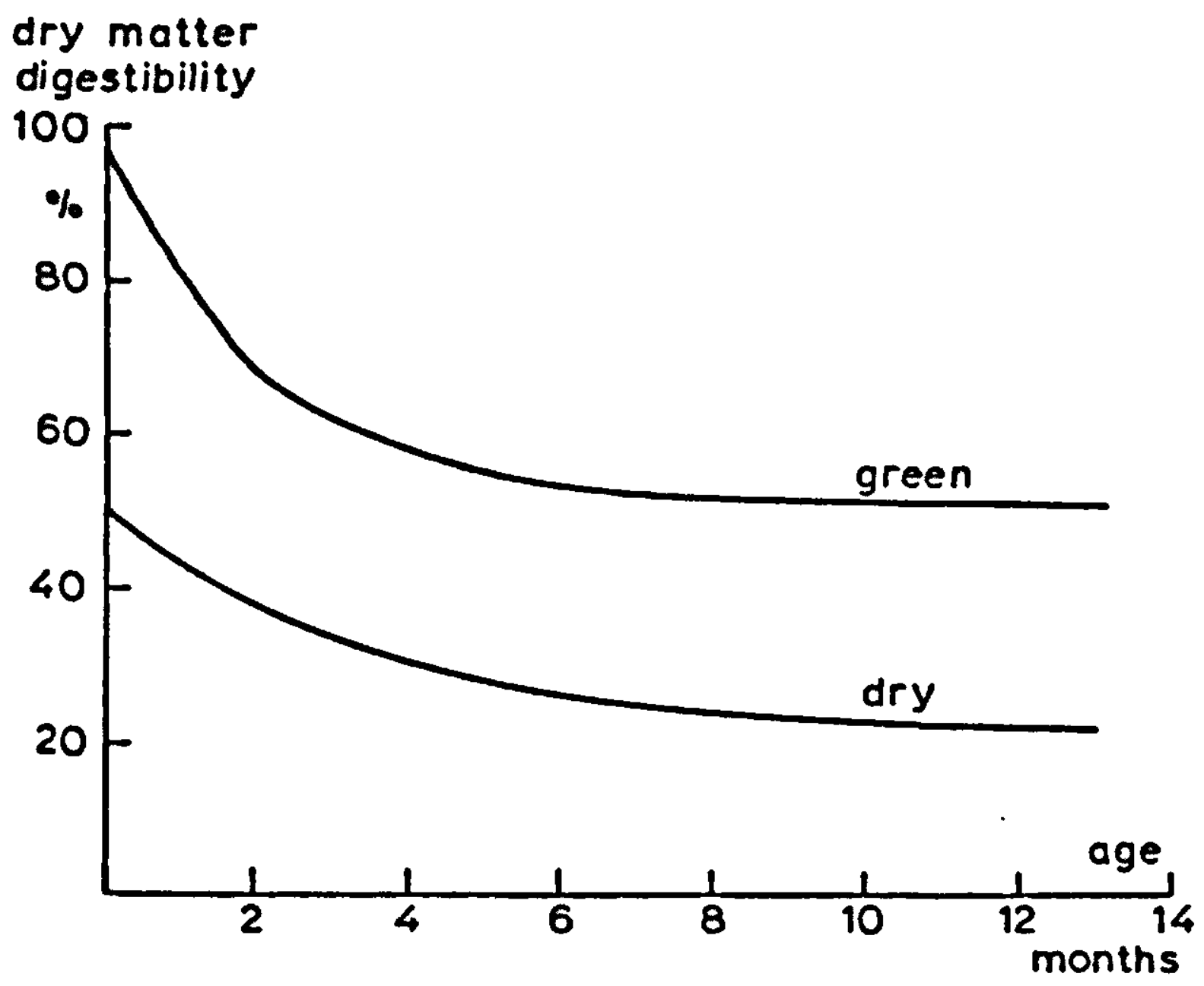

Fig. 13 | Armidale: Relationship between age and digestibility of green and dead herbage. (From Vickery \& Hedges, 1972a).

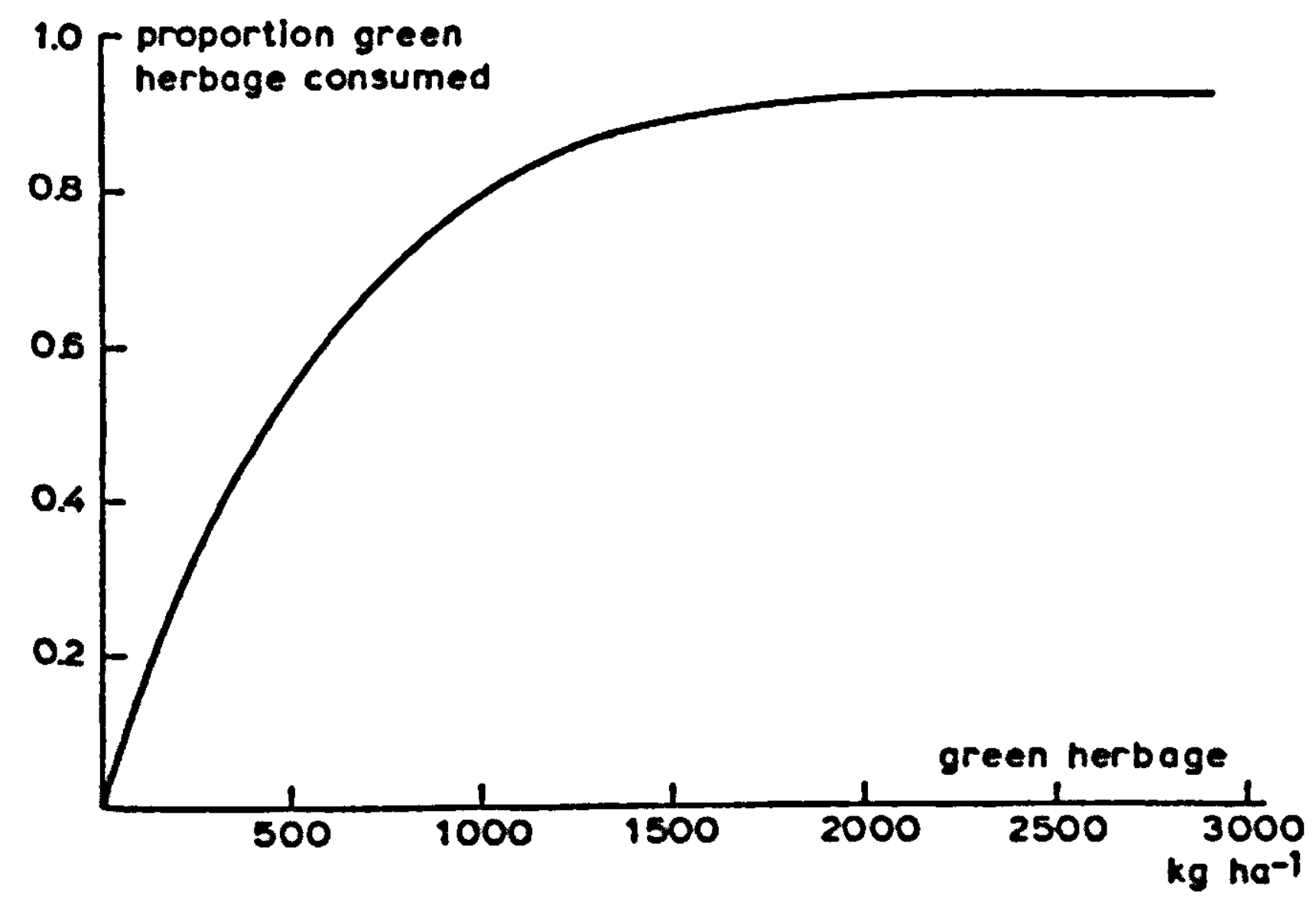

Fig. 14| Armidale: Relationship between green herbage availability and the proportion of green herbage in the diet. (From Vickery \& Hedges, 1972a). 
ages continuously, i.e. in weekly steps. Thus some herbage is moved from the one class to the next every week. The actual amount is determined by the proportion grazed in the current week. It is assumed that the same proportion was grazed in the previous 3 weeks. The amount of 4-week old herbage left over to be moved to the next class is calculated as an approximation of:

$$
P_{t}=\mathrm{e}^{-k_{t} t / t}
$$

where

$P_{i}=$ proportion of herbage in class $i$ that is transferred to the next age class;

$k_{i}=$ proportion of herbage in class $i$ that is currently being grazed; $t=4$ (weeks).

This again is a simplification but this time not because of lack of data: it is implied that in fact these are not 13 4-week age classes but 521 week age classes. If the herbage had been so divided, then the actual content of each class could have been aged every week and the digestibility and consumption calculations could then be made on the basis of 4-weekly classes by linking the 4 consecutive 1-weekly classes. However, the treatment as used results in a dispersion with a standard deviation of

$$
\sqrt{\frac{1-F}{N}} \simeq 0.24
$$

where

$$
\begin{aligned}
& F=\text { time step } / \text { residence time }=\frac{1}{4} \\
& N=\text { number of classes }=13 .
\end{aligned}
$$

If no dispersion at all was intended, then 52 1-week age classes would have been necessary (Goudriaan, 1973). It could be questioned whether in fact such detailed ageing was justified, or compatible with the detail of the digestibility and consumption calculations. Moving the total content of each 4-week class once every four weeks may have been sufficient for the purpose. This method and it's application to ageing processes is discussed by de Wit \& Goudriaan, 1974, Chap. 6.

The output of the model was checked against field observations and 

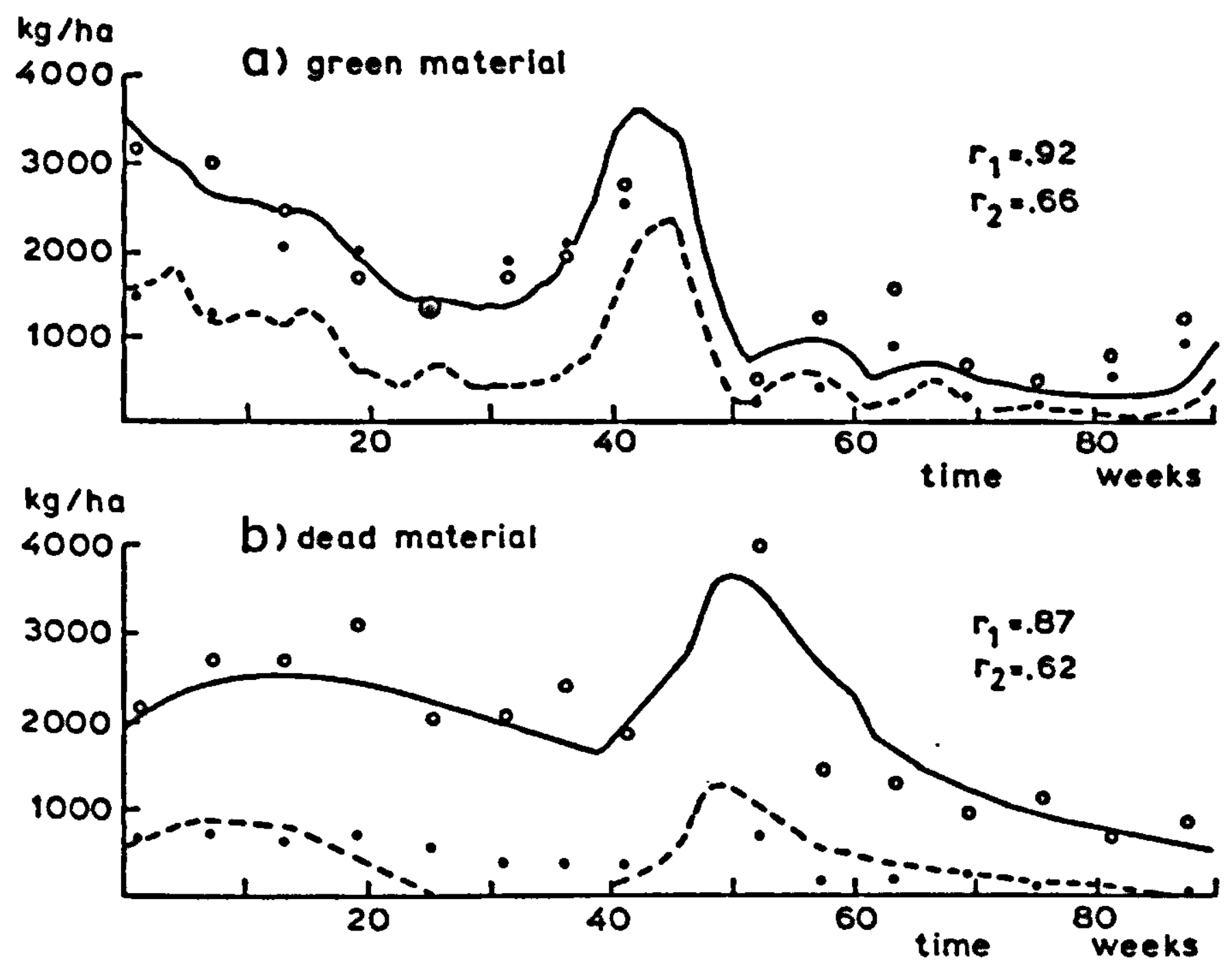

Fig. 15 Armidale: Comparisons of predicted values obtained from the sheep production model with actual data of Hutchinson (1969): (a) green herbage $\mathrm{kg} \mathrm{ha}^{-1}$; (b) dead material kg ha-1. Stocking densities 9.9 (and 29.7 (---) wethers $\mathrm{ha}^{-1}$. (From Vickery \& Hedges, 1972).

some of the results for herbage growth are given in Fig. 15 for two stocking densities, 9.9 and 29.7 wethers $\mathrm{ha}^{-1}$. The model results for the lower stocking density are much better than those for the higher stocking density. This would indicate that the interaction between the grazing animal and the growing pasture is not represented well enough to account for the actual growth of the pasture under conditions where this interaction is important, as it is at high stocking densities. The source of the discrepancy could be in the way that grazing is represented as influencing growth as well as in the way the forage consumption by the sheep is calculated.

The Armidale model is not a class exercise (Seligman et al., 1971) or a strenuous two week workshop effort (Wielgolaski, 1972). It is, like LEYFARM, a serious attempt to model a well defined situation in fair detail and is based on a wealth of experimental data. It has been carefully formulated and clearly represented (Vickery \& Hedges, 
1972a, b). Yet its performance is somewhat less than satisfactory. This is an indication that either the best information available or the conceptual basis (or both) are not yet good enough to allow construction of a reliable model in such detail. This is a useful result because it not only indicates that there is a dearth of knowledge on important aspects of pasture growth and grazing, but it provides a meaningful criterion by which to judge the contribution of new information and new concepts.

\section{A Simple Analytical Model}

Noy-Meir (1975a, b, c) has used a deliberately simplified model as the basis for an analytical approach to the problem of pasture stability under different stocking densities and different grazing systems. His model consists essentially of a vegetative growth rate function dependent only on 'quantity' of vegetation in the pasture and a family of consumption functions dependent on stocking density and on the quantity of pasture on offer. He shows that many properties of such a system under continuous grazing can be determined by simple graphic means (Noy-Meir, 1975a, b). However, to analyse the system for rotational grazing it is necessary to define an explicit mathematical model (Noy-Meir, 1975c). The model simulates net change in vegetative biomass, $V$,

$$
\frac{\mathrm{d} V}{\mathrm{~d} t}=G-C
$$

where $G$ is the growth rate of the pasture and $C$ the rate of consumption by the grazing animal.

$$
\begin{aligned}
& G=g V\left(1-\frac{V}{V_{m}}\right), \text { a logistic growth function; } \\
& C=c_{m} H \frac{V-V_{r}}{\left(V-V_{r}\right)+\left(V_{k}-V_{r}\right)} \text { if }\left(V<V_{r}, C=0\right), \text { a Michaelis satura- }
\end{aligned}
$$

tion function, 
where

$g$ = maximum relative growth rate;

$V_{m}=$ maximum plant biomass;

$c_{m}=$ maximum consumption rate per animal

$H=$ stocking density

$V_{r}=$ 'residual' ungrazable plant biomass

$V_{k}=$ plant biomass at which consumption is half that at satiation (Michaelis constant). Serves as a measure of 'grazing efficiency'.

When

$$
\frac{\mathrm{d} V}{\mathrm{~d} t}=0,
$$

the system is in equilibrium and stability conditions can then be defined.

"The rotational scheme was defined by two parameters: $n=$ the number of sub-plots (degree of subdivision) and $t_{r}=$ length of the whole rotation period or cycle. For continuous grazing $(n=1)$ animal density in the pasture $H$ was set equal to the average throughout the simulation. For rotational grazing, it was set to $H=n \bar{H}$ for the part $t_{r} / n=t_{g}$ days (grazing period) and to $H=0$ for the part $t_{r}-t_{r} / n=t_{d}$ (rest period)". The model was written in CSMP-II and run for 100-250 day periods. In addition to $V$, cumulative animal consumption, $\int \mathrm{Cdt}$, was calculated as a relative estimate of gross animal productivity (assuming $P=$ $e C-m$, where $e$ is a utilisation efficiency coefficient and $m$ is the amount of intake used for animal maintenance).

The behaviour of the model was studied for different management options by varying mainly $n, t_{r}, H$ and $V_{0}$, the initial biomass at the start of the growing period. The effects of changing $V_{r}$, the ungrazeable plant residual and $V_{k}$, an expression of the grazing efficiency of the animals, were also tested. $V_{m}, g$ and $c_{m}$ were held constant throughout the study as $500 \mathrm{~kg} \mathrm{dunam}^{-1}, 0.1$ day $^{-1}$ and $3.0 \mathrm{~kg}$ respectively ( 1 dunam $=0.1 \mathrm{ha}$ ).

An example of the graphic stability analysis of continuous grazing is given in Fig. 16 and an example of the effects on vegetative biomass of a given rotation scheme in Fig. 17. The graphic representation (and the analytical treatment) define five different stability situations: 1 under- 

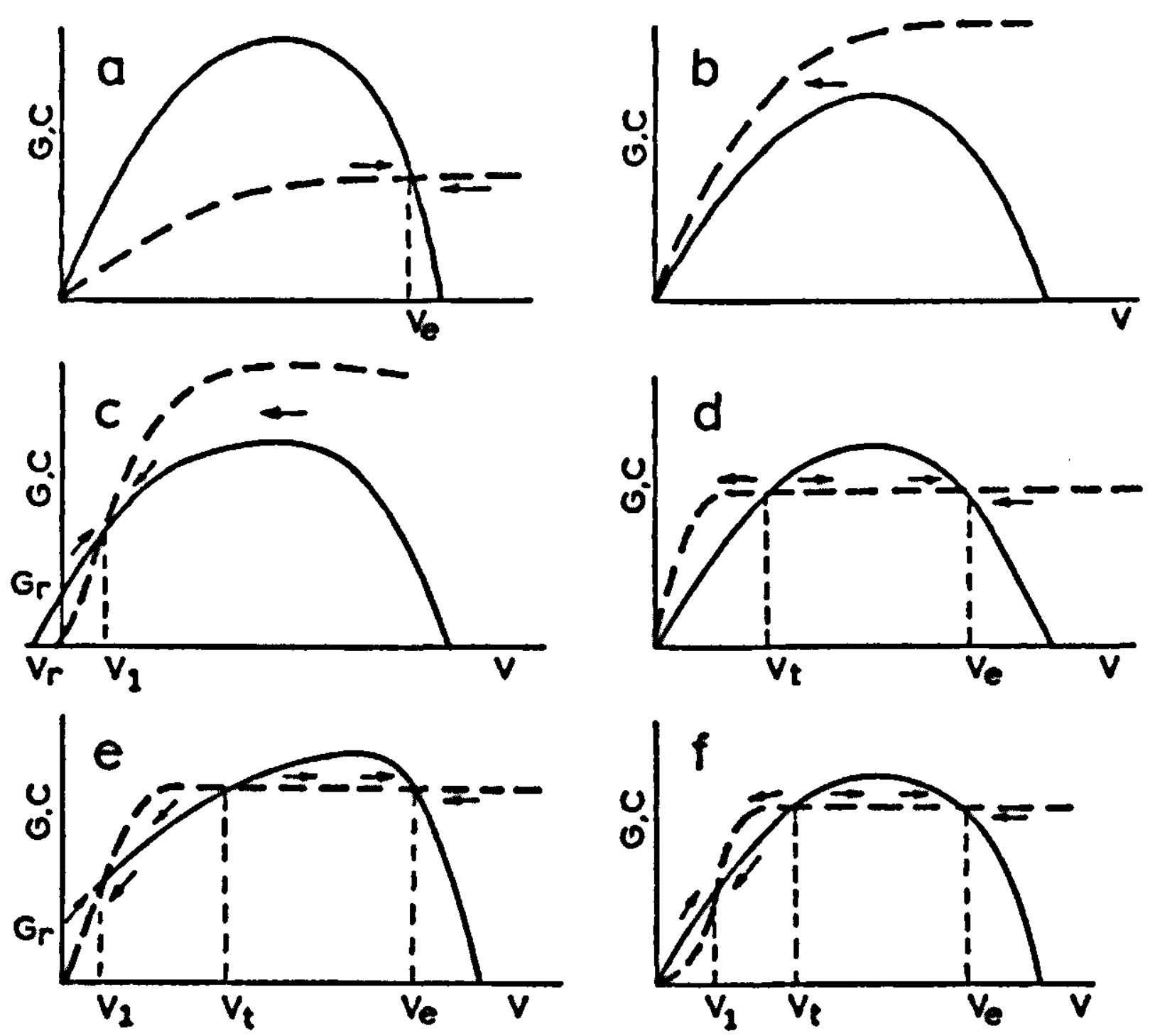

Fig. 16 | Stability of grazing systems: application of predator prey graphs. Possible stability conditions of $G$ and $C$ curves at given $H$.

a. undergrazed, stable steady state $\left(V_{e}\right)$.

b. overgrazed to extinction.

c. overgrazed to a low biomass steady-state $\left(V_{1}\right) ; V_{r}$ - reserve (ungrazable) biomass; $G_{r}$ - residual growth potential.

d. steady state $\left(V_{e}\right)$ and unstable turning point $\left(V_{t}\right)$ to extinction.

e. two steady states $\left(V_{e}, V_{1}\right)$ separated by a turning point $\left(V_{t}\right)$.

f. as e, but caused by a sigmoid $C$ - curve, not by ungrazable plant reserve. (From Noy-Meir, 1975b).

grazed steady state; 2 overgrazing to extinction; 3 overgrazing to a low biomass steady state; 4 steady state and turning point to extinction; 5 two steady states (Fig. 16).

Noy-Meir concludes that 'applied to a simple plant herbivore model this approach has yielded a series of general conclusions, about stability and productivity of the system. These appear to be relevant at least to some classes of real-world pastoral systems and to some problems in their practical management' (Noy-Meir, 1975b). It can be added that this approach allows for the stepwise development of a 


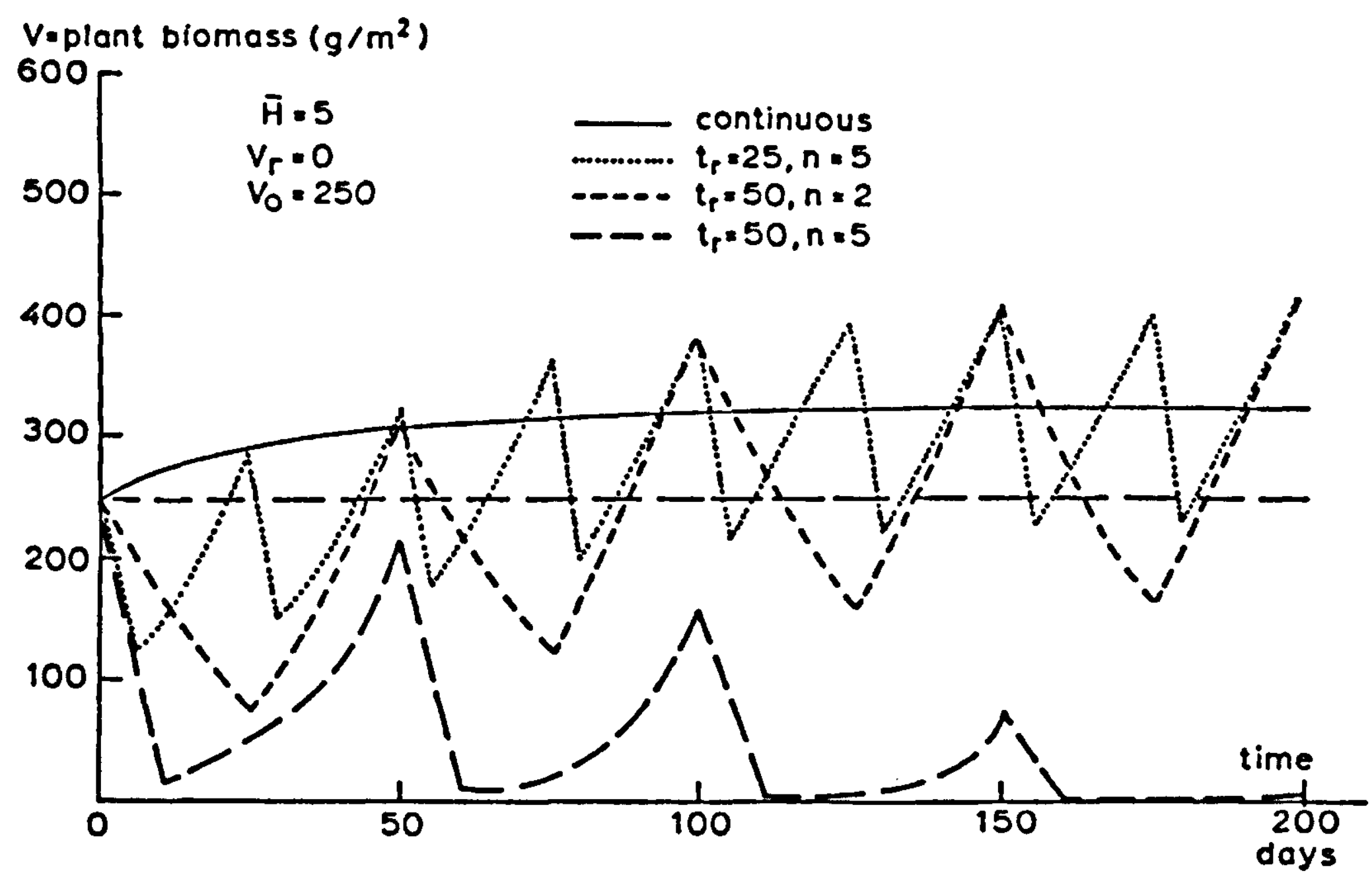

Fig. 17| Sample output of simple grazing model of pasture rotation.

$\mathrm{H}=$ mean stocking density in sheep dunam ${ }^{-1}(=0.1 \mathrm{ha}) ; V_{r}=$ residual ungrazable reserve in $\mathrm{kg}_{\text {dunam }}{ }^{-1} ; V_{0}=$ initial biomass in pasture in $\mathrm{kg}$ dunam ${ }^{-1} ; t_{r}=$ length of rotation cycle in days; $n=$ number of subdivisions of paddock.

The rotation scheme $t_{r}=50, n=5$ results in fluctuations to extinction; the other rotations fluctuate around an equilibrium value. (From Noy-Meir, 1974c).

comprehensive theory of grassland dynamics. It also links grazing problems to existing theory of prey-predator systems thus increasing, hopefully, the fruitful contact between grassland management and ecological theory. It is certainly refreshingly fundamental and whatever the shortcomings of such generalized grassland systems, their analysis does contribute significantly to a clear and exact statement of the problems.

\section{The PASTOR Model}

PASTOR (Goodall, 1967) is probably the first pasture management model to have been published and was meant to be an example of how such models could be constructed. It is a simulation study of the effect 


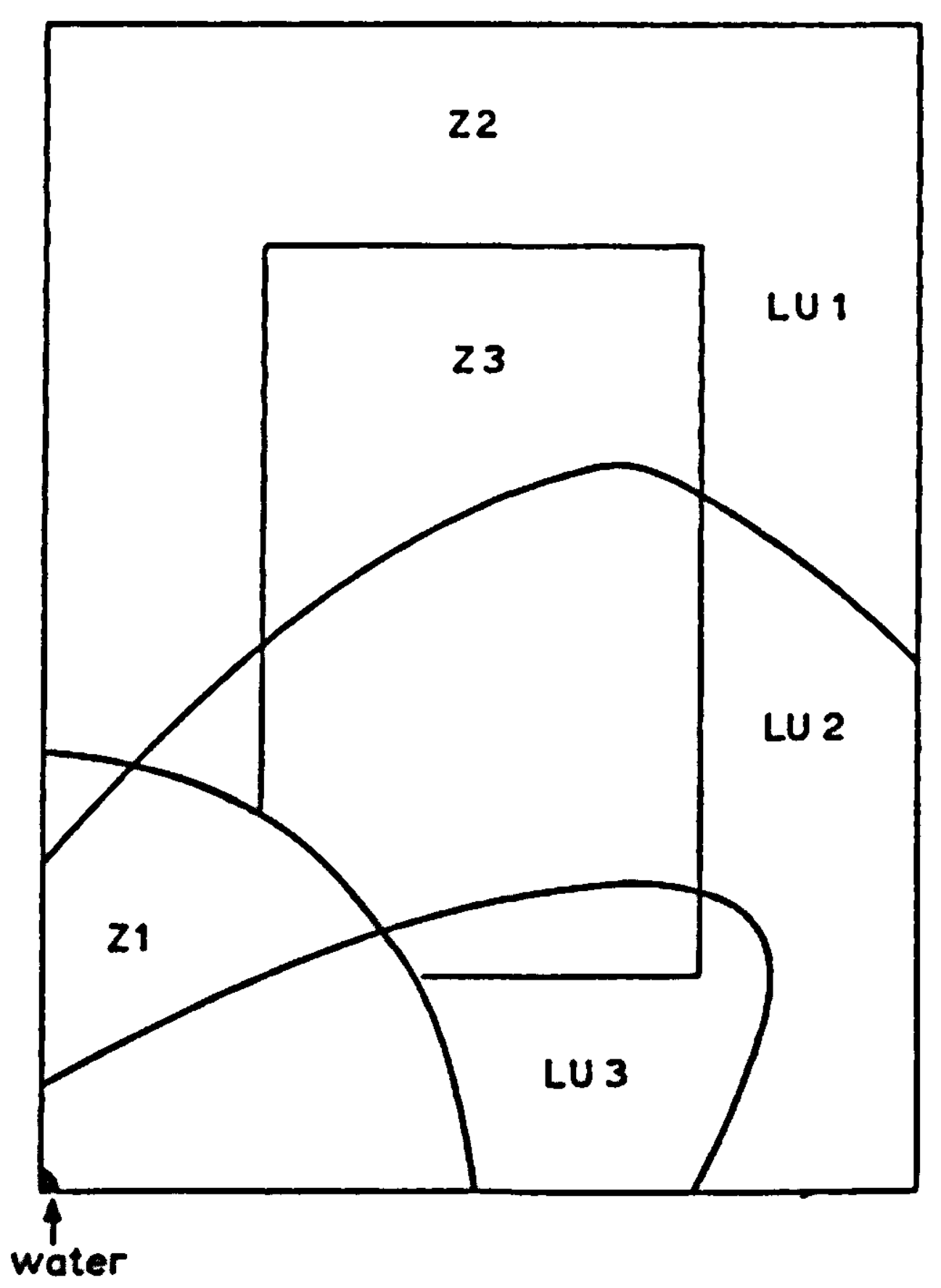

Fig. 18 | PASTOR: Map of hypothetical paddock. $Z_{i}=$ preference zones for sheep grazing, $L U_{l}$ - land units (From Goodall, 1967).

of fencing and the placement of watering points on the vegetation usage and livestock performance (Fig. 18). It considers five different plant species as forage sources with five different (forage?) growth parameters for each species and three land-unit types $\left(\mathrm{LU}_{1-3}\right)$ with different soil characteristics. The modelled paddock is subdivided into three preference zones $\left(\mathrm{Z}_{1-3}\right)$. The sheep that graze the paddock choose their forage according to the availability of the different species in the different preference zones and the species palatability.

The model results are presented for what they are worth without comparison with observed data. They are judged reasonable, the implication being that with suitable species and land parameters it could be used for actual management studies. However, this remains to be proved and considering the problems encountered in the less complex situations envisioned by LEYFARM and the Armidale model 
(herbage in one species class; one land type) there are grounds for doubting over-confidence in reasonable, unverified model results obtained from situations where many, if not most, of the critical growth and preference parameters would have to be guessed. A trial run of a recent version of PASTOR without grazing animals resulted in annual growth increases of $6.8-25.0 \%$ for the five hypothetical species. When growth curves are based mainly on statistical parameters, it is difficult to judge whether such small growth increases of available forage over a whole season intentionally mimic a real situation or are simply errors in parameterisation. The latter possibility is clearly a major hazard in all large and complex programs but especially when the model components contain many statistically fitted functions, often with parameters that do not represent a recognisable characteristic of the reality being represented. PASTOR, which is carefully and professionally programmed, contains at least another example of what appears to be an inadvertent error. The runoff function is intended to have the general shape shown in Fig. 19. The

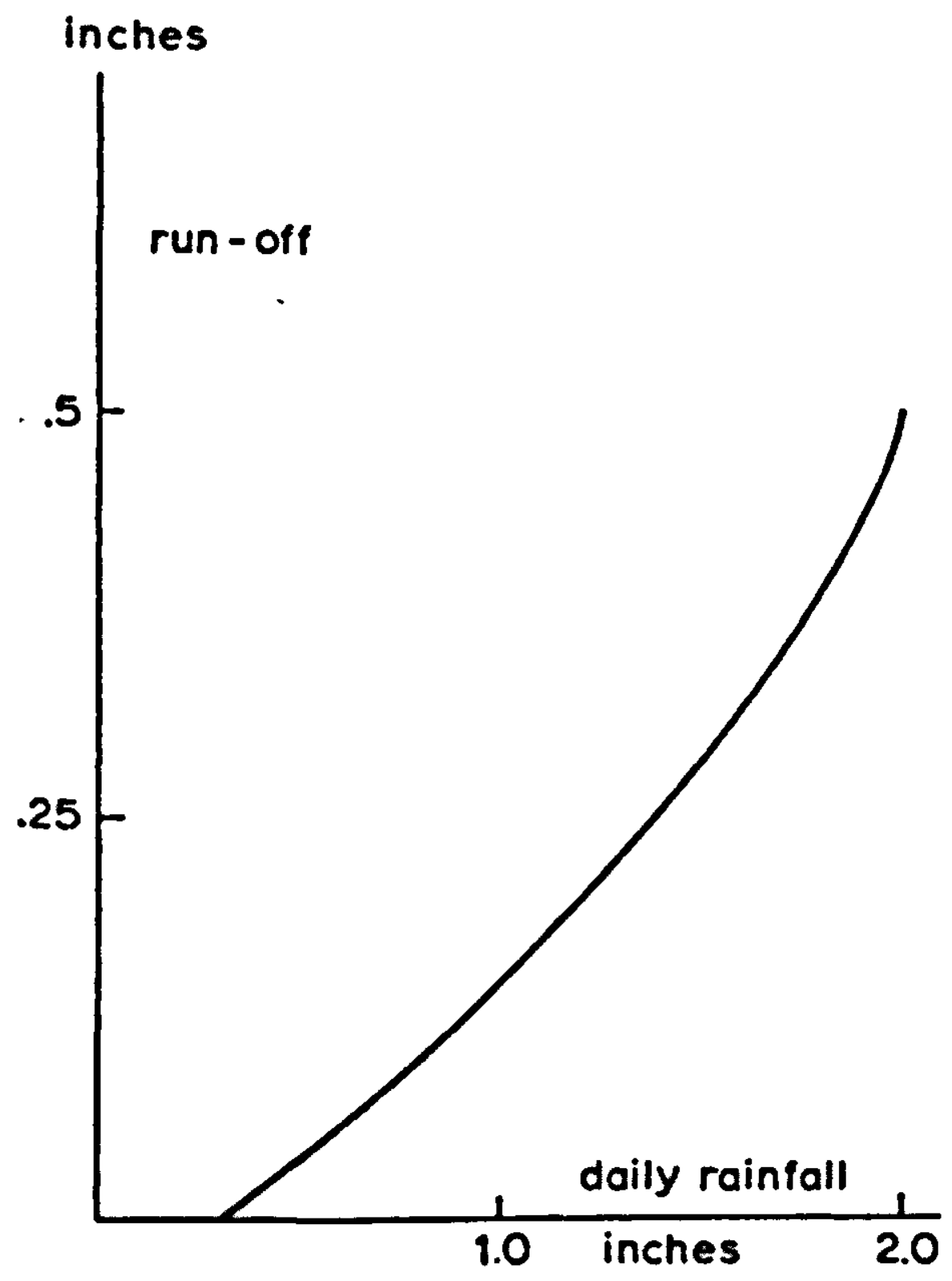

Fig. 19| PASTOR: Intended form of runoff-rainfall relationship. (From Goodall, 1967). 
curves generated by the program for the three land-unit types are given in Fig. 20. These could be intentional representations of special rainfall runoff relationships (e.g. runon in land unit 3 related to runoff from land unit 1) or unintentional error. It is often possible that misrepresentation of a function can be incorporated in a model and yet remain undetected.

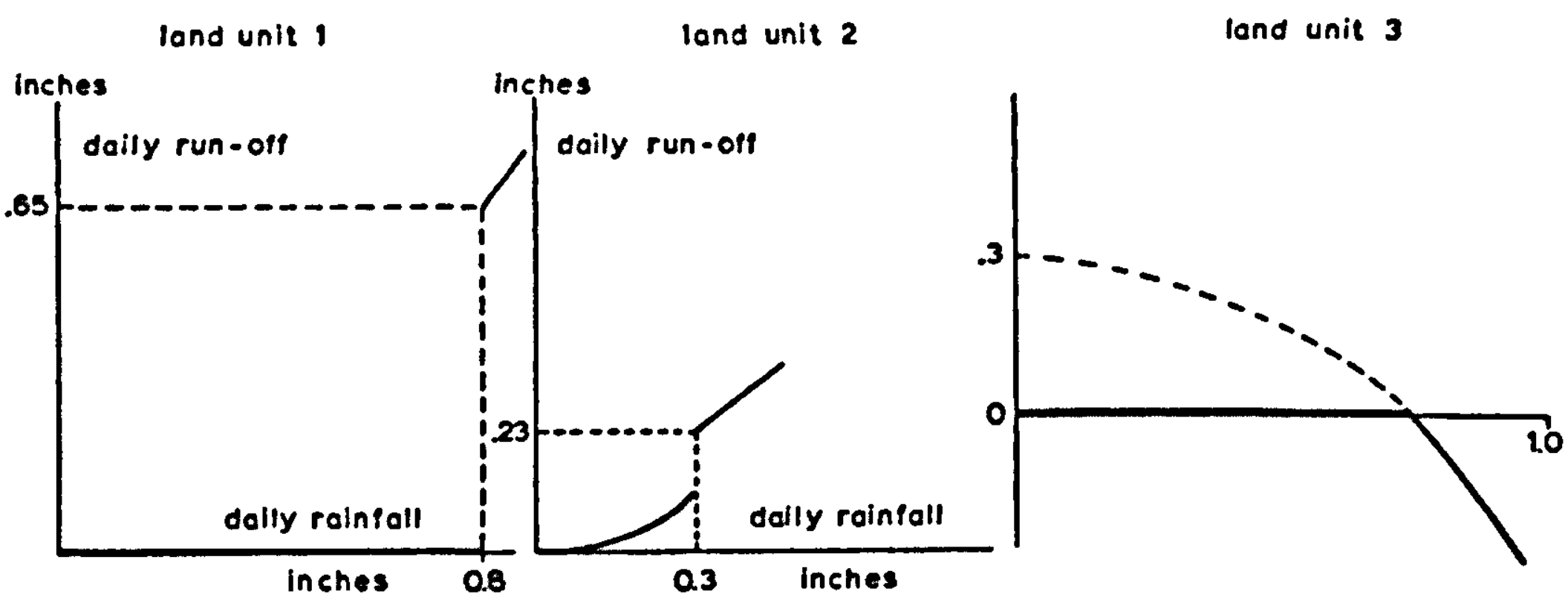

Fig. 20| PASTOR: Runoff-rainfall relationships used in a recent version. (Derived from Goodall, 1973).

When this will become practically important will depend on whether this function becomes critical under certain legitimate conditions. As one would hardly intentionally incorporate functions that are never important, it is self-evident that the aim must be to remove all conceptual and parameter errors from a model. Even then it will take a major intellectual effort to determine whether a complex model is really doing what it was intended to do. Of course, even if it does do all that it was intended to do, it may still be an unsatisfactory model because of deficiencies in the definition of the system and in the aim of the simulation.

\section{The Negev Model}

NEGEV (Seligman et al., 1972) is a model of a semi-arid winterrainfall grassland grazed by sheep. It was developed during and after a course in ecosystem modelling given in Jerusalem by Prof. G. M. Van Dyne of the U.S. Grassland Biome programme. It is of moderate complexity having four types of state variable (soil moisture, plant biomass, animal weight, animal numbers) which were subdivided 
by land-form, species or age into about 50 actual state variables. About 200 parameters were used in defining the system, most of which were estimates or 'intelligent guesses'; some had to be changed in order to 'tune' the model. Pasture growth depended on existing biomass, soil moisture and temperature. Regrowth was restarted each growing season from a fixed residual reproductive biomass (seeds, buds) as soon as moisture and temperature conditions were suitable.

The results were 'reasonable' in that they were qualitatively in keeping with what was known of pasture growth and animal production in the region. The model was then used to test the stability and productivity of the system. The main conclusion was that without management of the livestock, the system would always crash in severe drought years. In addition, the exercise was thought to be 'useful in inducing interdisciplinary cooperation and in improving our general understanding of the semi-arid ecosystem' (Noy-Meir, 1975a). It was also proved that even when very little data are available, a fairly complex grassland model can, after some adjustment, give reasonable results. The catch, of course, is that such a model cannot add very much to what is already known because its reliability for prediction is low: if an unusual result is obtained it is generally impossible to know without further experimentation whether it is valid or an error. The validity of a model depends on sound conceptualization and good experimental data. NEGEV does show that a grassland model can produce presentable results with neither. It also shows that the usefulness of such models is rather limited.

\section{The PWNEE Model}

PASTOR and NEGEV are in a way relatively simple ecosystem models. Whatever criticism holds for them, holds even more for the large, complex ecosystem models like PWNEE or ELM (Patten, 1972; Anway et al., 1972). Here a considerable concerted effort has been made to collect as much of the necessary information as was necessary to construct a reliable model. The program involves many trophic levels, many species at each of the trophic levels, and many processes, not a few of which are poorly understood quantitatively, like some of the soil microbiological processes for which quantitative data are particularly difficult to obtain. It needs only a good programmer to make such a program run, but it takes a super-biologist to comprehend 
the implications of some of the statistical constructions and most of the interactions and feedback mechanisms that are implicitly built into the model. It may be argued that the whole point of computer simulation is that the incomprehensible can be managed; that systems of analytically intractable differential equations are by nature incomprehensible, but that does not make the numerical solution less valid. That of course would be true whenever the formulation of the system of differential equations is both conceptually and parameterically sound. Can this be said of even the best of the ecosystem models?

\section{The ISLE ROYALE Model}

The Isle Royale biome model is quoted here as an example of a highly simplified ecosystem model run as a stochastic system (Beyer et al., 1973). The vegetation is entered as an initial amount that increases at a fixed relative rate due to growth in the growing season and decreases at a fixed relative rate due to death during the dormant part of the season. The vegetation is consumed by moose which reproduce and die at rates determined by the availability of the forage. The moose are also killed by wolves who do so at a rate dependent on a moose density: wolf density relationship. The data on which the parameters are based come mainly from Isle Royale itself. The programming approach for the stochastic processes of predation, birth and death is event dependent, which is apparently rather efficient in the use of computer time when the model simulates many discrete events with much 'dead time' between them. Even this relatively simple model contains some conceptual and parametric errors, at least in the version released for publication. Most of these could be corrected without adding significant complexity. The model is used to predict the population dynamics of Isle Royale and is said to be applicable to other situations too.

This model raises the question whether such gross simplifications of an ecosystem can be justified. The answer would depend on the objective of the simulation. If it was intended to predict what was going to happen to all the state variables in a given year, it would probably be unreliable. However, if it was intended to gain some insight into the effect of initial conditions, parameter values and function forms on the long term trends and population stability of the system, it could probably help to clear up some implications of the variables studied. 
These simplified simulation models, which are much less restricted than some of the classical formulations in population dynamics, can be useful as aids to reasoning in complex situations. Concepts can be worked out in simplified models (Noy-Meir, 1975a, b, c). They may even make further development unnecessary either due to the problem being solved satisfactorily or, as is more likely, due to the now obvious lack of quantitative understanding at even a relatively coarse level. The conclusion could be quite useful as it would then be possible to define fairly clearly what need be done to improve understanding of the system.

The limits of an ecosystem can be set arbitrarily; but once defined, every ecosystem is unique in the sense that there is no other exactly like it. It has been maintained that because every ecosystem is unique, it cannot be simulated (de Wit, 1973). This is because once it has been studied and used for obtaining initiation and validation data, it will have changed and the model would not apply anymore (de Wit, 1973). However, it is also true of agricultural research that most field experiments are done in specific situations which are not identical in all respects anywhere else. Yet agricultural field research is still conducted on a wide scale and many believe that some of it is useful partly because the uniqueness of the experimental situation is judged to be a minor source of variation compared to the effects that are being studied. In the same way it would have to be shown that general aspects of an ecosystem are being investigated and that they are more important to the study situation than the specific or unique aspects. The problem of recognising what is unique and what is general appears difficult to solve purely objectively and may depend on the intuition of an experienced ecologist. These considerations do restrict the validity of 'realistic' ecosystem models drastically and force attention towards the highly simplified but more general type of models cited above.

\section{Conclusion}

It has been said that even if a biological model is of necessity an approximation of reality, it should always be an exact representation of what one thinks about the system (de Wit, 1973). This may not be good enough to be useful but it at least allows one to test one's thoughts. With inspiration, luck and perseverance, these may bloom into veri- 
fied concepts capable of contributing to greater understanding of the worlds around us. Grassland models have a more immediate and practical objective: to optimize the management of the animal, herbage system and possibly some related systems too. Till now fairly complex grassland models have generally done little more, at best, than to confirm what has been known previously. Whereas this may not be a highly marketable result it should be seen in terms of the age of grassland modelling. What is being done is a start and a learning process which needs to be constantly checked with reality until the technique becomes really productive. The model development itself can be heuristically useful but the purpose of the exercise will always be to test ideas. This test, however, can generally only be a preliminary test. The crucial test in biological systems will be the experimental verification. If experiment and modelling go hand in hand, even some of the less convincing models that have been discussed here may yet become at least useful integrators of available research results and at best reliable extrapolators to significant management problems.

\section{Acknowledgements}

This essay reflects, albeit with some inevitable distortion, some of the views and prejudices held by members of the Department of Theoretical Production Ecology, headed by Prof. dr ir C. T. de Wit. He encouraged me to write it up after a seminar on grassland models given in his department. Jan Goudriaan, Herman van Keulen as well as Graham Arnold and Immanuel Noy-Meir read the draft and most of their suggestions have been incorporated. If any faux pas still shows I must take the blame.

\section{References}

Anway, J. J., E. G. Brittain, H. W. Hunt, G. S. Innis, W. J. Parton, C. F. Rodell \& R. H. Sauer, 1972. ELM: Version 1.0 I.S. I.B.P. Grassland Biome Techn. Rep. No. 156. Colorado State Univ., Fort Collins, 285 pp. Arnold, G. W., 1975. Effects of herbivores on arid and semi-arid rangelands: defoliation and growth of forage plants. US:AUSTR. Workshop on semi-arid rangelands, Adelaide 1972.

Arnold, G. W. and D. Bennett, 1975. The problem of finding an optimum solution. In: Symposium on the study of agricultural systems, University of Reading, Sept, 15-18, 1974. 
Arnold, G. W., \& N. A. Campbell, 1972. A model of a ley farming system, with particular reference to a sub-model for animal production. Proc. Aust. Soc. Anim. Prod., 9: 23-30.

Arnold, G. W., B. A. Carbon, K. A. Galbraith \& E. F. Biddiscombe, 1974. Use of a simulation model to assess the effects of a grazing management on pasture and animal production. Proc. XIIth Int. Grassl. Congr., Moscow.

- 1974b: Listing of LEYFARM. Personal communication.

Beyer, W. A., D. R. Harris \& R. J. Ryan, 1973. A stochastic model of Isle Royale Biome. Preprint: Los Alamos Lab., New Mexico.

Brockington, N.R., 1971. Using models in agricultural research. Span 14: 1-4. Carbon, B. A. \& K. A. Galbraith, 1975. Simulation of the water balance for plants growing on coarse textured soils. Aust. J. Soil Res. 13. (In press).

Edelsten, P. R., J. E. Newton \& T. T. Treacher, 1973. A model of ewes with lambs grazing at pasture. Internal Rep. No. 260, Grassland Research Institute, Hurley, Berks, U.K.

Goodall, D. W., 1967. Computer simulation of changes in vegetation subject to grazing. J. Indian Bot. Soc. 46: 356-362.

Goodall, D. W., 1973. Listing of PASTOR, personal communication. Goudriaan, J., 1973. Dispersion in simulation models of population growth and salt movement in the soil. Neth. J. agric. Sci. 21: 269-281.

Greenwood, E. A. N., Titmanis, Z. V. \& Campbell, N. A., 1974. The effects of defoliation on emergent annual grass swards under simulated grazing. J. Brit. Grassl. Soc. 9: 37-45.

Hutchinson, K. J., 1969. Fodder conservation and energy flow in grazing systems. Ph.D. thesis, Univ. of New England, Australia (quoted by Vickery and Hedges, 1972).

Keulen, H. van, 1975. Simulation of water use and herbage growth in arid regions. Pudoc, Wageningen (Simulation Monographs).

Lemon, E. R., D. W. Stewart and R. W. Shawcroft, 1971. The sun's work in a cornfield. Science (Wash. D.C.), 174: 371-378.

Noy-Meir, I., 1975a. The use of models in the study of grazing ecosystems. In: Ecological research on development of arid zones (Mediterranean deserts) with winter precipitation, Israel-France symposium. Agricultural Research organisation, Bet Dagan, Special Publication 39: 65-77. Noy-Meir, I., 1975b. Stability of grazing systems: an application of predatorprey graphs. J. Ecol. (submitted).

Noy-Meir, I., 1975c. A simple grazing model and the effects of rotation. Agric. Systems (submitted). 
Passioura, J. B., 1973. Sense and nonsense in crop simulation. J. Aust. Inst. Agric. Sci., 39: 181-183.

Patten, B. C., 1971. System analysis and simulation in ecology. Vol. 1, 2. Academic Press, New York.

Patten, B. C., 1972. A simulation of the shortgrass prairie ecosystem. Simulation, 16: 177-186.

Penning de Vries, F. W. T., 1973. Substrate utilization and respiration in relation to growth and maintenance in higher plants, Neth. J. agric. Sci. 22: $40-44$.

Seligman, N. G., N. H. Tadmor, I. Noy-Meir and A. Dovrat, 1971. An exercise in simulation of a semi-arid mediterranean grassland, Bull. Techn. Agron. Gembloux. Semaine d'étude des problèmes méditerranéens: $133-143$.

Stewart, D. W. \& E. R. Lemon, 1969. The energy budget at the earth's surface: a simulation of net photosynthesis of field corn. $R$ and $D$ Techn. Report ECOM 2-68 1-6, U.S. Army Electronics Command, Atmospheric Sciences Laboratory, Fort Huachuca, Arizona.

USDA, Bradfield Hall, Cornell Univ., Ithaca, New York, 18450.

Vickery, P. S. \& D. A. Hedges, 1972a. Mathematical relationships and computer routines for a productivity model of improved pasture grazed by Merino sheep. Division of Animal Physiology Tech. Paper No. 4, CSIRO, Melbourne.

Vickery, P. J. \& D. A. Hedges, 1972b. A productivity model of improved pasture grazed by merino sheep. Proc. Aust. Soc. Anim. Prod., 9: 16-22. Whitfield, D. W. A., 1972a. Empirical model of Dryas integrifolia net $\mathrm{CO}_{2}-$ assimilation. In: Measurement and modelling of photosynthesis in relation to productivity. IBP/Canadian Council, p. 53-58.

Whitfield, D. W. A., 1972b. Process model of Dryas integrifolia. In: Measurement and modelling of photosynthesis in relation to productivity. IBP/ Canadian Council p. 59-69.

Wielgolaski, F. E., 1972. IBP Grassland/Tundra International modelling synthesis workshop: Summary of output work-book. Techn. Rep. 19, NREL, Colorado State Univ., Fort Collins, Colorado, 34 pp.

Wit, C. T. de, 1958. Transpiration and crop yield. Versl. Landbouwk. Onderz. No. 64.6, Wageningen.

Wit, C.T. de, 1970. Dynamic concepts in biology. In: Prediction and measurement of photosynthetic productivity: 17-23. Pudoc, Wageningen. Wit, C. T. de \& J. Goudriaan, 1973. Simulation of ecological systems in CSMP: course of lectures given at the Hebrew University, Jerusalem. 
Wit, C. T. de et al., 1975. BACROS, a basic crop simulator. Simulation Monographs (in preparation).

Wit, C. T. de, R. Brouwer \& F. W. T. Penning de Vries, 1970. The simulation of photosynthetic systems. In: Prediction and measurement of photosynthetic productivity. Pudoc, Wageningen.

Wit, C. T. de \& J. Goudriaan, 1974. Simulation of ecological processes. Pudoc, Wageningen. (Simulation Monographs). 


\section{Future prospects of systems analysis in ecology}

\section{J. N. R. Jeffers}

\section{Introduction}

Born of the apparently unnatural liaison of ecology and mathematics some would say the rape of ecology by mathematics - and reared in the heady atmosphere of the International Biological Programme, systems analysis is now seen by many ecologists as a precocious adolescent, pampered by over-indulgence, and accorded more value than it is worth by its association with sophisticated, and sometimes elegant, companions like computers, electronics, and graphics. It is sometimes claimed that systems analysis has, so far at least, produced nothing of lasting value and has dispersed much valuable effort into unprofitable avenues of research.

It would be relatively easy to support such a view by a biased sample of the results of systems analysis and modelling applied to ecology, for, regrettably, much that is either unprofitable or scientifically unacceptable has found its way into the mainstream of scientific communication, both published and unpublished. In part, the difficulty lies in the relative unfamiliarity of many ecologists with the philosophy and concepts of mathematics, so that, if they have turned to mathematical techniques at all, they have used them as tools, often for the wrong purpose and with little or no understanding of their constraints, much as an unskilled carpenter may use a hammer to drive home screws in his impatience with the more tedious use of a screwdriver. Some of the fault, however, lies with the mathematician who, eager to show his skill and the power of his methods, leaps into the arena to find applications for some branch of mathematics, all too often with a bland disregard for the complexity of ecological systems and of the many assumptions which underlie our frail understanding of the living world.

However, this is a biased view, and much that is sound ecologically, mathematically, and, more important, practically has emerged from the application of systems analysis and modelling to ecology. Such work has most frequently come from small groups of scientists work- 
ing with a well-defined and rather narrow focus, having made great efforts to link the modelling effort, from the start, with a carefully designed research strategy and with rigorous data validation. We may even argue, without undue casuistry, that the surge of enthusiastic effort in the field of systems analysis was necessary and useful, even where misapplied. The very small subset of models and modelling approaches that now seems valid has contributed directly to the advancement of ecology as a science, by identifying unanticipated factors and interactions that have subsequently proved to be important, by forcing modification of our experimental and survey procedures, and by illuminating critical weaknesses in our hypotheses and assumptions.

This paper is intended to review briefly the present state of systems analysis in ecology, and to suggest its future prospects. If it is felt that the review is over-optimistic, it may be relevant to ask if there are any other methodologies which, strategically or tactically, are capable of meeting the challenge to ecology posed by the need for the world to feed its population, to meet its demand for energy, and to control the impact of its technology on our environment.

\section{What have we learnt?}

The terms 'systems analysis' and 'model' are now used in so many different ways that they are in danger of losing specific meaning. However, in this paper, I will assume the word 'model' to indicate a quantitative representation which, if complex, may require algebraic and arithmetic manipulation. Such models are essential elements of systems analysis, statistical analysis, and many forms of computer simulation. I assume 'systems analysis' to be the orderly and logical organisation of data and information into models, followed by the rigorous testing and exploration of the models necessary for their validation and improvement.

In ecology, as in other branches of science, models have been widely used as translations of verbal problems into mathematical form. The advantage of the mathematical representation lies in the abstract nature of mathematics, enabling the emotional overtones inherent in verbal descriptions to be substituted by neutral symbols, and forcing attention and emphasis on just those parameters and relationships which are essential to the hypothesis. In this form, much information 
can be assembled into a coherent whole, ideas can be clarified and thinking sharpened, new theories or hypotheses designed, and existing theories tested. From the comparison of the predicted responses of our model system with reality, we can draw attention to critical components of the system and identify those experiments which will enable us to eliminate contenders from among competing hypotheses.

Models and systems analysis have been increasingly employed by ecologists for the description of the population dynamics of plants and animals, for the exploration of spatial distribution of organisms, and for the representation of physical and chemical processes. Within the International Biological Programme, with its emphasis on the functioning of ecosystems and the flow of energy and nutrients through their major components, there has been a major incentive to exploit models of the complex interactions between organisms and their environment, and between several organisms. Success in the difficult stages of the formulation of the model has been dependent upon careful definition of the ecological problem, an understanding of the properties of the models proposed, and an adequate fit of the model to existing knowledge.

Above all, however, modelling is dependent on the availability of appropriate and reliable data. In the past, we have had to rely on such data as already existed, with a naive belief that all data can be made to serve our purposes and that, even where data are biased and unreliable, they can often lead us to the next stage of the systems analysis, to the formulation of the improved hypotheses. We now know we were wrong - indeed, we should have known we were wrong! Every form of data collection imposes its constraints on the subsequent use of the data. As I have argued elsewhere (Jeffers, 1974), the concept of the 'data bank' is rooted in the accounting theory of data collection, which assumes that the subsequent use of data is independent of the way in which data are collected. The statistical theory of data collection insists on the essential interdependence of data collection and data analysis, and, if we wish to use particular kinds of models, we must ensures that appropriate methods of data collection have been used. We have, too often, built our models on insubstantial foundations and the rejection of the models is a rejection of the foundations rather than of the model form itself.

If this were not enough, we have created a further problem. Models of 
complex systems are usually themselves complex, and we have not always appreciated the need to explore the models we have built, confusing this activity with the quite different activity of exploring data by the use of models. Perhaps one of the saddest sights of the last decade has been that of the plight of the new applied mathematicians in biological science, baffled by the complexity of the deterministic models of differential equations they have themselves created as analogues of biological processes. Having rejected the 'untidiness' of statistical methods - or perhaps never known them - in favour of the mathematical exactness of functional relationships, they have often rejected the methods they now need to explore their models in the computer simulations. Even the most famous exponents of systems dynamics seem to have had difficulty in realising that "... with separate experiments, we should obtain no light whatever on the possible interactions of the different ingredients, ..." (Fisher, 1935). We are now in the interesting situation of needing the statistical methods of design of experiments, developed to cope with the complexity of biological systems in the field, to explore the behaviour of models of biological systems.

A model developed from biological and mathematical theory, no matter how elegant in itself, is unlikely to be of value unless there is a practical way of assessing how well the theory fits the available data. "There is a sense of simplification, a mental ease which flows from any mathematically elegant summary of a wide corpus of figures. Call it mental laziness or mental efficiency; the mind believes that it can grasp more and grasp that more more clearly." (Williams, 1951). But a model which is incapable of verification is an essay in metaphysics and not an expression of the scientific method. The methods of testing hypotheses against observed data are well-established and are being continually improved. In particular, we now have many of the necessary algorithms for the fitting of models by minimizing the discrepancy between models and data, and we have the necessary computer techniques for data handling, including the combination of data sets, selection of sub-sets, storage and retrieval. Yet the available techniques have hardly been used and are insufficiently widely known because of the lack of published texts.

The difficulties that have been encountered in the use of systems analysis in ecology are not, however, confined to the technical problems 
of ecology and mathematics. As Mar (1974) has pointed out, the process of modelling itself is seldom, if ever, recorded, being inadmissible as a subject for scientific journals, and the technology of modelling has not been captured. Each new project starts from square one and fails to learn from past experiences, because those past experiences have not been recorded. But the three major issues are always the same, and they are solved with variable success, namely:

1 How to define and bound the model.

2 How to orchestrate the team needed to address the problems of construction and validation of the model.

3 How to document and communicate the model and its results.

Unless we can record our experience in the bounding of models, in project orchestration and documentation, and in the validation of models, the fragmentation and abuse of modelling will continue.

\section{What are the prospects?}

We now have a substantial body of experience with the application of systems analysis in ecology. While little of this experience has so far been recorded, and may, indeed, never be recorded within the conventions of the formal paper to a scientific journal, many of the exponents of systems analysis in ecology are still alive, and young enough to have a considerable influence on the developments of the next ten years. We have made our mistakes, and are in the happy position of knowing what they are. We have, therefore, no excuse for continuing to make the same mistakes.

In contrast, we are experiencing the unprecedented interest of administrators, managers, politicians and the general public in the changes taking place in our environment. This interest is too great for those concerned to be satisfied with polite evasions when we, as ecologists, are asked for information about the likely impacts of our search for more food, more energy, ever higher standards of life, and the right to dispose of our waste wherever and however we please. Ecology is no longer a gentlemanly pursuit for summer afternoons, and it can no longer be confined to the study of the rare and the beautiful, or to the confirmation of our prejudices about the appearance of the countryside. 
In Britain, the acceptance of what has come to be called the 'Rothschild principle', that government has the right to expect the scientists it supports to devote at least a proportion of their time and effort to the solution of the problems of government, has been established and is already having a major impact on research policy. The environmental impact assessment procedures in the United States of America were established and are carried out under the National Environmental Policy Act of 1969, and the main thrust of the Act is to ensure that environmental concerns receive adequate attention at all levels of governmental planning, decision-making and action. Almost every country in the world is now expressing concern at the lack of essential knowledge of the ecology of our world. Whether or not ecology has achieved its maturity, it is already having to bear adult responsibilities.

Given the necessary expertise to implement a strategy of systems analysis in ecology and the demand for ecological knowledge in the solution of essentially practical problems for the survival of our planet, why should one predict an increased emphasis on systems ecology in research and management? First, because ecological systems are complex in terms of their relationships with their environment and in terms of their interactions with other systems, not excluding those created by man, it is unlikely that verbal descriptions and hypotheses can express the necessary complexity, and increased reliance on models is inevitable. Second, because we can no longer regard the publication of a scientific paper as the satisfactory end-product of ecological research, and governments, managers, politicians, and the taxpayer the new patron of science - will demand our results in a form in which they can make direct use of them, models related to the decisionmaking process itself will increasingly be expected as the outcome of our research: models which the decision-maker can use to test the outcome of his proposals. It would be naive to suppose that the decision-maker will surrender the making of decisions to the ecologist, no matter how great the latter's expertise may be.

Systems analysis, in this context of social responsibility, may therefore be expected to achieve a synthesis between data collection and modelling in which five successive phases can be recognised.

\section{Setting of objectives and preliminary synthesis}

The first phase of any systems analysis requires the definition of the 
objectives of the investigation, including the range of ecological systems concerned, the types of manipulation, modification or disturbance to which the systems may be exposed, and the variables it is intended to measure and to predict. Much of this initial definition will require the review of existing and relevant information as an assessment, implicit or explicit, of the state of the art, and objectives may have to be re-examined and redefined several times as this information, or its absence, is revealed. As the definition of the objectives begins to settle upon a consensus agreed by the many individuals who may contribute to the initial discussion, some possible hypotheses, capable of direct or indirect verification, may be expected to emerge. Initially, the hypotheses may be many in number but rejection of some of these hypotheses may be possible from a consideration of existing information, leaving a smaller number of residual hypotheses worth testing explicitly. The nature of the hypotheses which emerge from this preliminary setting of objectives will usually help to define the kind of model which will be subjected to the next phase of the research, and an initial synthesis can then be attempted within the framework of this model. The predictions obtained from the model will be the ones to be compared with the observations of the next phase of experimentation, leading to carefully designed tests of the basic hypotheses.

\section{Experimentation}

The phase of experimentation involves the test, both in the field and in the laboratory, of the extent to which the models of the preliminary synthesis are capable of predicting the outcome of the direct manipulation of the ecological system or the range of variability of the system in both time and space. Characteristically, it is in this phase of the investigation that much of the extensive data collection necessary for ecological research takes place. Ideally, and where the preliminary synthesis has resulted in a model of some detail and clarity, the collection of data will be guided by rigorous experimental designs in which the precision of the derived estimates is focussed on the parameters of greatest interest. Such designs also enable uncontrollable, but extraneous, factors to be prevented from introducing a bias into either the parameter estimates or the measure of the experimental error and set bounds to the uncertainty in the estimation of the parameters 
themselves. Preliminary syntheses based on smaller amounts of initial information may lead to less rigorous experiments or to surveys of variation in time and space which, while they lack the experimental control of the designed experiment, still enable precise tests to be made of the defined hypotheses.

The results of the experiments lead to a redefinition of the preliminary synthesis, after adjustment or revision to find a better fit to the new data collected during the experimental phase, and provide for a rapid transformation of information on the structure and operation of the models developed which will lead to new ideas on the management of the ecological systems. For this stage to be effective, therefore, greater communication is required between experimenters, modellers, and decision-makers than has so far been achieved in research and management of ecological systems. Furthermore, this communication is an essential introduction to the next phase.

\section{Management}

The development of the improved and revised models at the end of the phase of experimentation leads logically to the next phase, during which pilot-scale management studies are implemented by the appropriate agencies. While such studies also require careful design, it will usually be less possible to exert as tight control on the conduct of these studies as on the research experiments. Nevertheless, it is important to subject the improved models to a further period of practical testing, under the normal conditions of management. Only in this way can the confidence of the managers of ecological systems and decision-makers be gained, and both the experimenter and the modeller may well discover facets of the problem which had previously been lost in the discussion of ecological mechanisms and processes. Failure of the results of the pilot study to match the predictions of the revised models will frequently indicate further changes that are required in the model.

\section{Evaluation}

With increased confidence in the synthesis, achieved during experimentation and pilot-scale management studies, evaluation of the effects of changes of management proposed as a result of the increased knowledge of the structure, functioning and stability of ecological systems becomes possible, with particular emphasis on environmental quality and the quality of human life. During this phase of the research, 
new ideas should become available for the determination of policies for the management and use of natural resources and systems.

By this phase, we hope to have achieved a working model, refined by experimentation and practical trials in the field, as an approximation to the ecological system with which we are concerned. The model is, to be sure, a caricature of reality and, almost certainly, a simplification of reality. Indeed, the attraction of the mathematical model to the working scientist is that the model enables him to abstract only those elements which are relevant to the problem to be solved. Having demonstrated that the abstraction gives a working approximation to a defined level of precision, we may explore alternative strategies for the management of the system with increased confidence.

\section{Final synthesis}

In one sense, there can never be a phase of final synthesis, as all models represent the starting point for new and improved models once it has been found that they are unsatisfactory in some respect. The phase of evaluation may, therefore, be regarded almost as the preliminary synthesis phase for the next round of research activity. Models are essentially transient, the product of a scientific mind, and they are also the true vehicles of knowledge, so that we should talk of 'model banks' rather than 'data banks'. However, in the uneasy state of ecological knowledge, there are many systems which we may be prepared to leave in a temporary 'final' phase, while we concentrate our scarce resources for ecological research on relatively unworked and unknown systems.

All this is a far cry from our present fragmentary use of models and systems analysis in ecological research and management. It represents a radical change from our traditional and academic forms of research in which the scope of our investigation is divided and limited by the segments into which it can be chopped to make the pieces suitable to be undertaken by the individuals and small groups from which our research organisations are assembled. A new orchestration of our efforts will be required if we are to meet the challenge of the demands made upon us and of the technology we now have in our hands. We might be justifiably pessimistic about the changes of this synthesis being achieved if the phases described were not taken from the report of an expert panel on the role of systems analysis and modelling approaches in the programme on Man and the Biosphere (UNESCO 
MAB Report Series No. 2, 1972). The scientific approach of the MAB programme can be categorized as including major components on the analysis of ecological systems, reciprocal studies of man-environment impacts, integration of information over various spatial levels, and inclusion of modelling techniques to allow quantitative predictions. Within this approach, the programme is intended to:

1 Identify and assess changes.

2 Examine the structure, functioning, and dynamics of ecosystems.

3 Study the interrelations between ecosystems and social and economic processes.

4 Develop the necessary techniques for measuring change in the environment.

5 Increase global coherence of environmental research.

6 Promote simulation and modelling as tools for environmental management.

7 Promote environmental education.

MAB has adopted the philosophy of systems analysis as the basis of its fourteen major projects, not because modelling was regarded as a substitute for empirical studies, but because the basis of systems and modelling approaches in ecology is the concept of integration. This concept is central to ecology and provides the best hope for the future of finding an optimal allocation of financial and manpower resources, and for the development of tools for prediction and planning. We, too, may therefore hope to see our precocious adolescent come to full maturity, stimulated but sobered by the weight of the responsibility that systems analysis and modelling in ecology will have to bear.

\section{References}

Fisher, R. A., 1935. The design of experiments. Oliver and Boyd, London. Jeffers, J. N. R., 1975. Constraints and Limitations of data sources for systems models. In: Study of Agricultural Systems, Ed. G.E. Dalton. Applied Science Publishers Ltd., London.

Mar, B. W., 1974. Problems encountered in multidisciplinary resources and environmental simulation models development. J. Environ. Manage. 2: 83-100.

UNESCO, 1972. Expert Panel on the Role of Systems Analysis and Modelling Approaches in the Programme on Man and the Biosphere. MAB Report Series No. 2. UNESCO, Paris. 
Williams, G. Prys, 1951. On the dangerous pursuit of elegance. The Incorporated Statistician 2: 23-29. 